Copyright

by

Julie Joanna Hunter

2010 
The Dissertation Committee for Julie Joanna Hunter

certifies that this is the approved version of the following dissertation:

\section{Presuppositional Indexicals}

Committee:

R. Mark Sainsbury, Co-Supervisor

David Beaver, Co-Supervisor

Daniel Bonevac

Lawrence Ray Buchanan

Josh Dever

Hans Kamp

François Recanati 


\title{
Presuppositional Indexicals
}

\author{
by \\ Julie Joanna Hunter, B.A.
}

DISSERTATION

Presented to the Faculty of the Graduate School of

The University of Texas at Austin

in Partial Fulfillment

of the Requirements

for the Degree of

DOCTOR OF PHILOSOPHY

THE UNIVERSITY OF TEXAS AT AUSTIN

December 2010 
For Isabel 


\section{Acknowledgments}

My advisors, Mark Sainsbury and David Beaver, helped me tremendously in writing this dissertation and I thank them first. The other members of my committeeFrançois Recanati, Josh Dever, Daniel Bonevac, Ray Buchanan, and Hans Kampdeserve thanks as well. I am especially grateful to François for numerous helpful discussions and multiple opportunities to present the material in this dissertation in his seminars.

This dissertation has benefited from many discussions with friends and fellow students including Alexandra Arapinis, Corien Bary, Derek Ball, Leah Lasell, Aidan McGlynn, Tim Pickavance, Bryan Pickel, Anders Schoubye, Magdalena Schwager, Frank Veltman, Sherilyn Villareal, and Malte Willer. I thank Maria Aloni and Emar Maier for helpful input on some of the work in this dissertation.

Finally, I am grateful to my family for supporting me through my many relationships with school and to Tasha and Boris for their warm, furry snuggles while I was writing my dissertation. My deepest gratitude goes to Nicholas and Isabel for their support and patience, among so many other wonderful things.

Julie Hunter

The University of Texas at Austin

December 2010 


\title{
Presuppositional Indexicals
}

\author{
Publication No.
}

Julie Joanna Hunter, Ph.D.

The University of Texas at Austin, 2010

Co-Supervisors: R. Mark Sainsbury

David Beaver

I present and defend an account of indexicals that treats indexicals as presuppositional expressions. I argue that the distinction between presupposed and asserted content can replace the more restrictive distinction between character and content that is characteristic of Kaplanian, two-dimensional views. My account, Presuppositional Indexicals (PI), is simpler than a two-dimensional account because it does not posit a special layer of meaning for indexicals that cannot interact with truth-conditional content. PI also has broader scope than two-dimensional theories. It opens the door to a general theory of definite noun phrases according to which all definites have two components to their meaning: an asserted component, which contributes new information to a discourse, and a presuppositional component, which determines where asserted information will be attached in a discourse. PI does not stipulate rigidity or referentiality for indexicals as many other theories do. Indexicals do receive a special semantic treatment in PI, but their special semantics are captured entirely in terms of a strategy that indexicals exhibit for the resolution of their presuppositions. 


\section{Table of Contents}

Acknowledgments $\quad$ v

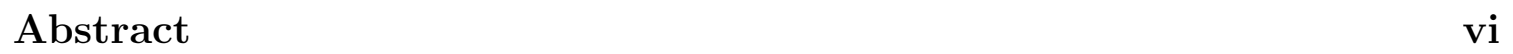

Chapter 1. Introduction: Presupposing Character 1

1.1 Constraints for a Presuppositional Theory of Indexicals . . . . . . . . 6

1.2 A Sketch of the Strategy . . . . . . . . . . . . . . . 15

$\begin{array}{lll}\text { Chapter 2. } & \text { Presuppositional Indexicals } & 18\end{array}$

2.1 Discourse Representation Structures . . . . . . . . . . . . . . . . . . . 18

2.2 PI . . . . . . . . . . . . . . . . . . . . 22

2.2 .1 Introducing $\uparrow \ldots \ldots \ldots . \ldots \ldots . \ldots \ldots$

$2.2 .2 \mathrm{~K}_{0} \ldots \ldots \ldots \ldots \ldots \ldots$

2.2.3 The lexical entries of indexicals . . . . . . . . . . . . . 27

2.2 .4 Wide Scope . . . . . . . . . . . . . . . . . . . 35

2.2 .5 Tense . . . . . . . . . . . . . . . . . . 42

2.2.6 More Sophisticated Entries . . . . . . . . . . . . . . 43

2.3 Demonstratives . . . . . . . . . . . . . . . . . 47

2.4 Conclusion . . . . . . . . . . . . . . . . . 51

Chapter 3. What Now? 53

3.1 The Behavior of Now . . . . . . . . . . . . . . . . . . . . 54

3.2 Kamp \& Reyle . . . . . . . . . . . . . . . . . . . . . . . . . 60

3.3 Recanati (2004) . . . . . . . . . . . . . . . . 64

3.4 PI and Intermediate Binding . . . . . . . . . . . . . . . . 67

3.4 .1 Is Now an Indexical? . . . . . . . . . . . . . . . . . . . . . . . 72

3.4 .2 Other Indexicals . . . . . . . . . . . . . . . . . . 76

3.5 Conclusion . . . . . . . . . . . . . . . . 80 
$\begin{array}{llr}\text { Chapter 4. } & \text { Wider Scope } & 87\end{array}$

4.1 Rigidity and Simple Sentences . . . . . . . . . . . . . . . . . 88

4.1.1 A Basic Introduction to Maier's IMA . . . . . . . . . . . . . . . 88

4.1 .2 The Worry for PI . . . . . . . . . . . . . . . . . 90

4.1 .3 PI's Response . . . . . . . . . . . . . . . . . . . . . . . . 93

4.2 Resolution Strategies . . . . . . . . . . . . . . . . . . 95

4.2 .1 At-Issue Content . . . . . . . . . . . . . . . . . . . . . . 101

4.2 .2 Givenness . . . . . . . . . . . . . . . . 106

4.3 Conclusion . . . . . . . . . . . . . . . . . . . . . . . . . 109

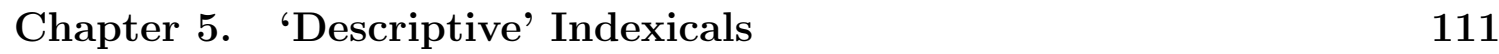

5.1 Descriptive Readings of Indexicals . . . . . . . . . . . . . . . . . . . . 113

5.2 Previous Accounts: Nunberg, Elbourne, and Recanati . . . . . . . . . 115

5.2.1 Proper Names and Definite Descriptions . . . . . . . . . . . . . 121

5.3 Coercion and reconstruction . . . . . . . . . . . . . . . . 128

5.3.1 Quantificational Coercion . . . . . . . . . . . . 128

5.3.2 Intensional Reconstruction . . . . . . . . . . . . . . . . . 133

5.3 .3 Plural Indexicals . . . . . . . . . . . . . . . . . . 137

5.4 Points for a Pragmatic Theory . . . . . . . . . . . . . . . . . . 138

5.4.1 Conventions ..................... 145

5.5 Conclusions . . . . . . . . . . . . . . . . . . . . 147

Chapter 6. Conclusion $\quad 149$

6.1 Recapitulation . . . . . . . . . . . . . . . . . . 149

6.2 Responding to (a)-(e) . . . . . . . . . . . . . . . 152

6.3 Looking Ahead: Bound and Shifted Indexicals . . . . . . . . . . . . 155

$\begin{array}{ll}\text { Bibliography } & 158\end{array}$

$\begin{array}{ll}\text { Vita } & 172\end{array}$ 


\section{Chapter 1}

\section{Introduction: Presupposing Character}

Every indexical expression type has a context-invariant, linguistic meaning that helps determine what entity, if any, is picked out by a given token of the indexical. Yet this level of meaning falls far short of delivering a referent for an indexical token; in every case, information provided either by the utterance itself or by the surrounding discourse context is required to fill the lacunae. An utterance of You must come over here will be infelicitous for an interpreter if it is not clear to the interpreter that there is an addressee or it is unclear who, among a possible set of addressees, is being singled out. An utterance of This is made of gold will be similarly infelicitous to an interpreter if it is not clear to him that there is a demonstratum or it is unclear which object, among a possible set of objects, is being demonstrated.

In other words, in order for an utterance of a sentence containing an indexical to be felicitous, it is necessary that the context of the utterance make salient, in the relevant way, a referent for the token of the indexical.

I contend that this fact about indexicals is best understood by treating indexicals as presuppositional expressions. The context-invariant level of meaning of an indexical expression places a constraint on the context in which a given token of the indexical is evaluated: the context must antecedently provide a referent for the 
indexical and it must present the referent in a way that conforms with the linguistic meaning of the indexical. A speaker who uses the expression you, for example, presupposes both that there is an addressee in the context and that this individual is presented in the context in such a way that her audience will be able to identify the addressee. Once a referent has been secured for a particular token of an indexical, the work of the context-invariant meaning of the indexical is finished and only the referent is passed on for predication and evaluation. This is precisely the behavior one would expect from presuppositional content.

Presuppositional Indexicals (PI), the presuppositional theory that I will motivate in this dissertation, is a discourse-based theory of indexicals that is inspired by presuppositional accounts of other definite noun phrases developed by, most notably, Heim (1982) and van der Sandt (1993). The aim of PI is to contribute an account of indexicals to a larger, unified account of definite noun phrases - one that would include indexicals, demonstratives, proper names, third person pronouns and definite descriptions - according to which all definite noun phrases conventionally presuppose their linguistic meanings and offer to asserted content only an individual. ${ }^{1}$ Previous discourse-based theories of definites have focused predominantly on definite descriptions and pronouns; indexicals have received comparatively little attention. ${ }^{2}$ Because indexical expressions differ from other definites in important and well known ways, however, bringing them into a discourse-based theory of definites requires extra care.

\footnotetext{
${ }^{1}$ In PI and the other discourse-based theories that I will consider, the individual contributed to asserted content is a discourse referent, as I will explain in the next chapter.

${ }^{2}$ Some notable exceptions are Zeevat (2000), Schlenker (2003, 2005), and Maier (2006, 2009).
} 
The idea that indexicals are presuppositional expressions is latent in Kaplan's theory of demonstratives and at first sight, his theory might bear a strong resemblance to mine (Kaplan 1989a,b). Kaplan formalized what I call the presupposed and asserted contents of indexicals with his character and content functions, respectively, and designed his logic in such a way that if character fails to deliver a value for a given indexical token, a sentence containing that indexical token fails to have a complete, truth-evaluable content. Nevertheless, there is a very important structural difference between the presuppositional account that I will defend here and Kaplan's logic of demonstratives. Kaplan's logic is two-dimensional in the sense that a) evaluation of logical form takes place relative to two indices and b) the two indices are of different types so that character cannot interact with content. This latter feature - the true innovation of Kaplan's double-index view - together with the assumption that character always yields a non-functional entity, was offered to ensure that indexicals would be de jure rigid designators whose values could never be affected by linguistic operators. The side effects of Kaplan's two-dimensional logic are severe: his logic ensures that context sensitive expressions are never sensitive to any linguistic operators (modal operators included), but this is intuitively wrong for expressions - such as third person pronouns, demonstratives, and (more controversially) definite descriptions - whose interpretations can be sensitive to the linguistic context as well as to the extra-linguistic context. ${ }^{3}$ For these pronouns, context sensitivity often amounts to operator sensitivity.

\footnotetext{
${ }^{3}$ cf. Dever 2004 for an interesting discussion of how Kaplan ties context sensitivity to rigidity and for an independent argument of why these two features should be kept apart.
} 
PI rejects any theory that is two-dimensional in the sense outlined above. Its aim is to offer an account of indexicals that can be subsumed under a more general theory of definites that treats all definites in a unified way regardless of whether their interpretations depend on the extra-linguistic context or on the linguistic context. A crucial feature of such a general theory would be that it allow presuppositional content to interact with linguistic operators. ${ }^{4}$ The most significant difference between PI and Kaplanian, two-dimensional theories is that PI has this feature. While it may be true that indexicals are not sensitive to modal operators, it is not necessary to create a special layer of meaning for indexicals that shields their characters from any interaction with the linguistic context to capture their standardly rigid behavior. It is important to emphasize this break from Kaplan's two dimensional theory, because the claim that indexicals require a special, protected layer of meaning still pervades much of the literature on indexicals. It even finds its way into presuppositional views of indexicals very much like PI. Maier (2009), for example, adopts a presuppositional theory of indexicals but argues that a presuppositional view must be supplemented with a two-dimensional, Kaplanian framework. Mainstream discussions of monsters also assume a two dimensional framework at least very similar to Kaplan's (Schlenker 2003, Anand 2006).

PI also adopts a broader notion of indexicality than does Kaplan and many

\footnotetext{
${ }^{4}$ My criticism of Kaplanian, two-dimensional theories echoes the work of Heim $(1982,1983)$, van der Sandt (1992), and Beaver (1997), among others, who rejected Karttunen and Peter's two-dimensional account of presupposition because it prohibited interaction between asserted and presupposed content (Karttunen \& Peters 1979). For a different argument against Kaplan's twodimensional system, see Stojanovic (2002).
} 
others. ${ }^{5}$ For Kaplan, a token of an indexical must refer to some feature of the utterance event in which it is tokened or to an entity that is functionally related to a given feature of the event, as is the case, for instance, with tokens of tomorrow. PI is less restrictive. My approach in this dissertation is to adopt the term indexical for a specific class of expressions for which the term is normally used-I, you, now, here, tomorrow, today, actual, actually, and so on (i.e., Kaplan's list)—without making an assumption about what indexicality is, or even about whether these expressions really do define a clear-cut class of expressions in virtue of sharing a unique set of semantic properties. My assumption is that there is an intuitive tie between these expressions and that they share enough semantically interesting properties to justify looking at them as a group, or at least taking them as a starting point, even if they don't end up being classified as a well-defined group in the end. If in exploring the above list of expressions, we find that not all of them need to depend directly on features of utterance events at all times, this does not require jettisoning these terms from the class of indexical expressions, according to PI. Any more liberally behaved expressions in the above list will nonetheless exhibit markedly similar behavior to any indexicals that might fit the narrower notion, and it is this behavior that I am interested in studying. I discuss the distinction between the narrow and broad notions of indexicality introduced here in more detail in What 'Now'?

Even in the absence of a definition of indexicality, however, I offer what I take to be basic marks of an indexical expression. The interpretation of a token of

\footnotetext{
${ }^{5}$ See, for example, Recanati 1993. Recanati adopts a fairly standard analysis of indexical expressions as token-reflexive expressions. I discuss his view in What 'Now'?
} 
an indexical will be, or depend on in some semantically constrained way, the agent, addressee, time, location or world of some eventuality. Normally the relevant eventuality is identical to the utterance event in which the indexical is tokened, but this is not necessary in PI. What is necessary is, first, that the interpretation of an indexical have an 'essentially' indexical nature in the sense that it cannot be replaced by a description or proper name that does not itself contain a demonstrative or an expression that I am listing as indexical (see 'Descriptive' Indexicals). ${ }^{6}$ Next, the interpretation of the indexical must depend on the perspective of the agent of the utterance.

This dissertation has two main goals:

1. Its primary goal is to show that a presuppositional theory of indexicals can replace, not merely supplement, a Kaplanian, two-dimensional theory of indexicals.

2. Its secondary goal is to show that a presuppositional theory of indexicals can do better than a two-dimensional theory by making way for a general theory of definite noun phrases.

\subsection{Constraints for a Presuppositional Theory of Indexicals}

To help frame our discussion, I review in this section the most persuasive arguments that have been used to motivate two-dimensional theories of indexicals

\footnotetext{
${ }^{6}$ cf. Perry (1979).
} 
and/or undermine presuppositional theories of indexicals. In so doing, I provide a list of constraints that a presuppositional view of indexicals must respect. I will return to this list of constraints in the final chapter, once all of the ingredients of PI are in place, in order to show explicitly how PI addresses them.

(a) Indexicals are not anaphoric pronouns (in the traditional sense). Certain indexicalsI, you, here and the temporal indexicals - cannot be used simply to pick up on individuals introduced in discourse, even if those individuals are highly salient due to recent mention. They are not anaphoric expressions in the traditional sense. ${ }^{7}$ This puts them in contrast with other seemingly similar expressions like he, she, there, then, before, later, next, that, this and so on, as well as with definite descriptions.

(1.1) John told Kate that I would be coming to the party tonight ( $\mathrm{I} \neq$ John).

(1.2) I like to think back on the summer of '95. *I was so happy now.

(1.3) The Richelieu house is special to me because I was born here. (Infelicitous if the Richilieu house is not the place of utterance) ${ }^{8}$

The insensitivity of indexicals to their linguistic environment as seen in (1.1)-(1.3) is partly what motivates two-dimensional, Kaplanian theories. By settling content

\footnotetext{
${ }^{7}$ I say that they are not anaphoric in the traditional sense, because they are not anaphoric in the way that third person pronouns, the paradigm anaphoric expressions, are.

${ }^{8}$ The fact that here cannot refer to the Richilieu house in this example is particularly interesting given that here can be used demonstratively and so can, at least prima facie, pick out places other than the place of utterance.
}

- I think we should go here [pointing at a map of Siberia] for our next winter vacation! 
before composition takes place, character ensures that indexicals cannot be effected by the discourse context.

(b) Indexicals are modally rigid. Indexicals, like proper names, are far more obstinate about their referents than are definite descriptions in modal contexts.

(1.4) a. (Necessarily) Aristotle was fond of dogs.

b. (Necessarily) The last great philosopher of antiquity was fond of dogs.

(1.5) a. (Necessarily) I am hungry.

b. (Necessarily) The (current) speaker is hungry.

As Kripke $(1972,1980)$ pointed out, there is a reading of $(1.4 \mathrm{~b})$ such that it is true in a world $w$ just in case whoever is the last great philosopher of antiquity in $w$ is fond of dogs in $w$. On this reading, (1.4b) could be made true by a world in which Aristotle was never born and Plato was the last great philosopher of antiquity and he was fond of dogs. This reading is unavailable for (1.4a): only worlds in which Aristotle was fond of dogs will serve as truth-makers for this example. The truth conditions of (1.4a) and (1.4b) differ, and thus we are to conclude that Aristotle is not synonymous with the last great philosopher of antiquity or any other (non-rigid) ${ }^{9}$ definite description that might be thought to give the meaning of the name Aristotle.

\footnotetext{
${ }^{9}$ Kripke did not consider rigidified definite descriptions, so I will ignore them here in this simple presentation of the modal argument.
} 
Similar remarks can be made for (1.5). In this case, there is meant to be a reading of (1.5b) according to which it is made true in a world $w$ just in case whoever is the speaker in $w$ is hungry in $w$. By contrast, (1.5a) can only be made true by a world $w$ if the person who is speaking in the actual world is hungry in w. Again, we are meant to conclude that because the truth conditions of (1.5a) and (1.5b) differ, $I$ is not synonymous with the (current) speaker or any other definite description that might be thought to give the meaning of the indexical $I$. Setting up the argument with indexicals is trickier than with names because it is difficult to find a definite description that is a good candidate for being a synonym of $I$ that is not itself indexical. The difference between the indexical and description should nevertheless be clear.

In the preface of Kripke (1980), Kripke laid out a wide-scope modal argument using (1.4) without the modal operators in parentheses. He claimed that even the simple sentence versions of (1.4a) and (1.4b) have different truth conditions and so the difference in truth conditions when we add the modal operators (as in the original argument) cannot be explained by saying that proper names are simply descriptions that take wide scope over sentential operators. Throughout this dissertation, when I refer to the Modal Argument (MA) or the Indexical Modal Argument (IMA), I am talking about the wide scope versions of the modal arguments.

(c) The linguistic meaning of indexicals never figures in truth-conditional content or 'what is said'. Following Kripke (1980), a proper name is not synonymous with a definite description (or a cluster of descriptions, etc.). Although speakers may 
associate a given name with a definite description, this association is not controlled by the semantics of the name. Descriptive information associated with a name can vary from one speaker to the next and does not determine the referent for the name.

The story is different for indexicals. Most indexicals do have context-invariable meanings that could be more or less captured by a description and on which speakers who know how to use these expressions would generally agree. Moreover, this meaning plays a very important role in determining a referent for the indexical. Still, at the level of truth-conditional content (asserted content in PI, content in Kaplan's theory), indexicals look a lot like names. The context-insensitive linguistic meaning of the indexical is rarely, if ever, relevant for truth conditions. The sole purpose of this meaning seems to be to find an object to contribute to asserted content.

(d) Indexicals are not blocked by plugs. Certain verbs like say, claim and tell standardly block, or plug, the projection of presuppositions triggered by expressions in their scope as seen in (1.9b). (In each example, I underline the presupposition trigger and italicize the associated presupposition.) Conditionals can also be used to block standard presuppositions. In (1.6a,b), for instance, the presupposition that John has a son does not project outside of the conditional. Indexicals, at least $I$, here and the temporal indexicals, appear to be unaffected by presupposition plugs. Not only does this mark a difference between indexicals and definite descriptions, but it is also a prima facie problem for the thesis that indexicals are presuppositional expressions. 
(1.6) John's son is tall. $\rightarrow$ John has a son

a. If John has a son, then John's son is tall. $\nrightarrow$ John has a son

b. Had John had a son, John's son would have been tall. $\nrightarrow$ John has a son

(1.7) I am speaking. $\rightarrow$ there is a speaker for this utterance

a. If there is a speaker for this utterance, then $\underline{I}$ am speaking. $\rightarrow$ there is a speaker for this utterance

b. Had John made this utterance, then I would have been a man. $\rightarrow$ there is a speaker for this utterance

(1.8) Had John made this utterance, then the speaker would have been a man $\nrightarrow$ there $\underline{i s}$ a speaker for the hypothetical utterance

(1.9) a. Mary recently stopped smoking. $\rightarrow$ Mary used to smoke

b. John said that Mary recently stopped smoking. (But that can’t be true because Mary never smoked.) $\nrightarrow$ Mary used to smoke

(1.10) a. I recently stopped smoking. $\rightarrow$ there is a speaker of this utterance, I used to smoke

b. John said that I recently stopped smoking. (But that's not true. I've never smoked a day in my life.) $\rightarrow$ there is a speaker for this utterance, $\nrightarrow I$ used to smoke 
(1.11) John said that the King of France recently stopped smoking, but that can't be true because France doesn't have a king. $\nrightarrow$ there is a King of France, $\nrightarrow$ the King of France used to smoke

Neither say nor conditionals block the entailment of the proposition that there is a speaker in examples involving $I$. In (1.7b), even though the speaker explicitly attempts to shift the context away from that in which she is the actual speaker, the presupposition of $I$ - that there is a unique speaker available in the context-scopes out of the conditional to be satisfied by the actual speaker. In (1.10b), the presupposition that the speaker used to smoke is blocked by the plug say while the supposed presupposition for $I$ escapes the very same plug. The presuppositions of the definite descriptions in (1.8) and (1.11) do not take scope over the plugs, as expected for presuppositional expressions. I do not mean to imply that the presence of $I$ is what accounts for the entailment that there is a speaker in the actual context when $I$ is used in the above examples. I wish only to report the fact that the proposition that there is a speaker is entailed when $I$ is used regardless of the presence of plugs or filters.

(e) Indexicals cannot be accommodated. Even third person and demonstrative pronouns, which can be plugged, cannot be accommodated. Again, this not only marks a distinction between indexicals and (some) definite descriptions, but it also appears to pose a problem for a presuppositional theory of indexicals and demonstratives (and, of course, third person pronouns). 
(1.12) You are nice.

(1.13) This is made of gold.

(1.14) It might have been the case that this was made of gold.

If the context does not already make an addressee salient for a token of (1.12), then an interpreter will be unable to accommodate the existence of an addressee. Simply adding the information that there is an addressee in the context will not work. Similarly, if there is no obvious demonstration accompanying an utterance of (1.13) or it is not otherwise clear what object is being picked out, then the addressee cannot simply add the information that something is being demonstrated or picked out in order to repair the context; the resulting utterance is deviant. Even if we put the demonstrative inside of a modal, as in (1.14), the same conclusion holds: we cannot accommodate a demonstration or demonstratum.

A widely accepted conclusion drawn from (a)-(e) - and especially from (b) is that indexicals, along with proper names, are rigid designators. That is, for an indexical $i$ in a context $c$ (represented as $i_{c}$ ): if there is an $x$ such that $i_{c}$ designates $x$, then for all worlds $w$, if $x$ exists in $w$ then $i_{c}$ designates $x$ in $w$ and there are no worlds $w^{\prime}$ such that there is a $y$ in $w^{\prime}$ and $i_{c}$ designates $y$ in $w^{\prime}$ and $y \neq x$. Rigidity, however, does not explain the extent of the insensitivity of indexicals to their linguistic environment. In particular, it cannot explain the behavior of indexicals exhibited in (a) and (d), for third person-pronouns have uses that are both discourse anaphoric and rigid, as the following examples show. 
(1.15) John is at home cooking because he is having a dinner party tonight.

(1.16) I told that man [pointing at a man] to come talk to you in a few minutes. He's having a dinner party and he needs some wine suggestions.

The second general conclusion drawn from the above arguments is that indexicals are semantically referential expressions. ${ }^{10}$ This claim is understood differently in different theories, but the general idea is that if an expression $e$ is a member of a class of referential expressions, then if $e$ is not empty, there is some object $x$ such that the truth of a sentence containing $e$ will in every world depend on how things are with $x .{ }^{11}$ Usually, the property of being referential is meant to underly and explain the property of being rigid and serves to more deeply separate indexicals (and proper names) from definite descriptions.

Another, admittedly less popular conclusion to draw, especially from (b) but also from (c) and to some extent (a) and (d) is that indexicals are definite descriptions that must take wide scope. This conclusion is less popular because it is unclear how to make sense of indexicals taking wide scope in seemingly simple sentences like (1.5a) (I am hungry). However, PI is similar to a wide scope theory in some important ways, so I introduce this conclusion here.

Neither the hypothesis that indexicals are referential nor the hypothesis that indexicals are wide-scope, descriptive expressions sheds light on the behavior of in-

\footnotetext{
${ }^{10}$ Recanati (1993) draws this conclusion, as does Kaplan (1989a), among many others.

${ }^{11} \mathrm{~A}$ stronger statement, that requires referential expressions to refer would take out the clause allowing empty referring expressions, but I don't want to get into these issues now. See Recanati (1993) and Sainsbury (2005) for further, in-depth discussion of what it means to be a referring expression.
} 
dexicals in (a). We have already noted that anaphoric expressions can be referential; saying that indexicals are referential, therefore, does not help explain why they differ from paradigmatic anaphoric pronouns with regard to (a). On the other hand, saying that they must take wide-scope is simply to reiterate what we see in (a), not to explain it. Wide-scope, descriptive theories of indexicals will not be able to explain (e), at least not straightforwardly, because accommodation for definite descriptions is common, even for descriptions that take wide scope.

\subsection{A Sketch of the Strategy}

All of the ingredients needed for PI will be laid out in chapters 2-6. Chapter 6 will summarize the main body of the dissertation and show how all of the ingredients presented in chapters 2-5 come together to address (a)-(e). It will also suggest some applications for PI. Chapters 2-5 run as follows.

2. Presuppositional Indexicals presents the basic PI theory. I begin by presenting a simple version of Discourse Representation Theory or DRT (Kamp 1981, Kamp \& Reyle 1993). Although PI's semantic theory requires only a generic dynamic semantics, the structured contexts of DRT (Discourse Representation Structures or DRSs) will be very helpful for explaining how PI works. PI extends the simple version of DRT in two ways. First, whereas original DRT was designed to model information from the linguistic context only, PI incorporates information from the extra-linguistic context into the discourse contexts of DRT. Second, PI introduces an operator, $\uparrow$, into the lexical entries of in-

dexicals. This operator takes scope over the presuppositional components of 
indexical meanings and forces the presuppositional content to be bound to a discourse referent for an actual utterance event in most cases. This feature corresponds to Kaplan's Principle 1 and will play a crucial role in explaining why indexicals are normally rigid and why their presuppositions do not normally bind to antecedents introduced in local contexts, despite the fact that PI does not stipulate that such binding is impossible. ${ }^{12}$

3. What 'Now'? demonstrates an application of $\uparrow$. I argue that the presupposition of now can in some cases bind to times introduced in discourse, contrary to the predictions of a Kaplanian, two-dimensional theory. Now is used when its presence either marks a contrast between two times or when a speaker wishes to emphasize the present time to the exclusion of alternative times. Thus, now makes a very important contribution to discourse that goes beyond its contribution to asserted content (which is often redundant due to tense). Normally, its contrastive or emphatic function is limited to times given in the extra-linguistic context, but sometimes, when the discourse itself has a contrastive structure, now can pick up on times introduced in discourse as well. The result is that now can refer to past times in very special situations. At the end of the chapter, I suggest that such discourse behavior is exhibited by other indexicals as well, including here, actual, and actually. This behavior is sufficiently widespread to be taken seriously by a semantic account of indexicals.

\footnotetext{
${ }^{12}$ Kaplan (1989)'s Principle 1, p. 492: "The referent of a pure indexical depends on the context, and the referent of a demonstrative depends on the associated demonstration."
} 
4. Wider Scope addresses a potential worry for PI, namely that even if PI can secure rigidity for indexicals by forcing their presuppositions to take wide scope, PI does not lay a solid foundation for a general theory of definites because it cannot distinguish between rigid and non-rigid readings of definites in simple sentences. I show that PI's contexts do in fact have the structure necessary to generate all of the requisite readings of definites in simple sentences. I then turn to the question of what makes indexicals different from their fellow, nonindexical definites. Why, for example, are indexicals incapable of having nonrigid readings in simple sentences? I argue that while this difference between indexicals and some other definites shows that PI cannot be extended straightforwardly to a general theory of definites, i.e. by prefixing the presuppositions of all definites with $\uparrow$, this is not a problem for PI. The idiosyncrasies of indexical semantics are understood in terms of the particular resolution strategies adopted by indexical presuppositions. To understand more about how indexical resolution strategies compare to those of other definites, we would have to look deeper at the resolution behavior of different definites. I suggest some frameworks that one might adopt to explore this question.

5. 'Descriptive' Indexicals discusses examples of so-called 'descriptive indexicals,' considered at length in Nunberg (1993). These examples would seem to pose a problem for PI, which does not allow indexicals to have descriptive interpretations, but I show that this problem is illusory. By supplementing PI with simple, constrained pragmatic mechanisms, we can provide an analysis of the data that are consistent with PI. 


\section{Chapter 2}

\section{Presuppositional Indexicals}

This chapter introduces the basic framework of Presuppositional Indexicals (PI). While each subsequent chapter will illuminate different features of PI, and thereby contribute to a deeper understanding of the theory, the basic machinery will be laid out here. I begin with a short introduction to Discourse Representation Theory or DRT. I will adopt a generic dynamic semantics as the basis for PI, but the Discourse Representation Structures (DRSs) of DRT will greatly ease our discussion. After introducing DRSs, I turn to PI and explain how it builds on the basic DRS framework. PI extends the notion of a discourse context to include not only the contents of sentences uttered in a discourse, but also information derived from the extra-linguistic context. It also introduces lexical entries for indexicals. These entries make use of a new operator $\uparrow$ whose basic features I will outline in section 2.2. I conclude with a brief discussion of how PI, which is designed for non-demonstrative indexicals, could easily be extended to cover demonstratives as well.

\subsection{Discourse Representation Structures}

PI is set in a dynamic semantic framework that blends features of Discourse Representation Theory (DRT; Kamp 1981, Kamp \& Reyle 1993) and Dynamic Pred- 
icate Logic (DPL; Groenindijk \& Stokhof 1991). The representational nature of DRT is intuitive and I use its hierarchical logical forms (Discourse Representation Structures) to facilitate the discussion of different semantic contributions made by different kinds of content, e.g. by presupposed and asserted contents. Nevertheless, the representational level of DRT is not essential to the arguments that I will make concerning PI, and the semantics of PI will be more in line with a dynamic semantic system like DPL.

Discourse Representation Structures (DRSs), the logical forms of DRT, are meant to be mental representations of information states, constructed from the point of view of an (idealized) addressee. ${ }^{1}$ Each DRS consists of a set of discourse referents, called the universe of the DRS, and a set of conditions. A discourse referent is a variable under an assignment function that stands for an entity introduced in discourse. The conditions in a DRS represent information that has been given in the discourse about the entities picked out by the discourse referents. Atomic conditions look like unbound, first-order formulas of the form $C(x)$, for some condition $C$, or $x=y$, where $x$ and $y$ are discourse referents. Compound conditions are formed by letting logical operators take DRSs as arguments. For example, where $\mathrm{K}$ and $\mathrm{K}^{\prime}$ are DRSs, compound conditions will have one of the following forms: $\neg \mathrm{K}, \mathrm{K} \rightarrow \mathrm{K}^{\prime}, \mathrm{K} \vee$ $\mathrm{K}^{\prime}$, or $\square \mathrm{K}$. Let (2.1) be the first sentence in a discourse so that the incoming DRS, $\mathrm{K}_{0}$, is empty (i.e. $\mathrm{K}_{0}$ has no discourse referents and no conditions).

\footnotetext{
${ }^{1}$ I will assume throughout this dissertation, unless I clearly say otherwise, that the addressee is a perfect addressee in the sense that if something is salient in the context, the addressee will realize this, or if the speaker says something, the addressee will understand it perfectly. This allows me to abstract away from specific problems of communication encountered in specific contexts and focus on the question of how mental representations are updated with the contents of sentences.
} 
(2.1) A man came in.

In DRT, as in DPL and Heim's File Change Semantics (Heim 1982, 1983), indefinite noun phrases are understood neither as quantificational expressions nor as referring expressions, but rather as expressions that introduce a discourse referent into the context. Therefore, the first thing that we do to construct the DRS for (2.1) is add a new discourse referent $x$ to the universe. We then add the conditions $\operatorname{man}(x)$ and came-in $(x)$ to the set of conditions. The final DRS will look like this:

$$
[x: \operatorname{man}(x), \text { came-in }(x)]^{2}
$$

The universe is the set of discourse referents to the left of the colon; the set of conditions lies to the right of the colon. Divisions between contexts and sub-contexts will be marked with square brackets.

Now suppose we add to our one sentence discourse the following sentence. He ordered a sandwich.

I will represent the logical form for (2.3) as follows.

$$
[y: \operatorname{ordered}-\operatorname{sand}(y) \wedge y=?]
$$

\footnotetext{
${ }^{2}$ I use linear notation for DRSs because I think the presentation is sufficiently clear and it takes up less space. It also makes clearer the relation between DRSs and their corresponding first order formulas.
} 
The question mark signifies that $y$ is anaphoric and needs to bind to a discourse referent from an accessible DRS (I will explain accessibility below). ${ }^{3}$ When we update (2.2) with (2.4), we can bind $y$ to $x$ with the following result:

$$
[x: \operatorname{man}(x), \text { came-in }(x), \text { ordered-sand }(y), x=y]
$$

DRSs are understood hierarchically: there is a global DRS which keeps track of information that has been accepted by the conversational participants during a discourse, but there can also be DRSs created within this global DRS, or even within other DRSs within the global DRS, depending on the structure of the discourse. ${ }^{4}$ Consider the following examples, each of which involves the creation of sub-contexts within the global context.

(2.6) I would like to get some chickens, but they might attract a fox. The fox would hurt our cats/*The fox will hurt our cats.

\footnotetext{
${ }^{3}$ There are different ways to signify that a discourse referent is anaphoric. Geurts (1999), e.g., underlines an anaphoric discourse referent. In Geurts' notation, (2.4) would have the form:

( $\underline{y}$ : ordered-sand $(y))$

I follow Wada and Asher (1986) in using the question mark notation. Kamp \& Reyle's original version of DRT does not have a mechanism for marking anaphoric discourse referents, but this is because in their theory, anaphoric discourse referents are bound during the DRS construction procedure, rather than as a separate, second step.

${ }^{4}$ The notion of a global context is not DRT's alone. The notion has been famously used by, for example, Stalnaker. Though Stalnaker would not endorse a semantic discourse theory like DRT, he would say that the global context is the common ground of information, determined by the shared beliefs and presuppositions of the conversational participants. Others would disagree that the global context should include so much information. In plain DRT, for instance, the starting DRS for a discourse is always assumed to be empty and therefore does not contain contents of beliefs shared by discourse participants at the start of a conversation.
} 
(2.7) a. There's a fly in the kitchen. I can hear it buzzing.

b. There isn't a fly in the kitchen. *I can't hear it buzzing.

(2.8) If John has a son, he is very tall.

In (2.6), an example of modal subordination, the modal might introduces a subcontext within the global context. The existence of the counterfactual fox under discussion is not asserted, i.e. it is not added to the global context, but only supposed inside of the context created by the modal. This is evidenced by the fact that a non-modal assumption cannot be made about the fox. (2.7) shows that sometimes indefinites introduce entities that can be picked up anaphorically and sometimes they don't. Whether or not they can be picked up anaphorically sometimes depends on the presence of operators like negation. One way to explain this is to say that negation creates a subcontext within the global context that is inaccessible to it in the second sentence of (2.7b). In the third example, we cannot add the claim he is tall to the global context, for he is linked anaphorically to John's son and it is not a part of the global context that John has a son. Within the context created by the conditional, however, talking about John's hypothetical son is perfectly natural.

\section{$2.2 \quad$ PI}

\subsubsection{Introducing $\uparrow$}

PI makes use of a new operator, $\uparrow$. Before we can introduce this operator, however, we will need the notion of a sequence of DRSs and a notion of how presup-

positions are resolved by a sequence of DRSs. Let the most global level of a DRS K 
be labeled $\mathrm{K}_{0}$. Let the sub-DRS immediately subordinate to $\mathrm{K}_{0}$ be labeled $\mathrm{K}_{1}$ and so on. If a DRS $\mathrm{K}_{n}$ contains more than one complex condition, number the sub-DRSs introduced by these conditions according to the order in which they are introduced into the DRS. We therefore get a sequence of DRSs, $\mathrm{K}_{0}, \mathrm{~K}_{1}, \ldots, \mathrm{K}_{n}, \mathrm{~K}_{n+1}, \ldots$ for the given DRS K. Now suppose that we have a sequence of $\mathrm{DRSs} \mathrm{K}_{0}, \ldots, \mathrm{K}_{n}$ in $\mathrm{K}$ and that a presupposition $\phi$ is triggered in $\mathrm{K}_{n}$. $\phi$ will be resolved in $\mathrm{K}_{0}, \ldots, \mathrm{K}_{n}$ (and therefore in $\mathrm{K}$ ) just in case some subsequence $\mathrm{K}_{l}, \ldots, \mathrm{K}_{m}, m \leq n$ satisfies the presupposition. If the presupposition has the form of an existential formula, satisfaction will involve choosing a witness for the presupposition in some DRS in the sequence $\mathrm{K}_{l}, \ldots, \mathrm{K}_{m}$. If there is no available witness, the presupposition can be satisfied by accommodation, i.e. addition, of a witness at some DRS in the sequence $\mathrm{K}_{l}, \ldots, \mathrm{K}_{m}$, so long as this does not lead to inconsistency.

Where $\phi$ is a presupposition, the operator $\uparrow$ in a formula of the form $\uparrow \phi$ forces the resolution of $\phi$ in the outermost context possible. ${ }^{5} \uparrow$ gives instructions to first look in the global context, $\mathrm{K}_{0}$, for an antecedent (a witness in the case of an existential presupposition). If there is no antecedent in $K_{0}$, the next option is to accommodate an antecedent in $K_{0}$. If accommodation is not possible at $K_{0}$ because of inconsistency, $\uparrow$ says that the next available option for resolution of $\phi$ is to bind in $K_{1}$. If an antecedent is not found in $K_{1}$, then the next option is to accommodate there if possible. This process will continue until an antecedent is found or until we arrive back at the DRS in which $\phi$ was triggered. If no antecedent is found there and

\footnotetext{
${ }^{5} \uparrow$ may very well have uses for contents that project but are not considered presuppositional, e.g. material in appositive constructions. I assume that $\phi$ is a presupposition here because I am only concerned with projective material that is also presuppositional in this dissertation.
} 
no antecedent can be accommodated, the result is presupposition failure. Update with the DRS in which $\phi$ is triggered cannot proceed.

So long as a presupposition $\phi$ in a formula of the form $\uparrow \phi$ can find an antecedent in a DRS $\mathrm{K}_{j}$, it will ignore potential antecedents in any sub-DRS of $\mathrm{K}_{j}$. $\phi$ will be resolved in the most global context possible. For example, suppose a formula of the form $\diamond \psi$ triggers the creation of a condition $\diamond \mathrm{K}_{m}$ in $\mathrm{K}_{0}$ of some DRS $\mathrm{K}$ and suppose that $\phi$ is triggered in a DRS $\mathrm{K}_{n}$ in $\mathrm{K}$ such that $m<n$. So long as $\phi$ finds an antecedent in some DRS $\mathrm{K}_{j}$ for $j<m, \phi$ will ignore the condition $\diamond \mathrm{K}_{m}$. If $\phi$ is resolved all the way at the top of $K$, at level $K_{0}$, then the interpretation of the expression that triggered $\phi$ will be rigid, as I explain in section 2.2.4. However, if an antecedent cannot be found in a DRS in $\mathrm{K}$ that is prior to $\mathrm{K}_{m}$ in the sequence $\mathrm{K}_{0}, \ldots, \mathrm{K}_{n}$ and $\mathrm{K}_{m}$ contains an available antecedent for $\phi$, or an antecedent can be accommodated there, then $\phi$ will be resolved in $\mathrm{K}_{m}$ and it will take narrow scope with regard to $\diamond$. Thus, although rigid interpretations will be preferred for expressions whose presuppositions are prefixed with $\uparrow$, there are cases in which the rigid interpretations are not possible. In these cases, a non-rigid interpretation of the expression can result.

A formula of the form $\uparrow \phi$, like a formula of the form $\neg \phi$ or $\square \phi$, etc., is added to a DRS at the level at which it is triggered. Thus presuppositional content will sit alongside asserted content in a DRS. ${ }^{6}$ This means that presuppositional content can

\footnotetext{
${ }^{6}$ DRSs are logical forms, so technically, conditions in a DRS cannot be contents of assertions. They are rather representations of the contents of assertions. I sometimes refer to the logical forms of asserted contents as contents, but it should be clear that I take them to be representations, not the contents themselves. In this chapter, I am keeping the discussion of semantics to a minimum
} 
be treated compositionally and it underscores an idea that will be important in this dissertation, namely that presuppositional content is a genuine form of content and therefore deserves to be represented in a DRS. ${ }^{7}$ The difference between presuppositional content and asserted content is simply that presuppositional content can, and generally will, be resolved outside of the DRS in which it is triggered. Presuppositional content and asserted content play different roles: asserted content adds new content to a DRS and presuppositional content locates a site in a DRS at which to attach this new information.

\section{$2.2 .2 \quad K_{0}$}

PI builds off of the relational DRT offered in the previous section and extends it in two important ways. First, DRSs in PI will include not only discourse referents and conditions introduced through discourse, but also discourse referents and conditions introduced via the extra-linguistic context. This means, for example, that DRSs can include representations of perceptual information. Most importantly for PI, this extension allows for utterance events to be represented in DRSs. When an agent utters a sentence $s$, not only will the content of $s$ (relative to the input context) be incorporated into the DRS for the discourse, but the event itself will be represented. Moreover, its agent, addressee (if there is one), time, location, and world will also be represented and they will be represented as the agent, addressee,

because I mainly want to bring out the structure of PI.

${ }^{7}$ Kaplan's two-dimensional theory does not treat character as a form of content. Character serves to determine a referent and then 'exits the scene'. PI presents a very different view of the context-invariable meanings of indexicals as will shortly become clear. 
time, location, and world of the particular utterance event.

Information from the extra-linguistic context will be represented in the most global DRS, $\mathrm{K}_{0}$, while the contents of sentences uttered will be represented by subDRSs of $K_{0}$. This hierarchy reflects both the fact that information from the extralinguistic context comes from a special source and the fact that discourses take place within an external context. ${ }^{8}$ It also reflects the fact that the extra-linguistic context can effect the interpretation of what is said in a discourse while the converse claim is not true.

The second way that PI extends DRT is by adding special lexical entries for indexicals. These entries have two key features. First, they are under-specified for an utterance event. That is, their presuppositions have an anaphoric element that must be bound to a discourse referent for an utterance event. This captures the fact that the interpretations of indexicals generally depend on features of utterances (or thoughts). Second, PI prefixes the presuppositional components of indexical lexical entries with $\uparrow$, which forces the presuppositions for indexicals to bind in the highest context possible. For indexicals, this will almost always be the global context, but I will discuss some exceptions to this general rule in What 'Now'? For now, what is important is that $\uparrow$ captures the fact that indexicals generally do bind at the global level without explicitly writing a rule into their entries to the effect that indexicals can only be bound to the actual utterance event. The interaction of the linguistic meanings of indexicals and their surrounding linguistic context is allowed in PI, if

\footnotetext{
${ }^{8}$ Works of fiction might be counterexamples to this claim. I am restricting my discussion here to non-fictional discourses.
} 
the conditions are right. The fact is that the conditions usually aren't right. From the point of view of the entries of indexicals, the global context is not a special kind of context. It contains discourse referents and conditions just like all other DRSs. It is simply more global.

\subsubsection{The lexical entries of indexicals}

As mentioned above, PI assumes that when an utterance $u$ of a sentence $s$ is made in a context $C$, information that the utterance has been made will be added to $C$ as will certain information about the utterance event itself, e.g. its agent, time, location. ${ }^{9}$ The content of $s$ will then be evaluated relative to the context $C^{\prime}$ which results from updating $C$ with information about $u$. PI formulates this assumption by stipulating that an utterance event will be represented in $\mathrm{K}_{0}$ for a DRS K. ${ }^{10}$ Consider the simple example (2.9).

Someone is tired.

An utterance of (2.9) will introduce a discourse referent $e_{\pi_{0}}$ for the utterance event ${ }^{11}$ as well as new discourse referents $x_{0}, y_{0}, z_{0}, t_{0}, w_{0}$ to represent relevant features of the utterance event. The predicates $a g, a d$, in, $a t_{t}$ and $a t_{w}$ below stand for functions

\footnotetext{
${ }^{9}$ Recall that contexts in PI are structured information states. This notion of context is in line with the dynamic semantic (and to some extent, the dynamic pragmatic) tradition, as we have seen, but is very different from Kaplan's very restricted notion of context.

${ }^{10}$ This stipulation is inspired by the utterance DRSs of Zeevat (2000).

${ }^{11} e$ is the standard discourse referent used for eventualities in DRT, following Davidson (1967). I subscript markers for utterance events with a $\pi$ to indicate that they are markers specifically for eventualities introduced by utterances. In addition, I also sometimes subscript $e_{\pi} \mathrm{s}$ in order to distinguish them, i.e. $e_{\pi_{0}}, e_{\pi_{1}}, e_{\pi_{2}}, \ldots$
} 
over utterance events that map each utterance event to an agent, addressee, location, time, and world, respectively. $\mathrm{E}_{\pi}$ is a non-descriptive condition that serves to pick out a particular utterance event in a given world. I will say more about it when I discuss how PI secures rigidity for indexicals.

- $\mathrm{E}_{\pi}\left(e_{\pi_{0}}\right)$

- $\operatorname{ag}\left(e_{\pi_{0}}, x_{0}\right)$

- $\operatorname{ad}\left(e_{\pi_{0}}, y_{0}\right)$

- $\operatorname{in}\left(e_{\pi_{0}}, z_{0}\right)$

- $\operatorname{at}_{t}\left(e_{\pi_{0}}, t_{0}\right)$

- $\operatorname{at}_{w}\left(e_{\pi_{0}}, w_{0}\right)$

Suppose that (2.9) is the first sentence uttered in a discourse. We start with an empty DRS $K_{\emptyset}$. Update with information on the utterance event contributes the following discourse referents and conditions to the global DRS, $\mathrm{K}_{0}$ :

$$
\begin{aligned}
& {\left[e_{\pi_{0}}, x_{0}, y_{0}, z_{0}, t_{0}, w_{0}: \mathrm{E}_{\pi}\left(e_{\pi_{0}}\right), \operatorname{ag}\left(e_{\pi_{0}}, x_{0}\right), \operatorname{ad}\left(e_{\pi_{0}}, y_{0}\right), \operatorname{in}\left(e_{\pi_{0}}, z_{0}\right), \text { at }_{t}\left(e_{\pi_{0}}, t_{0}\right),\right.} \\
& \text { at } \left._{w}\left(e_{\pi_{0}}, w_{0}\right)\right]
\end{aligned}
$$

Incorporation of the DRS for (2.9), $[y: \operatorname{TIRED}(y)]$, will then yield a new DRS $\mathrm{K}_{1}$. There are no indexical expressions in this example, so the incorporation of (2.9) will work as in standard DRT. Of course, the tense of the sentence could be treated as 
bound to the time of utterance. I include a very brief discussion of tense in the next chapter.

Now consider an utterance of (2.11).

(2.11) I am tired.

We first update with information concerning the utterance event. Suppose that update with information on the utterance yields the same DRS $\mathrm{K}_{0}$ introduced in our discussion of (2.9), i.e., the DRS in (2.10). The content of (2.11) will then be evaluated relative to this updated context, but to see how this works, we need to specify the lexical entries for indexicals. PI posits the following lexical entries for the indexicals $I$, you, here, now and tomorrow, where $\mathrm{T}_{2}$ in the entry for tomorrow stands for a function that takes a time as an argument and delivers the following day as output. ${ }^{12}$

- $\llbracket I \rrbracket: \lambda P\left(\exists x^{\prime}\left(\uparrow \exists e_{\pi}\left(\operatorname{ag}\left(e_{\pi}, x^{\prime}\right) \wedge e_{\pi}=\right.\right.\right.$ ? $\left.\left.) \wedge P\left(x^{\prime}\right)\right)\right)$

- $\llbracket y o u \rrbracket: \lambda P\left(\exists y^{\prime}\left(\uparrow \exists e_{\pi}\left(\operatorname{ad}\left(e_{\pi}, y^{\prime}\right) \wedge e_{\pi}=?\right) \wedge P\left(y^{\prime}\right)\right)\right)$

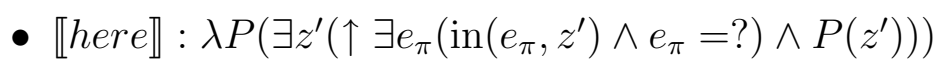

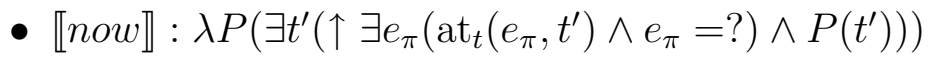

\footnotetext{
${ }^{12} \lambda$-terms are not used in standard DRT. However, I am interested in showing how the semantics of indexicals effect the semantics of sentences in which they figure; using compositional lexical entries for indexicals allows me to do this. Kamp \& Reyle's DRT is not compositional. I follow Asher (1993) and Muskens (1996), among others, in combining the $\lambda$-calculus with DRT. The semantics for the lexical entries I offer here can be understood in line with Muskens 1996.
} 


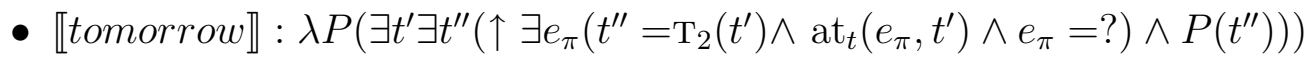

Each of these entries is underspecified with regard to an utterance event. This underspecification is captured by the condition $e_{\pi}=$ ?, which indicates that the discourse referent $e_{\pi}$ must be bound to a discourse referent for an utterance event that is accessible in the incoming context $\left(\mathrm{K}_{0}\right.$ or $\mathrm{K}_{1}$ in this case). Thus, indexicals have an anaphoric element just like anaphoric pronouns do. In fact, PI treats indexicals very much like anaphoric pronouns, albeit anaphoric pronouns that are very picky about their antecedents. Once the discourse referent $e_{\pi}$ has been bound, the discourse referent figuring in the predication (e.g. $x^{\prime}$ in the entry for $I$ ) will in effect be bound as well. Consider the entry for $I$ and assume that $e_{\pi}$ has been bound to an antecedent $e_{\pi_{0}}$ so that $e_{\pi}=e_{\pi_{0}}$. If $\operatorname{ag}\left(e_{\pi_{0}}, x_{0}\right)$ (given in the global context) then $\operatorname{ag}\left(e_{\pi}, x_{0}\right)$ (substitution). Because $\operatorname{ag}\left(e_{\pi}, x^{\prime}\right)$ (lexical entry for $I$ ), $x_{0}=x^{\prime}$, i.e. $x^{\prime}$ is bound to $x_{0}$.

The $\uparrow$ operator in each of the lexical entries forces the presuppositions of indexicals to be bound or accommodated in the highest context possible. ${ }^{13}$ As global binding will be possible in almost every case, this means that indexicals will almost always be bound to an antecedent in the global context, as desired. Note that once the material in the scope of $\uparrow$ is bound (either to an old or accommodated antecedent),

\footnotetext{
${ }^{13}$ Kamp (1981) posits a rule that a proper name will introduce a discourse referent and condition (e.g. $x$ and $x=$ john) into the most global DRS in order to make discourse referents introduced by names accessible to all sub-DRSs. The effects of $\uparrow$ resemble the effects of Kamp's rule for names in obvious ways. However, there are also important differences. First, $\uparrow$ is an operator on presuppositions. Second, $\uparrow$ is more nuanced than Kamp's rule because it allows for indexicals to interact with operators if binding in a more global DRS is not possible. Third, I don't think that names should be prefixed with $\uparrow$, as I mention in Wider Scope, but this claim is not central to the argument of this dissertation.)
} 
it becomes redundant at the level of the DRS in which it sits. Information is carried down through a DRS, so the indexical presupposition, once bound to old information, does not provide any new information to the DRS. It does not affect asserted content.

The final thing to note about PI's lexical entries for indexicals, before returning to example (2.11), is that indexicals do not have descriptive meanings in the sense that there is no definite description in natural language that can be said to capture the meaning - either the asserted content or the character - of the indexical. This is meant to account for the general observation that indexicals are irreducibly indexical (see Perry 1979).

Having laid out the lexical entries for a representative set of indexicals, we are now in a position to explain how update with the content of (2.11) will proceed in the context imagined above. I initially contributes the following under-specified content in virtue of its lexical meaning.

$$
\lambda P\left(\exists x_{1}\left(\uparrow \exists e_{\pi_{1}}\left(\operatorname{ag}\left(e_{\pi_{1}}, x_{1}\right) \wedge e_{\pi_{1}}=?\right) \wedge P\left(x_{1}\right)\right)\right)
$$

The discourse referent $e_{\pi_{1}}$ needs to be bound and the $\uparrow$ operator requires that it be bound in the highest DRS possible. We get $e_{\pi_{1}}=e_{\pi_{0}}$, which delivers the following LF.

$$
\lambda P\left(\exists x_{1}\left(\uparrow \exists e_{\pi_{1}}\left(\operatorname{ag}\left(e_{\pi_{1}}, x_{1}\right) \wedge e_{\pi_{1}}=e_{\pi_{0}}\right) \wedge P\left(x_{1}\right)\right)\right)
$$

We can now combine this contribution of $I$ with the predicate, whose lexical entry we will assume is simply $\lambda z(\operatorname{tired}(z))$. We get the following formula: 


$$
\exists x_{1}\left(\uparrow \exists e_{\pi_{1}}\left(\operatorname{ag}\left(e_{\pi_{1}}, x_{1}\right) \wedge e_{\pi_{1}}=e_{\pi_{0}}\right) \wedge \operatorname{tired}\left(x_{1}\right)\right)
$$

To tie this into the previous discussion, we can translate this into a DRS:

$$
\left.\left[x_{1}: \uparrow\left[e_{\pi_{1}}:\left(\operatorname{ag}\left(e_{\pi_{1}}, x_{1}\right), e_{\pi_{1}}=e_{\pi_{0}}\right)\right], \operatorname{tired}\left(x_{1}\right)\right)\right]
$$

Note that when we convert the first order (or rather, first order $+\uparrow$ ) formula in (2.14) into a DRS, the variables that were in the scope of existential quantifiers are converted into discourse referents in the universe of a DRS. There are no existential quantifiers in sight. Existential quantifiers, like indefinites, introduce discourse referents in DRT. Unlike variables in the scope of existential quantifiers, however, discourse referents in the universe of a DRS can be bound by other operators. This feature of DRT will be crucial for my discussion of the binding of indexicals. It might sound suspicious when I say that indexical presuppositions can be bound when I represent them as existential formulas. But keep in mind that once we convert the first order formulas into DRSs, the resulting discourse referents can be bound. This is what I have in mind when I say indexical presuppositions can be bound.

As I said above, once content in the scope of $\uparrow$ is bound in a superordinate DRS, it becomes redundant at the level of the sub-DRS in which it sits because this sub-DRS will inherit information from DRSs superordinate to it. As a result, this content can be eliminated without affecting the evaluation of the DRS as a whole. The logical form in $(2.14)$ is therefore equivalent to $\left(\operatorname{tired}\left(x_{0}\right)\right)$ in a DRS in which the indexical is bound at a superordinate level. I provide a derivation to show how the redundant content can be eliminated. 
1. $\exists x_{1}\left(\uparrow \exists e_{\pi_{1}}\left(\operatorname{ag}\left(e_{\pi_{1}}, x_{1}\right) \wedge e_{\pi_{1}}=e_{\pi_{0}}\right) \wedge \operatorname{tired}\left(x_{1}\right)\right)\left(\right.$ bind $e_{\pi_{1}}$ to $\left.e_{\pi_{0}}\right)$

2. $\exists x_{1}\left(\uparrow \exists e_{\pi_{1}}\left(\operatorname{ag}\left(e_{\pi_{0}}, x_{1}\right) \wedge e_{\pi_{0}}=e_{\pi_{0}}\right) \wedge \operatorname{tired}\left(x_{1}\right)\right)$ (substitute $e_{\pi_{0}}$ for $\left.e_{\pi_{1}}\right)$

3. $\exists x_{1}\left(\uparrow \operatorname{ag}\left(e_{\pi_{0}}, x_{1}\right) \wedge \operatorname{tired}\left(x_{1}\right)\right)$ (eliminate tautology and vacuous quantifier)

4. $\exists x_{1}\left(\uparrow \operatorname{ag}\left(e_{\pi_{0}}, x_{0}\right) \wedge \operatorname{tired}\left(x_{0}\right)\right)\left(\operatorname{ag}\left(e_{\pi_{0}}, x_{0}\right)\right.$ from global context $)$

5. $\uparrow \operatorname{ag}\left(e_{\pi_{0}}, x_{0}\right) \wedge \operatorname{tired}\left(x_{0}\right)$ (eliminate vacuous quantifier)

6. $\operatorname{tired}\left(x_{0}\right)$ (eliminate redundant information and vacuous modal operator $\uparrow$ )

Disregarding tense (for now), we get the following DRS for (2.11).

- $\left[e_{\pi_{0}}, x_{0}, y_{0}, z_{0}, t_{0}, w_{0}: \mathrm{E}_{\pi}\left(e_{\pi_{0}}\right), \operatorname{ag}\left(e_{\pi_{0}}, x_{0}\right)\left[: \operatorname{tired}\left(x_{0}\right)\right]\right]$

I have left out conditions introduced by the utterance event that are irrelevant for this example.

The lexical entries for indexicals reflect the sense in which indexicals are presuppositional, according to PI. The lexical entries for each indexical type will contain some content that falls in the scope of $\uparrow$ and some content that falls outside of the scope of this operator. The content in the scope of $\uparrow$ is the presuppositional content. The idea is that the presupposed content is content that has to be attached somewhere in the incoming DRS. Its role is not to add new content to the discourse, but to select a point in the DRS at which new content is to be added. For indexicals, this point will almost always be the global DRS. Once an attachment site has been found, the role played by the presupposed content is over. The presupposition does 
not add any new information; it does not figure in asserted content. This way of understanding presupposition lines up with the traditional notion that presupposed content is content that a speaker takes for granted. It also captures Kaplan's insight that the context-invariable meanings of indexicals do not show up in what he called 'content'; but it does this while still treating presuppositional content as a genuine form of content that is contributed to a DRS. The content that it contributes might end up being redundant, but this is because its content is already in the DRS. The presuppositional content of indexicals does not disappear; it shows up in the DRS as a whole. PI's presuppositions are unlike Kaplan's character in this way.

Another way in which PI's understanding of presupposition lines up with many other theories of presupposition is that presupposition failure leads to infelicity and/or it results in an inconsistent DRS. ${ }^{14}$ As I have already said, if a speaker uses an indexical and it is not clear to her audience that the presupposition of the indexical has been satisfied, the speaker's utterance will seem infelicitous to the interpreter. ${ }^{15}$ The interpreter will not be able to update her DRS with the content of the speaker's utterance. This normally does not happen, of course; it is difficult for the presuppositions of indexicals to fail to be satisfied, but it can happen. Suppose that a speaker $S$ is talking to an individual $A$. Suddenly he turns and looks at the

\footnotetext{
${ }^{14}$ I should note also that PI borrows the notion of binding of a presupposition from van der Sandt (1992). In addition, $\uparrow$ resembles Beaver's operator $\partial$ in some respects, but $\uparrow$, unlike $\partial$, imposes a requirement about where a presupposition is satisfied in the context $(1995,2001)$.

${ }^{15}$ This should be qualified. Suppose that a speaker says to an addressee, 'You should come over here,' and that someone overhears this comment but cannot see the speaker. In this case, the eavesdropper might not have independent evidence that there is an addressee in the context and she might not know where 'here' is. Still, the speaker's utterance won't necessarily sound infelicitous to her. An interpreter would need to have reason to doubt that the requisite presuppositions were satisfied in order for apparent infelicity to occur.
} 
doorway and says, You look very nice today. He then turns back to $A$ and asks, Don't you agree? A would be more likely to return a confused look than a yes or a no. But now suppose that both $S$ and $A$ are sharing a hallucination. They both think that one of their co-workers has just walked through the door, but they are wrong. No one is there. In this case, $A$ might very well agree with $S$ 's judgment. The utterance would seem felicitous to the conversational participants, but PI will still treat this as a case of presuppositional failure. There will be no way to successfully update the context with this utterance.

\subsubsection{Wide Scope}

There are certain features that all accounts of indexicals are bound to share. They all have to explain the (general) dependency of indexicals on utterances, for example. PI does this by introducing a layer of DRSs for information from the extra-linguistic context and by prefixing the lexical entries for indexicals with the $\uparrow$ operator; Kaplan achieved it with his more restrictive character function. Moreover, all theories of indexicals will have to do something to ensure rigidity for indexicals, at least in paradigmatic cases. Kaplanian, two-dimensional theories achieve rigidity for indexicals by making sure that character delivers a value for an indexical before composition takes place and by positing that indexicals contribute constants to logical form. ${ }^{16} \mathrm{PI}$ contends that the Kaplanian response is overly severe. We need only secure the insensitivity of indexicals to modal operators. Stipulating that the

\footnotetext{
${ }^{16}$ Kaplan said that indexical sentences express singular propositions. The first order correlate of a singular proposition is a formula containing a constant or a variable under a constant assignment function.
} 
presuppositional meanings of all context sensitive expressions can never interact with linguistic operators during composition is only one way to do this, and not a very profitable one.

PI ensures rigidity for indexicals by ensuring that indexicals take wide scope in the sense that an indexical presupposition must be bound outside of the sentence altogether when possible. In order to clarify both the sense in which PI is a widescope theory and the way that its account of indexical rigidity differs from that of two-dimensional theories, I will start by considering PI's treatment of two well-known examples that have been used to motivate two-dimensional theories of indexicals over wide scope theories. I will then show how PI secures rigidity.

(2.16) It is possible that in Pakistan, in five years, only those who are actually here now are envied (Kaplan, 499).

(2.17) One day all persons now alive will be dead. (Kamp, 1971)

These examples require that we offer entries for verb phrase modifiers.

$$
\begin{aligned}
& \llbracket n o w_{v p} \rrbracket=\lambda P \lambda e \lambda x \exists t\left(\uparrow \exists e_{\pi}\left(\operatorname{at}_{t}\left(e_{\pi}, t\right) \wedge e_{\pi}=?\right) \wedge P(e, x) \wedge \operatorname{at}_{t}(e, t)\right) \\
& \llbracket h e r e_{v p} \rrbracket=\lambda P \lambda e \lambda x \exists y\left(\uparrow \exists e_{\pi}\left(\operatorname{in}\left(e_{\pi}, y\right) \wedge e_{\pi}=?\right) \wedge P(e, x) \wedge \operatorname{in}(e, y)\right) \\
& \llbracket a_{c t u a l l y} \rrbracket=\lambda P \lambda e \lambda x \exists w\left(\uparrow \exists e_{\pi}\left(\operatorname{at}_{w}\left(e_{\pi}, w\right) \wedge e_{\pi}=?\right) \wedge P(e, x) \wedge \operatorname{at}_{w}(e, w)\right)
\end{aligned}
$$

Now let's run through (2.17). Again, ignoring tense, the important part of this example is the antecedent, which contains now. I assume that the entry for alive is 
$\lambda s \lambda y$ alive $(s, y)$ and use square brackets to mark the arguments below. We combine the lexical meaning for adverbial now with the lexical entry for alive as follows.

- $\lambda P \lambda e \lambda x\left(\exists t\left(\uparrow \exists e_{\pi}\left(\operatorname{at}_{t}\left(e_{\pi}, t\right) \wedge e_{\pi}=?\right)\right) \wedge P(e, x) \wedge \operatorname{at}_{t}(e, t)\right)[\lambda s \lambda y$ alive $(s, y)]$

- $\lambda e \lambda x\left(\exists t\left(\uparrow \exists e_{\pi}\left(\operatorname{at}_{t}\left(e_{\pi}, t\right) \wedge e_{\pi}=?\right)\right) \wedge \lambda s \lambda y(\operatorname{alive}(s, y))[e, x] \wedge \operatorname{at}_{t}(e, t)\right)$

- $\lambda e \lambda x\left(\exists t\left(\uparrow \exists e_{\pi}\left(\operatorname{at}_{t}\left(e_{\pi}, t\right) \wedge e_{\pi}=?\right)\right) \wedge \operatorname{alive}(e, x) \wedge \operatorname{at}_{t}(e, t)\right)$

An utterance of (2.17) will introduce the discourse referents $e_{\pi_{0}}$ and $t_{0}$ and the conditions $\mathrm{E}_{\pi}\left(e_{\pi_{0}}\right)$, at ${ }_{t}\left(e_{\pi_{0}}, t_{0}\right)$ as before. Once $e_{\pi}$ is bound to $e_{\pi_{0}}$, we can reduce the long logical form to $\lambda e \lambda x\left(\operatorname{alive}(e, x) \wedge \mathrm{at}_{t}\left(e, t_{0}\right)\right)$ using the same strategy for eliminating redundant content that we used for I am tired above. I will skip the details here, however, since the derivation runs exactly like the derivation above. The $\lambda x$ in the final contribution of now alive will be bound by the universal quantifier to get the final logical form for (2.17), which will be something along the following lines.

$$
\exists e \exists e^{\prime} \exists t^{\prime} \forall x\left(\text { alive }(e, x) \wedge \operatorname{at}_{t}\left(e, t_{0}\right) \rightarrow \operatorname{dead}\left(e^{\prime}, x\right) \wedge \operatorname{at}_{t}\left(e, t^{\prime}\right) \wedge t_{0}<t^{\prime}\right)
$$

Using our entries for here and actually in addition to now, we derive the following (reduced) analysis of (2.16).

$$
\begin{aligned}
& \diamond \mathrm{IN} \text { PAKISTAN IN FIVE YEARS } \forall x\left(\operatorname{envied}(x) \rightarrow \exists e \operatorname{located}(e, x) \wedge \operatorname{in}\left(e, z_{0}\right) \wedge\right. \\
& \left.\operatorname{at}\left(e, t_{0}\right) \wedge \operatorname{at}\left(e, w_{0}\right)\right)
\end{aligned}
$$


The discourse referents $z_{0}, t_{0}, w_{0}$ are contributed to the global DRS $\mathrm{K}_{0}$ by the utterance and the occurrences of here, now, actually, respectively, introduce discourse referents that are bound to these discourse referents in the now familiar way. Compare (2.21) with Kaplan's proposal for a wide-scope treatment of (2.16) and his criticism of this proposal below.

$(\exists w)(\exists p)(\exists t)[w=$ the actual circumstance $\wedge p=$ here $\wedge t=$ now $\wedge \diamond \mathrm{IN}$ PAKistan, In FIVE years $\forall x(x$ is envied $\rightarrow x$ is located at $p$ during $t$ in $w)]$

Kaplan immediately criticizes this analysis:

But such transformations, when thought of as representing the claim that indexicals take primary scope, do not provide an alternative to Principle 2 [indexicals are directly referential], since we may still ask of an utterance of (5) [(2.22) above] in a context $c$, when evaluating it with respect to an arbitrary circumstance, to what do the indexicals 'actual', 'here', and 'now' refer. The answer, as always, is: the relevant features of the context c. (In fact, although (4) [(2.16) above] is equivalent to (5) [(2.22)], neither indexicals nor quantification across intensional operators is dispensable in favor of the other.) (Kaplan, 499)

Given what I have said so far about PI, PI is vulnerable to Kaplan's criticism of the wide scope analysis of (2.22). The discourse referents $z_{0}, t_{0}, w_{0}$ in $(2.21)$ are bound outside of the scope of the modal operator to a discourse referent for an utterance event. But so far, I have said nothing about how PI ensures that this utterance event is picked out rigidly. Suppose there is a condition $a g\left(e_{\pi_{0}}, x_{0}\right)$ in the 
global DRS $\mathrm{K}_{0}$. If we let the set of all world-assignment pairs serve as input for this DRS, then the output will be the set of world-assignment pairs $\langle w, f\rangle$ such that $f$ assigns to $x_{0}$ an individual who is the agent in world $w$ of the event that $f$ assigns to $e_{\pi_{0}}$. The assignment functions in the world-assignment pairs that survive update with $\mathrm{K}_{0}$ will therefore assign $x_{0}$ to different individuals. $x_{0}$ will not be rigid.

At this point, we could introduce external anchors to ensure the rigidity of indexicals. An external anchor, following Kamp (1985) and Kamp \& Reyle (1993), is a function from a discourse referent to an individual in the domain of individuals. Its role is to constrain the assignment function for a DRS containing a discourse referent for a referential expression such that the discourse referent receives the same value regardless of the world at which the DRS is evaluated. External anchors are constructed alongside DRSs so that what is evaluated when we evaluate a DRS $K$ containing a discourse referent $x$ for a referential expression $r$ is $(K,\langle x, a\rangle)$ where $a$ is an element from the domain of individuals - the referent of $r$. An external anchor based account of indexicals would be the most straightforward way to bring Kaplan's character based theory into DRT. An external anchor function for indexicals would be exactly like the character function: it would be non-representational and constructed external to the DRS. In addition, its only role would be to determine the contribution of the indexicals to asserted content. What I am treating as presuppositional content would not be treated as content of a DRS at all.

Because PI rejects Kaplanian, two-dimensional theories, external anchors would be an inappropriate mechanism for PI to use in order to secure rigidity. I explain in more detail how PI secures rigidity for indexicals in Hunter (ms); for 
now, I want only to present the basic idea of how PI ensures rigidity for indexicals. First, the global context, $\mathrm{K}_{0}$ will always be evaluated relative to the actual world. This will serve to restrict the assignments of discourse referents in the universe of $\mathrm{K}_{0}$ appropriately. Consider the condition $a g\left(e_{\pi_{0}}, x_{0}\right)$ in $\mathrm{K}_{0}$. We start with the single world-assignment pair $\langle w, f\rangle$ such that $w=w_{@}$ and $f$ is the empty assignment function. ${ }^{17}$ Any assignment function $f$ that survives update with $\mathrm{K}_{0}$, therefore, will be such that it assigns to $x_{0}$ whoever is the agent of the utterance represented by $e_{\pi}$ in the actual world. Second, each utterance event comes with an individuating condition represented by a condition $\mathrm{E}_{\pi}$ in, e.g., $\mathrm{E}_{\pi}\left(e_{\pi}\right)$. This is not a descriptive condition that a conversational participant should be expected to report. An individual will in general have no non-indexical means of picking out an utterance event. But such identification is not required by the semantics of indexicals. ${ }^{18}$ What is required is that an utterance event be selected as the actual one, that this utterance event (generally) determine the values of indexical expressions in the sentence uttered and, once these values are fixed, that the values stay fixed even as the world of evaluation changes. PI secures this by selecting a world as actual for the $\mathrm{K}_{0}$. The semantics of indexicals strongly encourage them to bind at this level, so their interpretations will almost always be those determined by the actual world, as desired. ${ }^{19}$

\footnotetext{
${ }^{17}$ The assignment function will be empty at the start because we assume that we begin with an empty DRS. Evaluation of the DRS $K_{0}$ will lead to an extension $f^{\prime}$ of the empty assignment function $f_{\emptyset}$ such that the domain of $f^{\prime}$ is the universe of $\mathrm{K}_{0}$.

${ }^{18}$ cf. Kaplan's discussion of occurrences and utterances in Remark 1, section XIX, p. 546. Although PI uses utterance events rather than Kaplanian contexts for the semantics of indexicals, we agree that the semantics of indexicals should not be about speech acts. The use of utterance events allows for a very natural extension of DRT, which already uses an event based semantics.

${ }^{19}$ In Hunter (ms), graphs take the place of sequences of DRSs so that DRSs are evaluated relative to graphs. The top node of each graph is the output value of the DRS $\mathrm{K}_{0}$ for a given DRS K, where
} 
PI is a wide scope theory in the sense that indexical presuppositions almost always bind in the global context. To some extent, a wide scope theory is unavoidable. Even Kaplan's theory was a wide-scope theory of a sort. Character simply provides a way of ensuring, through brute force methods, that indexicals never fall in the syntactic scope of operators. They don't have wider scope than definite descriptions at the syntactic level, but their 'descriptive' meanings in effect take super scope outside of content altogether. PI's solution is more natural: it assumes that information from the extra-linguistic context will have a different status from information presented in the linguistic context because we acquire the information through such different means. Information presented via the extra-linguistic context, for example, might come with a stronger relation to the external world. But from the point of view of indexicals, this difference does not matter. The distinction between the global DRS $\mathrm{K}_{0}$ and its sub-DRS $K_{1}$ is no different from the distinction between $K_{1}$ and its sub-DRSs. The fundamental difference between PI and the kinds of two-dimensional theories that I am criticizing is that PI does not write the extra-linguistic/linguistic context distinction into the semantics for indexicals. It is true that indexicals prefer binding in the global DRS, but they can bind in intermediate DRSs and this possibility falls

the output value is the set of world assignment pairs that results from updating an empty DRS with $\mathrm{K}_{0}$. The world in each world-assignment pair in the top node will be the actual world, as explained above. Adding content from $\mathrm{K}_{1}$ triggers the construction of an arc and the introduction of a new node. This node is the output value of $\mathrm{K}_{1}$ given the input graph that resulted from update with $\mathrm{K}_{0}$. A complex condition in $\mathrm{K}_{1}$ will introduce further nodes in the graph that are the output values of the arguments of the complex condition, relative to the input graph from $\mathrm{K}_{1}$. And so on. A graph reflects the accessibility relations that hold between $\mathrm{K}_{0}$ and its sub-DRSs - each node will have access to the information in its ancestor nodes. Graphs therefore have more structure than the sequences of DRSs that I use in this chapter. The structure of the graphs together with the use of pointed models allows PI to secure rigidity for indexicals. 
out naturally on the theory. PI allows for the interaction between presupposed and asserted contents. $^{20}$ Moreover, PI does not block other definite noun phrases from binding in $\mathrm{K}_{0}$, as we will see later in this dissertation.

\subsubsection{Tense}

DRT uses an event based analysis of tense that is already well suited for the PI framework. A verb will introduce a discourse referent $e$ for an eventuality and times can be specified for these eventualities. Sometimes the time of the eventuality is related to the time of utterance in a conventional way and the tense provides information about this relation that is added to the DRS. The English simple past, for example, indicates that the event or state denoted by the verb lies strictly in the past of the utterance time. We make this relation explicit as in the following example.

Mary called.

$$
\left[e_{\pi_{0}}, t_{0}: \operatorname{at}\left(e_{\pi_{0}}, t_{0}\right)\left[x, e: \operatorname{mary}(x), \operatorname{call}(e, x), \operatorname{at}(e, t), t<t_{0}\right]\right]
$$

Binding to the utterance time then goes through as it does for overt indexical expressions.

\footnotetext{
${ }^{20}$ Maier (2009) offers a DRT-based, presuppositional account of indexicals that is very similar to PI. He, however, creates an extra layer in DRT in order to account for the special nature of indexicals. In so doing this, he supplements a presuppositional theory with a Kaplanian, two-dimensional theory and brings all of the limitations of a two-dimensional theory into a presuppositional one. This is exactly the kind of move I am arguing against in this dissertation.
} 


\subsubsection{More Sophisticated Entries}

In section 2.2.3, I introduced the functions, denoted by $a g, a d$, in, $a t_{t}$, and $a t_{w}$, that determine features of utterance events on which tokens of indexicals depend. In particular, these functions determine an agent, addressee, location, time, and world, respectively, for each utterance event. When an indexical is used, it triggers a presupposition that will depend on one of these features. Its lexical meaning then specifies a relation between this feature and the contribution of the indexical to asserted content. For simplicity, I treated this relation as identity in every case I

considered. For example, I assumed that for some utterance event $e_{\pi_{0}}$ and discourse referent $t_{0}$ where $a t_{t}\left(e_{\pi_{0}}, t_{0}\right)$ that an utterance of now would simply offer the time $t_{0}$ for predication. This assumption simplifies matters, but is not entirely accurate. Now is more naturally understood as picking out an interval of time that properly includes the utterance time. Our semantics need to be adjusted to let the contribution of an indexical come apart from the relevant feature of the utterance event in this way.

For explicitness, I look first at an example involving tomorrow for which the relation between the utterance time and the contribution to asserted content is determined by the semantics. The example is a slight variation on (2.17).

(2.25) One day all persons born tomorrow will be dead.

Recall that the lexical entry for tomorrow was:

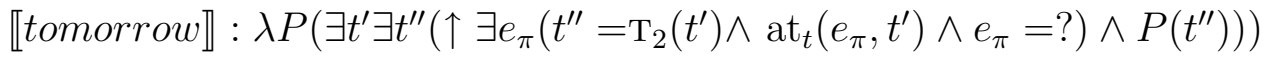

The entry for the adverbial use will then be: 


$$
\begin{aligned}
& \llbracket \text { tomorrow }_{v p} \rrbracket: \lambda P \lambda e \lambda x\left(\exists t ^ { \prime } \exists t ^ { \prime \prime } \left(\uparrow \exists e_{\pi}\left(t^{\prime \prime}=\mathrm{T}_{2}\left(t^{\prime}\right) \wedge \mathrm{at}_{t}\left(e_{\pi}, t^{\prime}\right) \wedge e_{\pi}=?\right) \wedge P(e, x) \wedge\right.\right. \\
& \left.\left.\operatorname{at}_{t}\left(e, t^{\prime \prime}\right)\right)\right)
\end{aligned}
$$

The problem is that not all of the content contributed by tomorrow can be bound in the global context, so the information contributed by tomorrow is not automatically rendered redundant once $e_{\pi}$ is bound to an antecedent in the global context. Every utterance event will introduce a time, but there's no obvious reason to assume that in so introducing a time into the context, an utterance also introduces a discourse referent for the day after the day of utterance (or the year after the year of utterance, or the day/year before the day/year of utterance, etc.). Thus, we will not be able to eliminate the presuppositional content of tomorrow from the logical form of (2.25) without some extra theoretical assumptions. To illustrate this, suppose that an utterance of (2.25) introduces $e_{\pi_{0}}$ and the other discourse referents and conditions introduced by the utterance are as before $\left(x_{0}, y_{0}, z_{0}, t_{0} \ldots \mathrm{at}_{t}\left(e_{\pi_{0}}, t_{0}\right) \ldots\right)$. Thus we bind $e_{\pi}$ in the entry for tomorrow to $e_{\pi_{0}}$ from the global context.

- $\lambda P \lambda e \lambda x\left(\exists t^{\prime} \exists t^{\prime \prime}\left(\uparrow \exists e_{\pi}\left(t^{\prime \prime}=\mathrm{T}_{2}\left(t^{\prime}\right) \wedge \mathrm{at}_{t}\left(e_{\pi}, t^{\prime}\right) \wedge e_{\pi}=?\right) \wedge P(e, x) \wedge \mathrm{at}_{t}\left(e, t^{\prime \prime}\right)\right)\right)[\lambda s \lambda y$ born $(s, y)]$

- $\lambda e \lambda x\left(\exists t^{\prime} \exists t^{\prime \prime}\left(\uparrow \exists e_{\pi}\left(t^{\prime \prime}=\mathrm{T}_{2}\left(t^{\prime}\right) \wedge \operatorname{at}_{t}\left(e_{\pi}, t^{\prime}\right) \wedge e_{\pi}=?\right) \wedge \lambda s \lambda y \operatorname{born}(s, y)[e, x] \wedge \operatorname{at}_{t}\left(e, t^{\prime \prime}\right)\right)\right)$

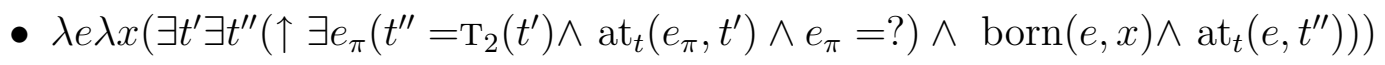

We then attempt to delete redundant material as before, but after deleting the tautology $e_{\pi_{0}}=e_{\pi_{0}}$, substituting $t_{0}$ for $t^{\prime}$, and deleting the vacuous quantifiers $\exists e_{\pi}$ 
and $\exists t^{\prime}$, we end up here: ${ }^{21}$

$$
\text { - } \lambda e \lambda x \exists t^{\prime \prime}\left(\uparrow\left(t^{\prime \prime}=\mathrm{T}_{2}\left(t_{0}\right) \wedge \mathrm{at}_{t}\left(e_{\pi_{0}}, t_{0}\right)\right) \wedge \operatorname{born}(e, x) \wedge \mathrm{at}_{t}\left(e, t^{\prime \prime}\right)\right)
$$

Because the formula at $t_{t}\left(e_{\pi_{0}}, t_{0}\right)$ is redundant (at the discourse level), we can further reduce the above logical form:

- $\lambda e \lambda x \exists t^{\prime \prime}\left(\uparrow\left(t^{\prime \prime}=\mathrm{T}_{2}\left(t_{0}\right)\right) \wedge \operatorname{born}(e, x) \wedge \operatorname{at}_{t}\left(e, t^{\prime \prime}\right)\right)$

But that is as far as we can go without adding material to the context.

I propose to treat examples with tomorrow as instances of partial matches of information. Consider the following example from Beaver (2002):

(2.28) Yesterday a man was shot in Utrecht. The Amsterdam father of four...

In this example of a partial match, the definite description the Amsterdam father of four is bound to the antecedent introduced by a man in the first sentence. But binding also results in the addition of conditions to the effect that the man was from Amsterdam, that he was a father, and that he had four kids. Similarly, in examples involving tomorrow, the utterance event from the presupposition of tomorrow will be bound to an antecedent in the global context, but we will have to add additional information. We will add a discourse referent for the day after the day of utterance, say, $t_{2}$, and the condition $\mathrm{T}_{2}\left(e_{\pi_{0}}\right)=t_{2}$. Now the information in the scope of $\uparrow$ can be bound to an antecedent in the global context and we can proceed with our elimination of redundant content and the consequently vacuous modal operator $\uparrow$.

\footnotetext{
${ }^{21}$ Deleting redundant material is not required by our theory. The point of deleting the material is to show that the presuppositional content does not affect the asserted content of the utterance.
} 
1. $\lambda e \lambda x \exists t^{\prime \prime}\left(\uparrow\left(t^{\prime \prime}=\mathrm{T}_{2}\left(t_{0}\right)\right) \wedge \operatorname{born}(e, x) \wedge \operatorname{at}_{t}\left(e, t^{\prime \prime}\right)\right)$

2. $\lambda e \lambda x \exists t^{\prime \prime}\left(\uparrow\left(t_{2}=\mathrm{T}_{2}\left(t_{0}\right)\right) \wedge \operatorname{born}(e, x) \wedge \mathrm{at}_{t}\left(e, t_{2}\right)\right) \quad\left(\mathrm{T}_{2}\left(t_{0}\right)=t_{2}\right.$ from the global context)

3. $\lambda e \lambda x\left(\uparrow\left(t_{2}=\mathrm{T}_{2}\left(t_{0}\right)\right) \wedge \operatorname{born}(e, x) \wedge\right.$ at $\left._{t}\left(e, t_{2}\right)\right)$ (eliminate vacuous quantifier)

4. $\lambda e \lambda x\left(\operatorname{born}(e, x) \wedge \mathrm{at}_{t}\left(e, t_{2}\right)\right)$ (eliminate redundant material and vacuous modal operator)

We can now proceed to the construction of the full logical form for the conditional in $(2.25)$, though I omit it here.

PI posits a similar solution for now and here, which pick out intervals with pragmatically determined boundaries.

- $\llbracket n o w \rrbracket: \lambda P\left(\exists t^{\prime} \exists t^{\prime \prime}\left(\uparrow \exists e_{\pi}\left(t^{\prime} \subseteq t^{\prime \prime} \wedge \mathrm{at}_{t}\left(e_{\pi}, t^{\prime}\right) \wedge e_{\pi}=?\right) \wedge P\left(t^{\prime \prime}\right)\right)\right)$

- $\llbracket n o w_{v p} \rrbracket: \lambda P \lambda e \lambda x\left(\exists t^{\prime} \exists t^{\prime \prime}\left(\uparrow \exists e_{\pi}\left(t^{\prime} \subseteq t^{\prime \prime} \wedge \mathrm{at}_{t}\left(e_{\pi}, t^{\prime}\right) \wedge e_{\pi}=?\right) \wedge P(e, x) \wedge \mathrm{at}_{t}\left(e, t^{\prime \prime}\right)\right)\right)$

We let the value of $t^{\prime \prime}$ be ultimately determined by broad discourse factors, as opposed to simply the features of the utterance event, and require only that the interval ultimately picked out by $t^{\prime \prime}$ includes the time of the utterance, $t^{\prime}$. As in the case of tomorrow, it is reasonable to expect accommodation of such material. We rarely, if ever, use now to pick out the utterance time; we rather exploit the utterance time plus pragmatic factors to determine a 'current' interval. In what follows, I will continue to use the simpler lexical entries given in section 2.2.3, having shown that the simpler lexical entries could be complicated as need be. 


\subsection{Demonstratives}

PI is a theory of non-demonstrative indexicals. However, because of the intuitively very close similarity between demonstratives and indexicals, this chapter would not be complete without a brief discussion of how PI's treatment of indexicals could be extended to a more general account of both indexicals and demonstratives. Roberts (2002) proposes a theory of demonstrative pronouns that is very much in line with the basic ideas of PI and I will use her account to demonstrate how a PI-like account of demonstratives would look.

Roberts maintains, quite reasonably, that demonstrative expressions are underspecified with regard to a demonstration. ${ }^{22}$ That is, an occurrence of a demonstrative will presuppose that there is a salient demonstration available in the context and that this demonstration has a demonstratum in the context. This presupposition is the counterpart to the indexical presupposition proposed by PI that there is an utterance event in the context and that this event has an agent, addressee, time, location, or world (depending on the indexical). Extending the framework of PI, we get the following lexical entry for the bare demonstrative that. ${ }^{23}$

- $\llbracket$ that $\rrbracket: \lambda P\left(\exists x\left(\uparrow\left(\exists \delta \exists e_{\pi}\left(\operatorname{DEM}(\delta) \wedge \operatorname{ACC}\left(e_{\pi}, \delta\right) \wedge \mathrm{OF}(\delta, x) \wedge e_{\pi}=? \wedge \delta=?\right)\right) \wedge P(x)\right)\right)$

Disregarding the $\uparrow$ clause for the moment, this entry looks like the entries given by PI for indexicals. The discourse referent $x$ is what is offered to asserted content.

\footnotetext{
${ }^{22}$ This is also very Kaplanian in spirit.

${ }^{23}$ This is not the way that Roberts presents the presupposition for that, but I believe that this formalization captures the aspects of Roberts' presentation that are relevant for the discussion at hand and using it saves the time and space that would be required to introduce a very different notation.
} 
Turning now to the $\uparrow$ clause, that presupposes the existence of a demonstration $(\delta)$ and an utterance event $\left(e_{\pi}\right)$ and also presupposes that $\delta$ is a demonstration $(\operatorname{DEM}(\delta))$, that $\delta$ accompanies the utterance event $\left(\operatorname{ACC}\left(e_{\pi}, \delta\right)\right)$, and that $\delta$ is a demonstration of $x(\operatorname{OF}(\delta, x))$. Thus $x$ serves both as the demonstratum and the referent of an occurrence of that.

To distinguish between this and that, we should also add proximality features to our presuppositions. Following Roberts, this will carry an additional presupposition that $x$ is $(+)$ proximal, while that will carry the additional presupposition that $x$ is (-)proximal. These features make demonstratives useful in contrastive constructions.

(2.29) That [pointing at a dress] is appalling, but this [pointing at another dress], I would like to try on.

Using this instead of a second occurrence of that doesn't change the truth conditions or update conditions of what is said, but it nevertheless plays the important role of underscoring a salient contrast in the discourse context.

One of the most important and interesting features of Roberts' account, at least from the point of view of PI, is that Roberts allows for the presuppositions of demonstratives to bind to entities introduced in discourse. In what she calls discourse deixis, the demonstration presupposed by a demonstrative is a piece of linguistic material. ${ }^{24}$ The demonstratum is the discourse referent introduced by

\footnotetext{
${ }^{24} \mathrm{An}$ alternative would be to construe the utterance of the linguistic material as the demonstration so that a demonstration would still be an act of some sort. That would be more intuitive to me, but it is not how Roberts treats the demonstrations in discourse deixis.
} 
the demonstration, as usual; discourse deixis is structurally like paradigmatic deixis except that the demonstration is linguistic instead of extra-linguistic.

Another important feature of Roberts' account is that it does not treat demonstratives as referential expressions. Instead, she says that the seemingly referential and rigid behavior of so many occurrences of demonstratives derives from the directness of certain kinds of demonstrations. If I point at a hat on the table and say, that is my hat, then my demonstration raises a particular hat to salience. The presupposition for the demonstrative then secures a connection between the token of the demonstrative and my demonstration. Because my demonstration picked out an actual object in the actual world, the demonstrative does, too. All of this is consistent with the possibility that the presupposition of a demonstrative could be bound by a quantifier. In such a case, the demonstrative would not have a referential or rigid interpretation. Roberts' analysis of the referential and rigid readings of demonstratives is therefore similar to PI's explanation for the seemingly referential and rigid behavior of indexicals: the presuppositions of indexicals do not require binding to the global context, but when binding is achieved at this level, rigidity follows because the utterance event is fixed to be an actual utterance event.

There is no doubt a lot of empirical work that remains to be done on demonstratives and I do not claim that Roberts' theory is entirely adequate as it stands. For example, it is not always clear in Roberts' theory how the presuppositions of demonstratives are satisfied when the demonstrative falls in the scope of a quantifier. I'm not sure what the demonstration would be for Every professor admires most that first book of his and other similar examples discussed by King (2001). In 
addition, Roberts' presupposition might be too strict in light of examples that have been discussed by Nunberg (1993) and Elbourne (2008), among others.

(2.30) That is a good wine. [pointing at an empty bottle on display in a restaurant]

(2.31) These [pointing at a single plate] are over at the warehouse, but those [pointing at another plate] I have in stock here. (Nunberg 1993)

(2.32) Now he [pointing at a painting] was a good painter.

In these cases, it seems that the demonstration raises an entity to salience, as expected, but it is not the demonstratum that is contributed to asserted content. For this reason, one might want to relax the connection that Roberts takes to hold between the demonstratum and referent of a given demonstrative token. We might add to the presupposition that the demonstratum and the referent are related by some relation $R$ and then let $R$ be specified by the context. Then, $R$ could be identity, as Roberts maintains, but it could also be another relation licensed by the discourse context.

I will not attempt to advance the discussion of demonstratives in this dissertation; my main focus is non-demonstrative indexicals. Nevertheless, I have suggested how PI could be extended to handle demonstratives. I think Roberts' theory is on the right track and it is certainly better suited to explain examples of local binding of, say, the sort that King talks about than is Kaplan's theory of demonstratives. Local binding of presuppositions is allowed in discourse-based, presuppositional theories of definites like Roberts' theory of demonstratives and PI's theory of indexicals. 


\subsection{Conclusion}

PI extends the basic framework of DRT in two important ways. First, it extends the notion of a DRS to include information introduced not only through discourse, but also through the extra-linguistic context in which a discourse takes place. Information from the extra-linguistic context is kept in the most global DRS, $\mathrm{K}_{0}$, because it is information that is in an important sense antecedent to the information presented in a discourse and because it is information determined by the actual world. Information presented in discourse is recorded in sub-DRSs of the global DRS. Second, PI adds lexical entries for indexicals in which the presuppositional components of the indexicals are prefixed with an operator $\uparrow$. The presuppositional components of the indexicals are anaphoric in the sense that they need to bind to an utterance event. The $\uparrow$ forces the presuppositions to bind to an antecedent in the highest possible context. Because $\mathrm{K}_{0}$ will always contain information on an utterance event when an utterance has been made, indexicals will easily bind to antecedents introduced by the actual utterance event, as desired.

PI captures the dependence of indexicals on the actual context that Kaplan insisted was so important. However, this dependence is not written explicitly into the lexical entries of indexicals. There is no feature in the entries of indexicals that says that they have to bind in the global context or that they have to be understood as referential or rigid, etc. It is true that indexicals do have a preference to bind to actual utterance events, but PI allows for the possibility that their presuppositions could be bound in intermediate contexts. Moreover, PI secures the context sensitivity of indexicals without treating the extra-linguistic context as a special kind of context 
from the point of view of definites. The global context is a DRS like any other DRS - it's just more global. As we will see in coming chapters, this allows PI to be consistent with a theory of definite descriptions that allows definite descriptions to also have their presuppositions satisfied in $\mathrm{K}_{0}$.

The semantics of $\uparrow$ together with the lexical entries for indexicals reveal the sense in which indexicals are presuppositional. Indexicals contribute two kinds of content: content in the scope of $\uparrow$ and content outside of the scope of $\uparrow$. The former is the presupposed content, which replaces Kaplan's character in PI, and the latter is the asserted content, which replaces Kaplan's truth-conditional content. The $\uparrow$ operator says that the content in its scope is supposed to be attached somewhere in the existing discourse structure; the role of this content is not to add information to the discourse context but to bind to a point in the discourse at which new content, i.e. the content outside of the scope of $\uparrow$, will be added. As we will see later, the under-specified entries for indexicals prevent them from overriding this preference and accommodating in the sub-DRSs in which the indexical presupposition is triggered. This ensures that the content in the scope of $\uparrow$ will always be old content, at least for indexicals. It also ensures that if the indexical presupposition cannot bind or be accommodated outside of the local context in which the indexical presupposition is triggered, that the sentence containing the token of the indexical will be infelicitous. 


\section{Chapter 3}

\section{What Now?}

In the last chapter, I claimed that one advantage of PI over two-dimensional theories of indexicals is that PI allows for the interaction between indexical presuppositions and content from the surrounding discourse context. I did not, however, make use of this fact. The aim of this chapter is to motivate a need for this feature of PI. My discussion will focus on adverbial uses of the indexical now that need not depend on the actual time of utterance but which presuppose a contrast between the material in the scope of the adverb and information nearby in the discourse context. For example, if I say, Mary, once an indefatigable optimist, now a disappointed cynic... I presuppose that there was a time at which Mary was not a disappointed cynic and the presupposition in this case is satisfied by the immediately preceding discourse. The use of now to refer to past times is therefore similar to uses of aspectual verbs like stop and begin which presuppose a change of state. I will argue that the lexical entry for now offered in the previous chapter should be extended to treat these uses and offer an analysis that makes use of the fact that PI allows indexical presuppositions to interact with the surrounding discourse. I will also show that there is reason to think that many indexicals, in particular here, actual and actually, also demonstrate intermediate binding. 


\subsection{The Behavior of Now}

It is well known that English now can be used in narratives to pick up on a time other than the utterance time. Consider the following example of free indirect style.

(3.1) What a folly! All his life long Peter had been fooled like that; first getting sent down from Oxford; next marrying the girl on the boat going out to India; now a wife of a Major in the Indian Army - thank Heaven she had refused to marry him! (Mrs. Dalloway, Virginia Woolf).

Free indirect style affords the reader a glimpse into the mind of a character. The judgment described in (3.1) is Mrs. Dalloway's, not the author's or narrator's, and now is Mrs. Dalloway's now. But Mrs. Dalloway's thoughts are not being quotedshe certainly did not think to herself (even in the story), "All his life long Peter had been fooled like that", nor did she refer to herself in the third person ${ }^{1}$. Woolf employs more subtle means to shift the perspective. Even though the tense and person do not match those of Mrs. Dalloway's thoughts, she is nevertheless understood as the agent of the thought and indexicals like now follow the shift to her perspective.

Banfield (1982), Doron (1991), and Schlenker (2004) argue on the basis of examples in free indirect style, that indexicals should be evaluated relative to two contexts, which Schlenker calls the context of thought and the context of utterance.

\footnotetext{
${ }^{1}$ For a discussion of how free indirect style differs from direct discourse, see Banfield (1982) and Schlenker (2004).
} 
Following Banfield and Doron, ${ }^{2}$ the context of thought is the context from which a given thought is taken to originate and the context of utterance is the context in which the thought is expressed. Supposedly, person and tense are determined by the context of utterance while all other indexicals, including here, the temporal indexicals, and demonstrative pronouns, are given their values by the context of thought. Either one of these contexts can come apart from the context of speech, which is determined by the actual agent, location, time and world. In free indirect discourse, the hypothesis is that the context of utterance is aligned with the context of speech, or actual context, while the context of thought comes apart from the context of speech and is determined by the point of view of a character. In (3.1), for example, the context of thought is the context of Mrs. Dalloway's thought.

Schlenker argues that the same distinction between context of thought and context of utterance can be used to analyze the behavior of tense and indexicals in examples of the historical present, such as (3.2).

(3.2) Fifty eight years ago to this day, on January 22, 1944, just as the Americans are about to invade Europe, the Germans attack Vercors.

The historical present, maintains Schlenker, is the 'mirror image' of free indirect discourse: in the historical present, the context of thought is aligned with the context of speech while the context of utterance comes apart from both of these. Thus, the value of the temporal indexical expression fifty eight years ago to this day is given by the context of thought/speech, while the tense is determined by the context of

\footnotetext{
${ }^{2}$ Following them in spirit- - the terminology is Schlenker's.
} 
utterance. (3.2) expresses a thought about a time in the past, but the thought is attributed to the actual speaker. The time at which the events are taken to unfold is not the time of the actual speech event, however, despite the use of the present tense. It is as though we have been shifted to the past and someone else is narrating the events as they unfold.

I will not pursue a more thorough discussion of Schlenker's proposal, or of Banfield's or Doron's, because I think that these accounts cannot possibly do justice to the full range of behavior exhibited by now. They may very well shed light on certain aspects of particular literary styles - this question is beyond the scope of this dissertation-but we must look beyond them to construct a full semantic account for now. Schlenker's analysis of the historical present is particularly ill-suited for the task, for consider the following example from Predelli (1998).

(3.3) It is 1796. Napoleon, now commander of the French troops in Italy, defeats the Sardinian forces and turns against Austria. (Predelli 1998)

In (3.3), now is not the now of the actual speech act, despite Schlenker's predictions that now follows the context of thought and that the context of thought is aligned with the context of speech in the historical present.

The real shortcoming of all of these views, at least from the point of view of someone who wants to explain the full range of now's behavior, is that now can pick up on a time other than the time of actual utterance even outside of the historical present and free indirect discourse. As Recanati has pointed out, examples like (3.3) are often perfectly felicitous in the past tense, even with now, as shown in (3.4). 
(3.4) It was 1796. Napoleon, (who was) now commander of the French troops in Italy, defeated the Sardinian forces and turned against Austria. (Predelli 1998).

Here now picks out a time from the past, but this is clearly not an example of the historical present as the present tense is not used. Nor is it an example of free indirect speech, as no one's thought is being recorded here except for the author's.

Examples like (3.3) and (3.4) are common, at least in written discourse. They are found in, for instance, old English narratives, the Bible (at least in parts translated from Greek) as well as current newspapers and blogs.

(3.5) Behold a wonder! they but now who seemd/ In bigness to surpass Earths Giant Sons/ Now less than smallest Dwarfs... (Paradise Lost, J. Milton, Book I, 777-779)

(3.6) But the ship was now in the midst of the sea, tossed with waves: for the wind was contrary. ${ }^{3}$ (King James Bible, Matthew 14:24)

(3.7) The writer was Lucy Mercer Rutherfurd, who decades before had been FDR's mistress and who now was making arrangements for what would be their last fateful meeting at the president's rural retreat. (The Washington Post) ${ }^{4}$

(3.8) It finally dawned on me that what she had was irreversible. As she started to recover from her hip injury, we discovered she had lost the capacity to speak

\footnotetext{
${ }^{3}$ Now in this example is a translation of $\eta \delta \eta$, which is also translated as even now, already, by this time. But comes from $\delta \epsilon$.

4'What was for FDR's eyes only is now for yours', July 29, 2010.
} 
properly. She was now able to emit only a series of sounds mixed with the occasional word. Her frustration was tangible. She cried for her lost voice. $(\text { Daily Mail) })^{5}$

(3.7) is an excerpt from a newspaper article about a recent acquisition of the National Archives. This particular quote is about a personal letter written to President F.D. Roosevelt by a former mistress of his; now is the time of the letter writing. (3.8) is from a personal article written by Fiona Phillips about her mother's struggle with Alzheimer's. Now in this example picks out a time after Phillips' late mother had suffered a hip injury. I provide many more examples like (3.5)-(3.8) at the end of this chapter.

(3.5)-(3.8) are all narrative examples, but they are not examples of free indirect discourse or the historical present. A requirement of the historical present is, of course, that the present tense be used. This is not the case in any of (3.5)-(3.8). ${ }^{6}$ Free indirect discourse, on the other hand, is used to indirectly report the thoughts of a character. (3.5)-(3.8), however, are very direct reports. The point of view is the narrator's and the tense is determined by the time of writing. One might suggest that they are indirect reports of the narrator's thoughts. Perhaps, but the examples

\footnotetext{
${ }^{5}$ MailOnline, 'Her misery was now so deep, her existence so shallow... I wanted to grab her pillow and smother her - Fiona Phillips on dealing with Alzheimer's', August 28, 2010, http://www.dailymail.co.uk/tvshowbiz/article-1307015/Her-misery-deep-existence-shallowI-wanted-grab-pillow-smother-her.html

${ }^{6}$ This is less clear in the example from Paradise Lost, but we could change the example slightly to show that now need not be accompanied by the present tense in this example: 'Behold a wonder! they but now who seemd/ In bigness to surpass Earths Giant Sons/ Now were less than smallest Dwarfs......
} 
don't really seem to be about thoughts at all; they are rather straightforward narratives. Moreover, note that in examples very similar to (3.7) and (3.8), now can easily be used to pick up on the actual time of utterance. This suggests that it is not merely the perspective or tense in (3.7) and (3.8) that explains the shift of now in these examples.

(3.8') Thinking about her frustration brings tears to my eyes even now/to this very day.

(3.7') The writer was Lucy Mercer Rutherfurd, who decades before had been FDR's mistress and who was making arrangements for what we now know would be their last fateful meeting at the president's rural retreat.

(3.8') is a perfectly felicitous continuation of (3.8) and (3.7') involves a very minimal change from (3.7). There is no forthcoming reason for arguing that the perspectiveeither of the narrator or some other thinker-has shifted between either (3.8) and $\left(3.8^{\prime}\right)$ or $(3.7)$ and $\left(3.7^{\prime}\right)$. The behavior of now cannot be explained in terms of perspective only. Nor can it be explained by studying a particular literary stylethere is no style, genre or even literary period that ties (3.5)-(3.8) together.

I conclude that any account of now that tries to preserve the traditional picture of now as an indexical expression that must refer to the time of utterance or thought will be unsuccessful. Under certain conditions, the presupposed meaning of now can simply be bound in an intermediate discourse context. This possibility, is, of course, predicted by PI. I turn now to a more positive discussion of how examples (3.5)-(3.8) should be treated. 


\subsection{Kamp \& Reyle}

Kamp and Reyle (1993) recognize that now can be used to refer to past times, even outside of special literary environments. They argue that the interpretation of now depends on a temporal perspective point, subject to two constraints. First, the relation between the temporal perspective point and the time of utterance - and, consequently, the relation between the interpretation of now and the time of utteranceis sensitive to tense. Kamp and Reyle, influenced by Reichenbach $(1947)^{7}$, claim that in the following example, the simple past sets the perspective point to 10.00, rather than, say, 6.00 or the time of utterance.

(3.9) Fred arrived at 10. He had set off at 6. (p. 593)

10.00 serves as the temporal perspective point not because it is closer in some sense to the utterance time (though of course it is), but rather because it is introduced by the simple past and then exploited, in this case by the past perfect. Kamp and Reyle explain that the function of the past perfect "is to situate the described state or event in the past of some point which is itself in the past of the time of utterance" (593). In the case of a simple-past/future construction, as in the example below, the temporal perspective point will again lie behind the time of the utterance, but the time of the eventuality described by the future tense clause will lie between the temporal perspective point and the utterance time.

(3.10) Mary got to the station at 9:45. Her train would arrive at 10:05.

\footnotetext{
${ }^{7}$ Hans Reichenbach (1947): Elements of Symbolic Logic, London: Macmillan.
} 
In this example, the perspective point is 9:45, and the tense of the future clause is determined relative to the temporal perspective point rather than the utterance time.

The second constraint on the temporal perspective point for Kamp and Reyle is determined by aspect. They argue that now can only depend on a past time in sentences which describe states, not in sentences that describe events. Consider the following pair from Kamp and Reyle:

(3.11) Bill had come home at seven. Now he wrote a letter.

(3.12) Bill had come home at seven. Now he was writing a letter.

They claim, correctly I think, that (3.11) is not good, while (3.12) is acceptable. As a result of this disparity, they propose that the English simple past is ambiguous. When it is used in a sentence describing an event, the temporal perspective point is given by the utterance time; when it is used in a sentence describing a state, the temporal perspective point lies (or at least can lie) in the past relative to the utterance time. The intuitive explanation is that while the past tense suggests that the temporal perspective lies in the past, in order for it to really shift away from the context of utterance, it needs to be used - events or states described by the past tense clause must be described as unfolding or holding at the relevant time in the past. In Kamp and Reyle's words, "when one describes something as going on at the time of description, one must describe it as just that, viz. as something that is then going on" (596). For this reason, say Kamp and Reyle, states are more naturally described from the perspective of a past point than are events. 
There is a lot of data, however, that do not support the second constraint regarding aspect. The first thing to note is that (3.11) is not a particularly good example even without now.

(3.11') (?) Bill had come home at seven. He wrote a letter.

While it may be acceptable, it begs for extra scene-setting from the context. But now, compare (3.11) with the following examples, which are very similar.

(3.13) That was the kind of people in whom Paul had become so interested, and to whom he now wrote his letter. ${ }^{8}$

(3.14) In Macedonia he was rejoined by Timothy, whose name is associated with his own, in the opening salutation of the Second Epistle, which he now wrote to Corinth. ${ }^{9}$

Even without much help from the context, these examples are far more felicitous than (3.11). I believe that this is because they hang together in a way that the two sentences of (3.11) do not. The event described by the second sentence in both (3.13) and (3.14) concerns an entity introduced in the first sentence. By contrast, the two sentences in (3.11) don't obviously have anything to do with each other and are thus awkward even without now.

\footnotetext{
${ }^{8}$ From, 'The Story of the New Testament,' by Edgar J. Goodspeed, http://www.religiononline.org/showchapter.asp?title $=584 \& \mathrm{C}=803$

${ }^{9}$ The International Standard Bible Encyclopedia, http://www.searchgodsword.org/enc/isb/view.cgi?number=T8794
} 
The infelicity of (3.11) does not clearly stem from the combination of now with a verb phrase denoting a past event and cannot help us to predict when now will be sensitive to past times. Moreover, a Google search produced a wealth of examples like (3.13) and (3.14) in which now modifies a verb phrase denoting a past event, including (3.15) and (3.16). (3.17) is a contrived example.

(3.15) But Rokiroki, exerting all his strength, gripped the strangers wrists so that he could not draw his hatchet. And now he called again to his little daughter, who stood trembling on the bank above.

(3.16) Before being dipped into the liquid air, it would not burn; but now it exploded, it was consumed so rapidly.

(3.17) Napoleon, having taken control of the French troops in Italy, now laid siege to Stagira.

Even in variations of these examples in which the simple past is preceded by the past perfect (to mirror (3.11) and (3.12)), now still combines easily with past tense clauses describing events.

(3.18) He had gripped the stranger's wrists so that he could not draw his hatchet. Now he called again to his little daughter, who stood trembling on the bank above.

(3.19) Normally, it wouldn't explode, but the scientist had dipped it in liquid hot air. Now it exploded, it was consumed so rapidly. 
(3.20) Napoleon had taken control of the French troops in Italy. Now he laid siege to Stagira.

A final point is that now does not always combine felicitously with simple past clauses describing past states.

(3.21) a. John just arrived. I'm hungry now so I think we should go to the restaurant.

b. John (had) arrived at 10. *I was hungry now, so I thought we should go to the restaurant.

(3.22) a. It's noon. I'm always hungry now

b. It was noon. (?) I was always hungry now

Kamp \& Reyle mention the possibility that now might pick out the utterance time even in past tense clauses that describe past states. But I think that this fact, combined with the fact that now can pick out past times in past tense clauses that denote events, is more problematic for their account than they seem to think it is. Tense and aspect no doubt have something to do with now's behavior, but they fall far short of giving us the full story.

\subsection{Recanati (2004)}

Recanati (2004), who also writes about the use of now in examples like (3.5)(3.8), suggests that what is missing from a story like Kamp \& Reyle's is a requirement 
of contrast between two times. Recanati claims that now can pick up on a past time just as long as this time is contrasted with another time which is in some sense less close than the time of now. Consider (3.7) again.

(3.7) The writer was Lucy Mercer Rutherfurd, who decades before had been FDRs mistress and who now was making arrangements for what would be their last fateful meeting at the president's rural retreat.

Here the time at which Lucy Rutherford was writing the letter is contrasted with a period of time decades before the time of the letter writing, so the use of now to pick out a past time is felicitous.

Based on the fairly liberal behavior of now, Recanati proposes that now is not a true indexical, but a perspectival. The interpretation of now need not depend on the context of utterance or the context of thought - the perspective on which a perspectival depends need not belong to any agent in the context. Rather, now depends on a time that serves as a perspective point in the sense of Kamp \& Reyle's temporal perspective point. Recanati uses come to illustrate what a perspectival is.

(3.23) When the beggars came to town, the rich folk went to the shore. But soon the beggars came after them, so they went home. [Lewis 1983: 243]

For an utterance of (3.23) to be felicitous, the agent (or addressee) need not be in town or at the shore, nor must she imagine or present herself as being in either location. Nevertheless, the shore and the town are perspective points, according to Recanati: the first occurrence of come is directed towards the town and the second 
is directed towards the shore. Clearly, the perspective points are not determined by the agent's location; in this example, it seems to be the discourse context that introduces the first perspective point and then changes the perspective to the next perspective point.

Recanati doesn't say much about what determines a temporal perspective point in his theory. Although he cites Kamp \& Reyle when he introduces the concept of a temporal perspective point, he gives no reason to believe that he endorses their theory concerning how temporal perspective points are introduced and shifted, or that he accepts their judgments on data. He simply says that now "can refer to any period, provided it is contrasted with another more distant period" and that "the only constraint [on the reference of here and now] is that the place or time referred to be close in a sense which need not be absolute but may be as relative as you wish" (Recanati 2004). Yet surely now is not so free as this quote suggests, for we can easily come up with examples in which two times are contrasted, one of which is in some sense 'closer', but in which now is not felicitous.

(3.24) Bill came home at 7:00 after leaving work an hour before. He poured himself a glass of wine ${ }^{*}$ now.

(3.25) When I came back to Rome in 2005, having set off six months earlier for Tokyo, I was really excited to be in Italy ${ }^{*}$ now $/$ then. ${ }^{10}$

Clearly, more is required than a contrast between two times.

\footnotetext{
${ }^{10}$ This is a variation on an example that Recanati uses to show that here does not always follow the perspective point of come.
} 


\subsection{PI and Intermediate Binding}

A fundamental claim in Kamp \& Reyle's proposal was that the interpretation of now can be anaphoric on a time - the temporal perspective point-introduced in discourse. In terms of PI, this means that the presupposition of now can be bound in an intermediate context. Recall that according to PI information concerning an actual utterance event is represented in the global DRS and all information introduced through discourse is represented in sub-DRSs of the global DRS. Thus, binding to a time introduced in previous discourse amounts to intermediate binding in PI.

Intermediate binding is allowed in PI; the lexical entries for indexicals do not require that their interpretations be determined by the actual utterance event. Indexicals have a strong preference to bind at the global level, but under certain conditions, they can bind elsewhere. To the extent that Kamp \& Reyle's proposal is that now can be anaphoric and that tense and aspect play a crucial role in determining when this is possible, I think they are certainly correct. Now does not contribute a time of its own so it will either have to get one from the extra-linguistic context or it will have to get one from the discourse. Tense and aspect are clearly important for constructing the temporal structure of a discourse and they will play an equally important role in shaping the interpretive possibilities for a token of now. What was missing from Kamp \& Reyle's proposal was a convincing story about when now can

pick up on a past time, given that a past time has been introduced and is salient in the context.

Recanati suggested that what was missing was a requirement of contrast and I think that he is right. However, as we saw, we can not leave it at that, for a contrast 
is not always sufficient to bring about a felicitous past time use of now. Let's take apart one of our examples to get a better look at how a contrast is involved. Consider (3.8) again.

(3.26) As she started to recover from her hip injury, we discovered she had lost the capacity to speak properly. She was now able to emit only a series of sounds mixed with the occasional word.

The clause as she started to recover introduces a time which overlaps the time at which the author discovered that her mother had lost the capacity to speak properly. The clause containing now depends on this time as well; this sentence merely elaborates on what the author meant when she said that her mother had lost the ability to speak properly. The clause we discovered she had lost the capacity to speak properly implies (in this example) that the author's mother had the capacity to speak properly before the hip injury. This makes salient a contrast between a period in which her mother could speak properly and a period, following the first period, during which she could not speak properly. Now then modifies the clause denoting the closer to 'current' period.

PI's proposal is that a felicitous use of now requires a very specific discourse structure. It must be the case that the discourse sets up a contrast between two times, one at which a certain eventuality holds and another time at which this eventuality does not or did not hold. Moreover, the contrast must be very local and salient in the sense that the now clause either immediately follows the clause with which it is contrasted or it elaborates on a clause that is immediately contrasted with another 
clause. Past uses of now are like pronouns in the sense that they cannot reach back very far in a discourse to find their antecedents. I provide some examples for illustration.

(3.27) The U.S., which had been self-sufficient in energy as recently as 1950, was now importing some $35 \%$ of its energy needs.

In (3.27), the parenthetical clause provides background information that is explicitly contrasted with the now clause. In (3.28), the paragraph preceding the one that I include here introduces Abu Ghraib as an Iraqi prison. (3.28) then describes the transfer of control from Iraq to the US. The contrast is between the time at which Iraq was in control of the prison and the time at which the US gained control. The now clause is not explicitly contrasted with another clause - in the sense that it is not preceded by the contrastive clause - but rather elaborates on one of two eventualities that are contrasted in the immediately preceding discourse.

(3.28) In the looting that followed the regimes collapse, last April, the huge prison complex, by then deserted, was stripped of everything that could be removed, including doors, windows, and bricks. The coalition authorities had the floors tiled, cells cleaned and repaired, and toilets, showers, and a new medical center added. Abu Ghraib was now a U.S. military prison. ${ }^{11}$

(3.8) is similar to (3.28) in that the now clause is not contrasted with the preceding clause. It rather elaborates on a clause that presupposes a contrast.

\footnotetext{
${ }^{11}$ The New Yorker, 'Torture at Abu Ghraib,' May 10, 2004, http://www.newyorker.com/archive/2004/05/10/040510fa_fact.
} 
I propose that we change the lexical entry for now to reflect its contrastive function. I provide the lexical entry from Chapter 2 in (3.29) and the new lexical entry in $(3.30) .{ }^{12}$

$$
\begin{aligned}
& \llbracket n o w_{v p} \rrbracket=\lambda P \lambda e \lambda x \exists t\left(\uparrow \exists e_{\pi}\left(\operatorname{at}\left(e_{\pi}, t\right) \wedge e_{\pi}=?\right) \wedge P(e, x) \wedge a t(e, t)\right) \\
& \llbracket n o w_{v p} \rrbracket=\lambda P \lambda e \lambda x \exists t\left(\uparrow \exists e _ { 1 } \left(\operatorname{at}\left(e_{1}, t\right) \wedge e_{1}=? \wedge \exists e_{2} \exists t^{\prime}\left(a t\left(e_{2}, t^{\prime}\right) \wedge \neg P\left(e_{2}, t^{\prime}\right) \wedge\right.\right.\right. \\
& \left.\left(\left(t^{\prime}<t \wedge \neg \exists t^{\prime \prime}\left(t^{\prime}<t^{\prime \prime}<t\right)\right) \vee\left(t^{\prime}>t \wedge \neg \exists t^{\prime \prime}\left(t^{\prime}>t^{\prime \prime}>t\right)\right)\right) \wedge P(e, x) \wedge a t(e, t)\right)^{13}
\end{aligned}
$$

The content outside of the scope of $\uparrow$ is the same in both entries, so I will ignore it here. Let's break down the presuppositional part of the entry. The first part, $\exists e_{1}\left(\operatorname{at}\left(e_{1}, t\right) \wedge e_{1}=?\right)$, looks fairly normal. It says that the presupposition for now must be bound to a discourse referent for an eventuality $\left(e_{1}=\right.$ ?) and that $t$ is the time of the eventuality $\left(\operatorname{at}\left(e_{1}, t\right)\right)$. With regard to this part of the entry for now, the biggest difference between the new entry for now and the old entry is that the original entry required that now be tied to an utterance event, while the new entry requires only that it be tied to some eventuality. What the data from this chapter show is that now doesn't have to pick out times of utterance events, even if it normally does. $^{14}$

\footnotetext{
${ }^{12} \mathrm{My}$ research on the discourse sensitivity of now is ongoing. An alternative approach would be to derive the contrastive features of now using pragmatic principles rather than writing the contrast explicitly into the lexical entry. I use the more explicit lexical entry in order to illustrate more clearly the important features of now that are under discussion in this chapter.

${ }^{13}$ This entry treats now as a verb phrase modifier. Now can also operate on sentences, as in Now, the next story that we are going to read is called 'Goodnight Moon'. These cases call for a more complicated analysis because there is no event to modify. What is important for the present discussion, however, is that even these uses require a contrast between two times of the sort that PI posits for now .

${ }^{14}$ We might change the presuppositions of other indexicals accordingly. I will argue at the end
} 
The next part of the new lexical entry for now, $\exists e_{2} \exists t^{\prime}\left(a t\left(e_{2}, t^{\prime}\right) \wedge \neg P\left(e_{2}, t^{\prime}\right)\right)$, says that there is another eventuality $\left(e_{2}\right)$ and another time $t^{\prime}$ such that $t^{\prime}$ is the time of $e_{2}$ and that $e_{2}$ is not an event or state for which $P$ holds. The final part of the new entry, $\left(t^{\prime}<t \wedge \neg \exists t^{\prime \prime}\left(t^{\prime}<t^{\prime \prime}<t\right)\right) \vee\left(t^{\prime}>t \wedge \neg \exists t^{\prime \prime}\left(t^{\prime}>t^{\prime \prime}>t\right)\right)$ says that $t^{\prime}$ lies either in the past or the future of $t$ and that in either case, there is no time $t^{\prime \prime}$ that lies between $t^{\prime}$ and $t$. The new entry, therefore, says that $P$ holds at time $t$, but that $P$ did not hold or will not hold at some time immediately in the past or immediately in the future of $t$, where $t$ is either the time of utterance or a time introduced in discourse. This captures the intuition that now is used to contrast two times or at least emphasize a specific time (or interval).

When now binds in an intermediate context, as I am here arguing that it can, it is not only because the intermediate context provides the right kind of contrast, but also because binding at the global level is blocked by the combination of now with the past tense. PI predicts that now cannot bind in the global context when used with the past tense unless it is in the scope of an attitude or speech verb, as the following discourse demonstrates.

A. I wonder if Mary is still depressed all of the time.

B. John said that Mary was much happier now.

PI also predicts that now will bind at the global level when used in the present

of this chapter that here, actual and actually have uses very similar to the ones currently under discussion for now. I see no reason to conclude that the presuppositions of $I$ and you do not depend on utterance events, however, so I will continue to use discourse referents for utterance events in their lexical entries. 
tense unless it is used as part of a special style like the historical present. In this case, I assume that world knowledge about the events being reported will keep the presupposition of now from binding in the global context.

\subsubsection{Is Now an Indexical?}

Following Reichenbach, Recanati defines indexicals as expressions that are token-reflexive, where an expression is token-reflexive if the interpretation of a token of the expression depends on features concerning the token itself, such as its agent and the time and location at which it was uttered. ${ }^{15}$ For now to count as an indexical for Recanati, it would have to be token-reflexive in the following sense:

- The meaning of now is the rule that a token of now will refer to an interval of time which includes the time at which the token is produced. (Recanati 2004)

This rule is clearly not followed by English now. If we maintain Recanati's (and others') hard and fast notion of what it is to be an indexical, then we must conclude that either now is not an indexical or now is ambiguous in English between an indexical use and a non-indexical use. ${ }^{16}$

Let's reconsider what we know about now, without worrying about how to classify it for the moment. Now almost always picks out the time of utterance. It can, at least in written discourse, refer to past times; however, the cases in which it can do so are highly restricted. There must be a salient contrast between two states

\footnotetext{
${ }^{15}$ In H. Reichenbach (1947): Elements of Symbolic Logic, New York, pp. 284-287.

${ }^{16}$ These appear to be the two options that Recanati considers, though he does not choose between them.
} 
or events in the local discourse structure. In these cases, now, when used, is used in the clause that is most central to the main point of what is being said in order to center the reader's attention on that clause.

There is an undeniable relation between paradigmatic, present uses of now and uses of now to refer to past times (call these past uses to save space): both uses have the effect of emphasizing a certain time and both presuppose alternative times to the one under discussion. For past uses of now, the alternatives have to be given by the discourse. Generally this happens because there is a contrast between two events or states that are under discussion. The eventualities provide two different times, or intervals of time, and the contrast presents these times as alternatives. For present now, the alternatives do not have to be explicitly given in the discourse. We already have a sense of the past, present, and future; now picks up on the present interval.

It might seem less obvious that present uses of now presuppose alternatives or any sort of contrast, but alternatives play an important role in these cases as well. Tense can almost always do what now can do; adding now to a sentence in the present tense often does not effect the asserted content of the sentence. Yet now is frequently used with the present tense and my prediction is that it is used when its use has a certain effect on the discourse. For example, it can be used to emphasize one out of two events or states that are being contrasted as in, e.g., One day, all persons now alive will be dead. It can also be used when another time is not explicitly contrasted with the present, but the speaker wants to emphasize the present time. Donate now is a call to immediate action-don't wait, do it now. I'm 
hungry now is a good way either to tell someone that you have recently become hungry or to emphasize the immediacy of your hunger, depending on the intonation used. In other words, the semantic effect of an utterance of now is largely felt at the discourse level, not the sentential level, even for present uses. In this way, now is like but: it doesn't (usually) change sentential truth conditions, but it certainly affects what information is communicated by an utterance.

So, is now an indexical? According to PI, yes. As I explained in the introduction, I am interested in a broad notion of indexicality, marks of which are sensitivity to certain properties of eventualities, an essentially non-descriptive component and dependence on an agent's perspective. The class of English indexicals that are truly token-reflexive appears to be very small. It arguably includes $I$ and some temporal indexicals in English, as I hint in the following subsection. Nevertheless, there is a significantly larger class of expressions that show strikingly similar behavior to the best candidates for token-reflexive expressions. If we opt for the narrow, tokenreflexive notion of indexicality, we will not be able to explain what we thought was interesting about these expressions in the first place. I am more interested in what makes these expressions interestingly similar than I am in token-reflexivity.

Moreover, the interpretation of now, even in the examples I am discussing in this chapter, is determined by the perspective of the agent. Recanati says that now can be used to refer to a past time so long as it is contrasted with another time that is in some sense less 'close'. He does not, as we have seen, elaborate on this notion of closeness, but he does warn that it should not be understood in terms of closeness to the agent. I don't see why it shouldn't be. Recanati offers no counterexamples 
to the claim that closeness for now depends on the perspective of the agent. It is true that eventualities denoted by past now clauses are presented as occurring in the past of the agent's actual time. However, I think what now is sensitive to in these cases is not so much the actual times of the events themselves, but the temporal structure of the narration of the events and the agent's perspective on these events. The speaker uses now to emphasize something in the discourse, something that she wants her addressee to focus on. It is the perspectival and 'presentifying' nature of now that allows it to play this focussing role in discourse. What the agent's use of now contributes to the discourse will be a time, and it will be a time that lies in the past. But what licenses the use of now is a certain discourse structure and this structure is set by the point of view that the speaker has on the discourse. ${ }^{17}$

In examples like (3.5)-(3.8), the perspective remains that of the agent even when now is used to pick out a past time. Note that even in contexts in which a past use of now is licensed, it is also possible for the speaker to use then to refer to the past time.

\footnotetext{
${ }^{17}$ Sometimes now is used in a seemingly non-temporal way. For example, suppose that I have been presenting a certain viewpoint on a controversial issue. I might stop and say, Now, I'm not saying that this is the right way to think about things. I just want to point out that it is a reasonable perspective. Similarly, suppose I've talking about a girl who has a very praiseworthy character. I might shift the topic to her brother by saying, Now that brother of hers is a different story. He's always up to no good. In these cases, now seems to be deprived of its temporal meaning and appears only to shift the discourse topic, or at least a perspective on the topic. Here I would say that now still serves its normal function of spotlighting a current event or state and contrasting alternatives. However, what is relevant is not the the temporal relations between actual eventualities, but rather the structure of the discourse. Now in these cases marks the current bit of discourse that is under discussion and presupposes that there has been a change. In this case, the change is something like a change in discourse topic, though this is admittedly vague.
} 
(3.32) I was alone in her bleak room. Alone, because there was none of her in it, just a body that now held no essence of my mum. I could have killed her there and then.

Kamp \& Reyle's notion of a temporal perspective point - and, I take it, Recanati'sdoes not help explain what is going on in this example. The tense and aspect of the final sentence do not suggest a change in time between the second sentence and the final sentence. Yet now is used to pick out the past time in the second sentence and then is used to pick out the very same time in the third sentence. The tense and aspect of a sentence can no doubt serve to introduce a time into a discourse or to make a time salient, but perspective is something that belongs to an agent.

PI does not require token-reflexivity for indexicals; it adopts a broader notion of indexicality. For this reason, one might think it would be better for indexicals not to be called indexicals in PI. We might, for example, reserve indexical only for those expressions that fit the narrow notion of indexicality. But this issue is purely terminological, and I have already said that I take the broader notion of indexicality to be the interesting one. When I say that now is an indexical, I mean that it should not be rejected from the class of expressions I introduced as indexical in the introduction of this dissertation based only on the fact that it has discourse anaphoric uses. I think we had rather broaden our idea of what it is to be an indexical.

\subsubsection{Other Indexicals}

My focus in this chapter has been exclusively on now and this might suggest that now is unique among the indexicals in exhibiting unorthodox behavior. This is 
far from the case. While I will not offer an in-depth analysis of how other indexicals behave, I do want to point out, so that we don't make too rash a conclusion about now's status as an indexical expression, that other indexicals exhibit similar behavior. Actual and actually are well known to suggest a contrast of some sort.

(3.33) A poet's object is not to tell what actually happened but what could or would happen either probably or inevitably.... For this reason poetry is something more scientific and serious than history, because poetry tends to give general truths while history gives particular facts. ${ }^{18}$

(3.34) The ceaseless, senseless demand for original scholarship in a number of fields, where only erudition is now possible, has led either to sheer irrelevancy, the famous knowing of more and more about less and less, or to the development of a pseudo-scholarship which actually destroys its object. ${ }^{19}$

(3.35) I am come, young ladies, in a very moralizing strain, to observe that our pleasures of this world are always to be for, and that we often purchase them at a great disadvantage, giving readi-monied actual happiness for a draft on the future, that may not be honoured. ${ }^{20}$

(3.36) At this time they are called to rejoice that the struggle is over, the aim achieved and the women of the nation about to enter into the enjoyment of their hard-earned political liberty. Of all the conventions held within the

\footnotetext{
${ }^{18}$ Aristotle's Poetics, 1451a, translated by W.H. Fyfe (Loeb).

${ }^{19}$ Hannah Arendt (1972): 'On Violence,' in Crises of the Republic.

${ }^{20}$ Jane Austin (1818), Northanger Abbey, Henry Tilney, ch. 26.
} 
past fifty-one years, this will prove the most momentous. Few people live to see the actual and final realization of hopes to which they have devoted their lives. That privilege is ours. ${ }^{21}$

As with now, using actually or actual merely to talk about actual things is generally redundant. We have modal expressions that we use when we want to talk about non-actual situations or objects, and if one doesn't use such an expression, then it is reasonable for the addressee to assume that it is the actual world that is under discussion. Actual and actually are used to emphasize a contrast between, say, a fake object and a real one, an expectation of what would happen versus something that actually did or would happen, or a hope versus the realization - or lack thereof - of the hope, and so on. Again, this use seems to be derived from the paradigmatic 'indexical' use. Actual and actually do modify noun phrases and verb phrases (respectively) that denote real events or objects, just as theories of indexicals predict. But their contribution is often at the discourse level, not the sentential level. Moreover, as with now, there are examples in which actual and actually are not even bound in the global context, but rather in contexts introduced by modals.

(3.37) If McCain had won the election, then the Commander in Chief would actually be an experienced military man.

(3.38) Had Pakistan not been created, all of the money spent on defence by the whole of South Asia in the past 60 years would have actually been spent on

\footnotetext{
${ }^{21}$ Carrie Chapman Catt (1859-1947), U.S. suffragist. As quoted in History of Woman Suffrage, vol. 5, ch. 19, by Ida Husted Harper (1922).
} 
welfare and development. ${ }^{22}$

(3.39) Perhaps if those tapes had been made available to the police and to the public we would have had actual images of the person or persons she was actually seen talking with. ${ }^{23}$

Here is well known to have demonstrative uses and thus need not pick out, or even depend on, the location of utterance in a token-reflexive way. These nonstandard uses can be sensitive to a demonstration, as when a speaker points at a country on a map, far away from where she actually is, and says, I want to go here. But here can also be sensitive to locations introduced in discourse, as the following examples by Predelli show.

(3.40) Here, to the sheltered columned coolness, Ramanujan would come. Here, away from the family, protected from the high hot sun outside, he would sometimes fall asleep... (Kanigel 1991: 29-30) (1998a)

(3.41) If an entire neighborhood could qualify as an outdoor museum, the Washington district would probably charge admission. Here, just northwest of downtown, are several picture-book expressions of desert culture within a few blocks. (1998b)

\footnotetext{
${ }^{22}$ Adapted from http://pkpolitics.com/discuss/topic/had-pakistan-not-been-created-whatwould-have-happened-to-india-today/page/2

${ }^{23}$ Adapted from http://www.c-ville.com/index.php?cat=11101808092903167\&ShowArticle_ID=11800802104188707.
} 


\subsection{Conclusion}

I have argued that the presupposition of now can bind in intermediate contexts. Although now strongly prefers binding in the global context, under special conditions, i.e. when it modifies a clause that is contrasted with another clause in the immediate discourse environment, it can bind in a lower context. This use of now is very sensitive to discourse structure, but I have argued that the paradigmatic, present tense uses of now often have a discourse functional role as well. They are generally used to contrast two times or to emphasize one time to the exclusion of others. Present and past uses of now are not so different; past uses therefore do not motivate an ambiguity based account of now. Moreover, when we consider the fact that other indexicals, such as here, actual, and actually, and demonstratives (see Chapter 2) also have uses in which they do not depend on features of the actual, extra-linguistic context but rather depend on the discourse context, it is hard to deny that these uses should be taken seriously by any semantic account of indexicals.

\section{More Now Examples}

(3.42) Originally touted as a tool in the struggle against terrorism, the Patriot Act now was being used in the hills of East Tennessee as part of a shadowy war that had been going on for decades, a struggle that pitted the federal government against a homespun Appalachian culture that had churned out generation after generation of proud outlaws. (Knox News, 'Sneak-and-peek warrants debated; Patriot Act used to search for evidence in cockfighting case', August 13, 2007, http://www.knoxnews.com/news/2007/aug/13/sneak-and- 
peak-warrants-debated/)

(3.43) The weather by now was beautiful: sunny and warm, but not too hot. As we crested range after range, the view was one of gorgeous isolation, nary a sign of humanity to be seen in any direction. Off in the distance, to the west, was a thin purple line that any coastal Californian knows means dense fog, but it was many miles away. (Loose Grave (blog), 'What Once Was Lost, Now Is Found; California's Lost Coast,' by Sam Taylor, http://www.loosegravel.us/LostCoast/lost.htm

(3.44) I was alone in her bleak room. Alone, because there was none of her in it, just a body that now held no essence of my mum. I could have killed her there and then. I could easily have killed my mum. In the eyes of the law, I would have murdered her. In anyone else's eyes, I would have relieved the misery, the pain, the suffering, the indignity. (MailOnline, 'Her misery was now so deep, her existence so shallow... I wanted to grab her pillow and smother her - Fiona Phillips on dealing with Alzheimer's', August 28, 2010, http://www.dailymail.co.uk/tvshowbiz/article-1307015/Hermisery-deep-existence-shallow-I-wanted-grab-pillow-smother-her.html)

(3.45) Last June, Janis Karpinski, an Army reserve brigadier general, was named commander of the 800th Military Police Brigade and put in charge of military prisons in Iraq. General Karpinski, the only female commander in the war zone, was an experienced operations and intelligence officer who had served with the Special Forces and in the 1991 Gulf War, but she had never run a prison system. Now she was in charge of three large jails, eight battalions, and 
thirty-four hundred Army reservists, most of whom, like her, had no training in handling prisoners. (The New Yorker, 'Torture at Abu Ghraib,' May 10, 2004, http://www.newyorker.com/archive/2004/05/10/040510fa_fact)

(3.46) Dresens theatre director father, Adolf Dresen, was exiled to West Germany for supporting dissident poet-singer Wolf Biermann in 1977. "A wall was now between us," Andreas recalls, explaining how his political consciousness was forged. "Politics was not an abstract thing." (New Zealand Listener, 'A wall was now between us,' November 7-13, 2009, http://www.listener.co.nz/issue/3626/artsbooks/14

(3.47) President Nixon, as part of his ill-fated price control program, had slapped controls on oil in March 1973. The U.S., which had been self-sufficient in energy as recently as 1950, was now importing some 35\% of its energy needs. U.S. petroleum reserves were nearly gone. Governments, corporations and individuals were entirely unprepared for what would happen next. (Buy and Hold, 'The Arab Oil Embargo of 1973-74,' by Brian Trumbore, http://www.buyandhold.com/bh/en/education/history/2002/arab.html)

(3.48) When OPEC announced the sharp price rise, the shock waves were immediate. Industrial democracies, accustomed to uninterrupted sources of cheap, imported oil, were suddenly at the mercy of a modern Arab nationalism, standing up to American oil companies that had once held their countries in a vise grip. Many of these "new" Arabs were Harvard educated and familiar with the ways of the West, and to many Americans it was impossible to understand how their standard of living was now be- 
ing held hostage to obscure border clashes in strange parts of the world. (Buy and Hold, 'The Arab Oil Embargo of 1973-74,' by Brian Trumbore, http://www.buyandhold.com/bh/en/education/history/2002/arab.html)

(3.49) Brutally, the banks knowingly gamed the system to grow their balance sheets ever faster and with even less capital underpinning them in the full knowledge that everything rested on the bogus claim that their lending was now much less risky. That was not all they were doing. (The Gaurdian, 'Now we know the truth. The financial meltdown wasn't a mistake - it was a con,' April 18, 2010, http://www.guardian.co.uk/business/2010/apr/18/goldman-sachsregulators-civil-charges)

(3.50) Elizabeth Cotten was born into the Nevilles family on January 5 in 1895, near Chapel Hill, North Carolina. Her parents couldn't agree on a name, so, she was called "Little Sis," "Babe," and "Shug," until her first day of school, when she announced that her name was now Elizabeth. ('Remembering Elizabeth Cotten,' by L.L. Demerlee, http://www.eclectica.org/v1n1/nonfiction/demerlee.html)

(3.51) Cotten and her daughter Lillie moved to Syracuse, New York. Now in her 90's, her hands were becoming weak and she had trouble with the guitar. ('Remembering Elizabeth Cotten,' by L.L. Demerlee, http://www.eclectica.org/v1n1/nonfiction/demerle

(3.52) $\mathrm{C}$ reported on his recent talks in Washington. There was a perceptible shift in attitude. Military action was now seen as inevitable. Bush wanted to remove Saddam, through military action, justified by the conjunction of terrorism 
and WMD. (The Times online, 'The Secret Downing Street Memo,' May 1, 2005, http://www.timesonline.co.uk/tol/news/uk/article387374.ece)

(3.53) The discharge was now very proftuse [sic], running continually from the mouth. The patient continued in this state till August 27th. (British Medical Journal, 'A Case of Foot-and-Mouth Disease in the Human Subject,' October 26, 1872 by William T. Briscoe, http://www.bmj.com/content/2/617/464.1.citation)

(3.54) At lap 8, Lewis had a lead of 5.5 seconds, and he looked comfortable. It looked like nothing but a mechanical failure or situation beyond his control was going to stop him. Good consistent sector times followed, and he set another fastest lap time on lap 11. So far, so good. Jarno Trulli in fifth place, was now looking comfortable with a small margin between him and Kimi Raikkonen. The pace of the Ferrari was nowhere it seemed, and Kimi knew he was in for a long day. (Bleacher Report, 'Lewis Hamilton Gives the Brits that Special Feeling at Hockeheim!' by Andrew Davies, http://bleacherreport.com/articles/39379lewis-hamilton-gives-the-brits-that-special-feeling-at-hockenheim)

(3.55) It was now evening, and I immediately dressed myself in the costume of an Indian, equipped with a small hatchet, which I and my associates denominated the tomahawk, with which, and a club, after having painted my face and hands with coal dust in the shop of a blacksmith, I repaired to Griffin's wharf, where the ships lay that contained the tea. ('An Eyewitness Account of the Boston Tea Party, As Told By George Hewes,' http://www.earlyamerica.com/review/2005_wint 
(3.56) Now Thomas, one of the twelve, named Didymus, was not with them when Jesus came. (Bible in Basic English, John 20:24, http://bible.cc/john/2024.htm)

(3.57) he is also said to be "one of the twelve" apostles, which was their number at first, though Judas now was gone off from them, and therefore are sometimes only called the "eleven"; but this having been their complement, it is still retained... (Commentary on John 20:24, http://bible.cc/john/20-24.htm)

(3.58) It was now about the sixth hour, and darkness came over the whole land until the ninth hour. (Luke 23:44, New International Version, 1984)

(3.59) This was now the third time Jesus appeared to his disciples after he was raised from the dead. (New International Version, 1984, John 21:14, http://bible.cc/john/2114.htm People's New Testament)

(3.60) When he had finished praying, Jesus left with his disciples and crossed the Kidron Valley. On the other side there was an olive grove, and he and his disciples went into it. Now Judas, who betrayed him, knew the place, because Jesus had often met there with his disciples. (John 18:1-2, http://bible.logos.com/passage/NIV/Jn\%2019.28\#ref=Jn\%2019\%3A28\%2Chi\%3DJn\%2019\% $\mathrm{Jn} \% 2019 \% 3 \mathrm{~A} 28 \& \mathrm{ver}=\mathrm{NIV})$

(3.61) Then the Jews led Jesus from Caiaphas to the palace of the Roman governor. By now it was early morning, and to avoid ceremonial uncleanness the Jews did not enter the palace; they wanted to be able to eat the Passover. (John $18: 28)$ 
(3.62) That wasn't so hard to say, now was it? 


\section{Chapter 4}

\section{Wider Scope}

Intuitions about the rigidity of indexicals and definite descriptions play a crucial role in motivating Kaplanian, two-dimensional theories. It is claimed that a wide-scope theory of indexicals alone cannot explain why (S') has a non-rigid reading while (I') does not (Kaplan (1989), Maier (2009), and Zeevat (2000); cf. also Kripke $(1980))$.

(I') I am speaking.

(S') The speaker is speaking.

Both (I') and (S') are atomic sentences and share the same syntactic form. The only difference between them is that (I') contains an indexical in subject position where (S') contains a definite description with a meaning closely related to that of $I$. On the surface, then, an analysis of the Indexical Modal Argument (IMA) that holds that I in (I') takes wider scope than the speaker in (S') is hopeless. An extra dimension of meaning is needed.

This is the charge presented in Maier (2009) against a wide-scope presuppositional view of definites with the structure of PI. However, a careful analysis of the modal argument and PI's treatment of it will dispel the illusion that the IMA poses 
a problem for PI. I start with a review of the argument and what it is supposed to show. I then turn to an analysis of the argument using PI and a straightforward extension of PI for definite descriptions. I then argue that while the IMA does not show that PI needs more structure, it does show that PI cannot be extended entirely straightforwardly to a general theory of definite noun phrases. We will have to allow for different definites to have different strategies for the resolution of their presuppositions.

\subsection{Rigidity and Simple Sentences}

\subsubsection{A Basic Introduction to Maier's IMA}

Consider the following two sentences:

(I) Necessarily, I am speaking

(S) Necessarily, the speaker is speaking.

From (1) and (2) below, we can conclude (C1).

1. An utterance of $(\mathrm{I})$ is false

2. An utterance of $(\mathrm{S})$ is true

C1. I and the speaker do not make the same contribution to asserted content.

Now suppose that we remove the modal operators from (I) and (S) and consider:

(I') I am speaking. 
(S') The speaker is speaking.

From (3)-(5) below, we can conclude (C2). Adding (6), we arrive at (C3).

3. An utterance of (I') is contingently true.

4. An utterance of $\left(\mathrm{S}^{\prime}\right)$ is necessarily true.

5. (I') and (S') are both simple sentences.

C2. The semantic difference between (I') and (S') cannot be explained in terms of scope. In particular, we cannot say that $I$ makes the same contribution to asserted content as the description the speaker does when it takes wide scope, for there is no sense in which $I$ in (I') takes wider scope in (I') than the speaker does in $\left(\mathrm{S}^{\prime}\right)$.

6. The semantic difference between ( $\left.\mathrm{I}^{\prime}\right)$ and $\left(\mathrm{S}^{\prime}\right)$, namely that $I$ and the speaker make different contributions to asserted content, is the same semantic difference seen between $(\mathrm{I})$ and $(\mathrm{S})$.

C3. The semantic difference between (I) and (S) cannot be explained by appealing to differences in scope either.

In order to bring out the difference between the relevant readings of (I') and (S'), one could say, 'Imagine a context in which I am speaking' and, 'Imagine a context in which the speaker is speaking'. In the former case, the contexts imagined will all be contexts in which the actual speaker is speaking; in the latter case, the speaker will 
vary from one context to another and every context (understood in a Kaplanian way here) will be a context in which the speaker is speaking. In the IMA, of course, the sentences are not prefixed with 'Imagine a context in which'. The idea is that even without this prefix, we can still detect the requisite distinction between (I') and (S').

\subsubsection{The Worry for PI}

To understand Maier's criticism of a wide-scope theory like PI, let's look first at a 'naive' presuppositional view of indexicals. Suppose that the presuppositional component of $I$ were simply: $\exists x($ speaker $(x))$ and that the asserted component were $P(x)$ for some predicate $P$. Now suppose that the presuppositional component of the speaker were $\exists y(\operatorname{speaker}(y))$ and that the asserted component were $P(y)$ for some predicate $P$. The naive view will not be able to derive the requisite distinction between (I') and (S'). The indexical $I$ in (I') and the description the speaker in (S') will both presuppose that there is a speaker. Moreover, when uttered in the same context, the presuppositions of both definites will be bound to the same antecedent. The individual assigned to $x$ will be identical to the individual assigned to $y$ by any assignment function - both will be assigned to the speaker in the context. Because the definites in (I') and (S'), when uttered in the same context, will have the same presuppositional content and the same antecedent, they will also have the same asserted content. There will be no semantic difference between (I') and (S').

Now suppose that we add the operator $\uparrow$ to the lexical entry of $I$. Maier claims that this will not help the naive view. $\uparrow$ will force the presupposition of $I$ to take the widest scope possible. That is, it will force the presupposition of $I$ to bypass 
accessible sub-DRSs created by logical operators and bind in the global context. This is trivial in (I') because (I') is a simple sentence; the global context is the only option for resolution. Now because ( $\mathrm{S}^{\prime}$ ) is also a simple sentence, the global context will be the only option for resolution of the speaker's presupposition in (S'). Even if the presupposition of $I$ is prefixed with $\uparrow$ and the presupposition of the speaker is not, then, (I') and (S') will still receive the same interpretation. The presuppositions of $I$ and the speaker will be bound to the same antecedent in the same context, because there is only one context to choose from, and will therefore have the same asserted content once again. Here is how Maier puts his worry: 'the proposed mechanisms [i.e. $\uparrow$ ] only work in embedded contexts, so, like the naive theory and the presuppositional account of proper names [Geurts (1997)] it fails the Kripke test: it cannot generate distinct outputs for [I am speaking] and [the speaker is speaking], given a suitable input context with a speaker. As there are no embeddings, there is nothing to take scope over and the uparrow in the indexical PrelDRSs will not affect resolution at all.'

Maier's worry is slightly obscured by his use of the IMA to make his point. $\left(\mathrm{S}^{\prime}\right)$ is awkward; one is left wondering, 'what speaker?' or 'the speaker in what context?'. (S') would sound better if the speaker were replaced with a description such as the current speaker, the present speaker, or the agent of this utterance. These descriptions, however, are themselves indexical, and the tendency to understand them as rigid descriptions is pronounced enough that they would be less useful for Maier's purposes. He needs a definite description with a clear non-rigid reading to make his point. 
Despite the obscured way in which Maier presents his worry, however, his concern is justified. It could be brought out more clearly by forgetting indexicals for the time being and considering rigid and non-rigid readings of definite descriptions in simple sentences.

\section{(4.1) The President of Iran is tall.}

(4.1) has two readings. On the one hand, were it used today in a normal, nonphilosophical conversation, it could be understood as saying of Mahmud Ahmadenijad that he is tall. On the other hand, (4.1) has a non-rigid reading according to which it is true in a world $w$ just in case whoever is the President of Iran in $w$ is tall in $w$. Using (4.1), we can reframe Maier's worry as follows. Were we to extend PI to a more general theory of definite noun phrases, the resulting theory would have to be able to generate both the rigid and the non-rigid readings of the President of Iran. Because PI is a wide-scope theory, it will not provide enough structure to do this; the definite description the President of Iran has two different readings in (4.1), but its scope does not change.

Maier concludes that the structure provided by a theory like PI is insufficient. We must supplement a presuppositional theory of indexicals with a two-dimensional logic so that the presuppositions of rigid definites can exist in a dimension apart from the presuppositions of non-rigid definites. ${ }^{1}$

\footnotetext{
${ }^{1}$ Maier does not believe that definite descriptions can have truly 'semantic' rigid interpretations and I take it that this belief is in part what leads him to present his worry by comparing indexicals to definite descriptions, rather than by comparing rigid and non-rigid readings of definite descriptions directly. His prohibition on rigid definite descriptions leads him to draw a slightly different
} 


\subsubsection{PI's Response}

Maier's criticism hinges on the assumption that because (I') and (S') are simple sentences, there will be only one context for the presuppositions of $I$ and the speaker to choose from in these examples. This assumption is true in presuppositional theories that do not distinguish a context dedicated only to information from the extra-linguistic context (e.g. Heim (1982, 1983), van der Sandt (1992), Geurts (1997)), but it is false in PI. Even for simple sentences, there will be a choice between binding or accommodating at $\mathrm{K}_{0}$ and binding or accommodating at $\mathrm{K}_{1}$.

PI distinguishes between $K_{0}$ and $K_{1}$ for the intuitive reason that the extralinguistic context and the linguistic context constitute different sources of information. These contexts also have different properties. Discourse contexts are hierarchical, for example. PI takes the further step of making the extra-linguistic context more global than the linguistic context because it is assumed that when there is an extra-linguistic context ${ }^{2}$, discourse takes place within the extra-linguistic context. This assumption is supported by the fact that while the extra-linguistic context can affect the interpretation of discourse, discourse cannot affect the interpretation of the extra-linguistic context. Because of the accessibility constraints in DRT, this asymmetry is captured best by making the extra-linguistic context superordinate to the linguistic context.

Because of the distinction between $\mathrm{K}_{0}$ and $\mathrm{K}_{1}$, PI can generate distinct out-

conclusion from the one I draw here. It is that the presuppositions of indexicals (and proper names) must exist in a dimension apart from the presuppositions of definite descriptions.

${ }^{2}$ This might exclude fictional contexts, though I remain agnostic on this point. 
puts for $\left(\mathrm{I}^{\prime}\right)$ and $\left(\mathrm{S}^{\prime}\right)$. The presupposition of $I$ in (I') will be bound at $\mathrm{K}_{0}$. The non-rigid reading of $\left(\mathrm{S}^{\prime}\right)$ that is relevant for the IMA will be derived by allowing the presupposition of the speaker to accommodate in $\mathrm{K}_{1}$. I assume local binding is not an option because we are considering ( $\left.\mathrm{S}^{\prime}\right)$ in isolation. ( $\left.\mathrm{S}^{\prime}\right)$ will be non-rigid, as desired, and (I') will be rigid, also as desired, because the presupposition of $I$ will be bound at $\mathrm{K}_{0}$.

PI gets the desired readings of (I') and (S') without positing two-dimensionalism, contrary to Maier's claim that a wide-scope, presuppositional account of indexicals cannot do justice to the basic IMA without adopting two-dimensionalism. What's more, PI can also generate the logical form for the rigid reading of ( $\left.\mathrm{S}^{\prime}\right)$, according to which ( $\mathrm{S}^{\prime}$ ) is only contingently true, and it can do this without positing ambiguity for definite descriptions. The non-rigid reading of ( $\left.\mathrm{S}^{\prime}\right)$ is generated by allowing the presupposition of the speaker to bind or accommodate at $\mathrm{K}_{0}$ along with the presupposition of $I .^{3}$ However, note that even if the presupposition of the speaker binds at $\mathrm{K}_{0}$ and (I') and (S') have the same asserted content, on the assumption that they are uttered in the same context, (I') and (S') still won't have the same overall meaning. Given the lexical entry that PI posits for $I$, (I') will have the logical form in (I'b):
a. I am speaking
b. $\quad \exists x\left(\uparrow \exists e_{\pi}\left(\operatorname{ag}\left(e_{\pi}, x\right) \wedge e_{\pi}=?\right) \wedge \operatorname{speaking}(x)\right)$

\footnotetext{
${ }^{3}$ I say that it can be bound or accommodated at $\mathrm{K}_{0}$ because $\mathrm{I}$ have not taken a stand on whether the antecedent for the speaker will already be available in $\mathrm{K}_{0}$. I assume that it will be so long as someone is speaking in $\mathrm{K}_{0}$, but I need not settle this issue for the purposes of my argument here.
} 
There is no reason to assume that the definite description the speaker will have the same presupposed content as I. I and the speaker will not be synonymous, so neither will (I') and (S').

\subsection{Resolution Strategies}

A wide-scope, presuppositional theory of definites based on PI will have the structural resources needed to generate all of the requisite readings of (I') and (S'). Addressing the IMA, it turns out, does not require the structure of Kaplanian, twodimensionalism as Maier (2009) argues that it does. Nevertheless, showing that PI can generate the requisite readings is not enough to show that PI fully addresses the issues brought out by the IMA. One might want to know what it is that makes indexicals different from other definites. Why, for example, does $I$ in (I') not have a rigid reading when the speaker in (S') does?

The IMA reveals that we will not be able to extend PI straightforwardly to all definites. Different definites have different strategies for the resolution of their presuppositions. Here is one way to bring out the point. Suppose that PI could be straightforwardly extended to a general theory of all definite noun phrases. Definite descriptions would be presuppositional just like indexicals. Their presuppositions would not be prefixed with $\uparrow$, perhaps, but it would still be reasonable to expect that local accommodation would be the least preferred strategy for the resolution of their presuppositions - being presuppositional implies a preference for having one's content presupposed. In van der Sandt's system, this preference is reflected in his algorithm: local accommodation is chosen only when all other options have been 
exhausted. I am positing local accommodation for the presupposition of the definite description in $\left(\mathrm{S}^{\prime}\right)$, but is it really the case that all other options have been exhausted in the IMA? Not likely. It would be easy enough to consider (I') and (S') uttered in a context in which there is a speaker (just imagine that the tokens are spoken rather than written). Binding at $\mathrm{K}_{0}$ would be an option for the presupposition of the speaker, but still, the non-rigid, i.e. $\mathrm{K}_{1}$, reading would also be available. Furthermore, if binding or accommodating at $\mathrm{K}_{0}$ were really blocked in the IMA, we would expect that binding at $\mathrm{K}_{0}$ would be blocked for $I$ as well and that (I') would have a non-rigid, or perhaps a non-sensical, reading. But it doesn't. This difference between indexicals and definite descriptions needs to be accounted for. We cannot simply extend PI to a general theory of definites after all.

So what makes indexicals different from definite descriptions? We might turn the above point around and argue that the fact that indexicals can't have non-rigid readings in the IMA, when definite descriptions can, shows that indexicals are semantically referential or rigid after all. Recanati (1993) offers an account of indexicals that is structurally similar to PI — it is not two-dimensional-but which nevertheless stipulates that indexicals and proper names are referential in order to ensure rigidity for these expressions. Recanati posits a feature $+\mathrm{REF}$ in the lexical entries of all indexicals and proper names, and this feature indicates that the truth conditions for a name or indexical will be singular. Definite descriptions lack this feature; the truth conditions for one token of a definite description might be singular but the truth conditions for another token of the same description might be descriptive. The fact that indexicals have $+\mathrm{REF}$ and definite descriptions do not accounts for the different 
interpretive possibilities of indexicals and definite descriptions brought out by the IMA.

$\uparrow$, like $+\mathrm{REF}$, is a lexical feature, but it is subtly and importantly different from + REF. An indexical - in fact, any definite noun phrase - will have a referential and, therefore, rigid interpretation if its presupposition is bound at $\mathrm{K}_{0}$, but referentiality is not stipulated as such in PI. While a feature like + REF would not allow binding or accommodation outside of $\mathrm{K}_{0}$, $\uparrow$ does allow binding or accommodation at other levels when the conditions are right. Moreover, while Recanati holds that proper names also have the feature $+\mathrm{REF}$, which would explain their rigid behavior in the modal arguments for proper names, I do not think that $\uparrow$ is appropriate for proper names. I will elaborate on this point below but the picture I want to motivate is one on which definites have far more nuanced strategies for the resolution of their presuppositions than a theory like Recanati's would suggest. Having +REF and not having + REF would come down to having to bind at $\mathrm{K}_{0}$ versus not having to bind at $\mathrm{K}_{0}$ in PI. This distinction is unhelpful. First, as I have emphasized repeatedly, I don't think that there are any expressions that have to bind at $K_{0}$ as a matter of semantic fact, so the class of expressions with the feature +REF would be empty in PI. Second, even if there were expressions that could only bind in $K_{0}$ as a matter of semantic fact, the simple distinction between $+\mathrm{REF}$ and not $+\mathrm{REF}$ would not provide all of the distinctions that we need. It encourages us to throw definites into a single group that are importantly different from one another-like indexicals and proper names - and thus sets us on the wrong track if we're aiming for a more general account of definites. 
I claim that all definites vary according to a single theme: their strategies for presupposition resolution. Arguing for this claim would require an in depth study of all definites, which would certainly take us too far afield. Still, I think that a brief comparison of some differences observed between the behavior of different definites will be enough to suggest that we ought to allow for a wide range of presupposition resolution strategies and that these strategies are what we must explore if we are to find out what makes indexicals special and why their presuppositions cannot accommodate locally.

Let's consider some basic possibilities for resolution in PI and look at which possibilities are open to which definites. I divide the possibilities into four general groups: binding and accommodation at $\mathrm{K}_{0}$ and binding and accommodation at $\mathrm{K}_{1}$ or lower. Looking at these differences alone we get a variety of strategies among definites. Indexicals, as we have seen, can bind at $\mathrm{K}_{0}$ and, in very special situations, they can bind below $\mathrm{K}_{1}$. They cannot accommodate anywhere. Demonstratives, like indexicals, are happy to bind in $\mathrm{K}_{0}$. They can also bind in $\mathrm{K}_{1}$ and they seem to do so more easily than indexicals - they have well accepted discourse anaphoric uses. Like indexicals, however, they cannot accommodate anywhere. Third person pronouns bind very easily at both $\mathrm{K}_{0}$ and $\mathrm{K}_{1}$ or below and I am hesitant to say that their their presuppositions are prefixed with $\uparrow$. I stand by my choice of $\uparrow$ for indexicals, but determining the resolution strategies for other definites will require more empirical work. Note that we cannot simply adopt van der Sandt's algorithm for pronouns in PI. Van der Sandt did not discuss the level of content that I am calling $\mathrm{K}_{0}$; his algorithm applied only to $\mathrm{K}_{1}$ and below. Pronouns, like indexicals 
and demonstratives, cannot accommodate.

Unlike indexicals, demonstratives and third person pronouns, proper names can accommodate, though accommodation at $\mathrm{K}_{1}$ and below, if possible at all, is markedly more difficult than accommodation at $\mathrm{K}_{0}$. Geurts (1997) argues that the following example from Bach (1987) is one example of local accommodation:

(4.2) The electoral process is under attack, and it is proposed, in light of recent results, that alphabetical order would be a better method of selection than the present one. Someone supposes that 'Aaron Aardvark' might be the winning name and says, 'If that procedure had been instituted, Ronald Reagan would still be doing TV commercials, and [(4.2)] Aaron Aardvark might have been president' (Bach 1987: 146-7).

Local accommodation at $\mathrm{K}_{1}$ is likely to be far more difficult than accommodation at lower levels - as is well-noted, proper names have rigid readings in the IMA. However, it would be interesting to study what effect discourse topic would have on the interpretation of names. In Bach's example, the discourse topic makes it clear that an interpreter need not look for a referent for Aaron Aardvark in $\mathrm{K}_{0}$. This might make a difference.

Not only do names accommodate, but contrary to fairly conventional wisdom, they also bind locally and without too much fuss. ${ }^{4}$

\footnotetext{
${ }^{4}$ See Geurts 1997 for an interesting and in depth discussion of the interpretive possibilities for proper names.
} 
(4.3) Had John had a son, he would have named him John Jr. and John Jr. would have inherited this house.

(4.4) My daughter thinks that there is a monster under her bed named Manny and she can't sleep at night because she's scared that Manny will attack her in her sleep.

(4.5) If a child is christened Bambi, and Disney Inc. hear about it, then they will sue Bambi's parents (Geurts 1997).

And it might even be that local binding is preferred to global binding when the choice presents itself. Suppose, while lecturing on Aristotle the philosopher, a lecturer goes off on the following small tangent.

(4.6) Kripke said that Aristotle was fond of dogs. I named my first dog Aristotle because of that. Aristotle was very intelligent. I miss him very much.

It seems that even in the context in which Aristotle the philosopher would be available and salient in the global context, the third occurrence of Aristotle above would still pick out the speaker's dog. Again, discourse topic is likely to make a difference in where the presuppositions of names decide to bind.

Definite descriptions have the most liberal resolution strategies of all. All four options are available for definite descriptions. However, as van der Sandt (1992) recognized, it might be more difficult to accommodate the presuppositions of definite descriptions with very impoverished descriptive contents (see also van der Sandt \& Geurts (1999), Geurts (1997)). 
(4.7) The table is brown.

(4.8) The table in the Oval Office at the White House is brown.

If there is no table salient in the context, one cannot simply accommodate the existence of some unique table in some context in order to interpret an utterance of (4.7). However, if there is no antecedent for the more robust description the table in the Oval Office, then, assuming the interpreter knew that the Oval Office was a name for a particular office, accommodation of an antecedent would be very easy.

Definites exhibit a wide range of resolution behavior. In the following, and final, two subsections I present two frameworks in which to think about the different resolution strategies of definites and suggest how the frameworks might be relevant to our question of what makes indexicals special. However, I leave a proper study of these frameworks for future research.

\subsubsection{At-Issue Content}

The resolutions strategies of some definites appear to be more influenced by discourse structure and topic than do other definites. In particular, I think that discourse topic can affect when a definite description will accommodate locally or not. If this is true, then the presuppositions of definite descriptions should be able to accommodate locally even when global binding or accommodation would not lead to inconsistency. This is what we see in the IMA.

Suppose that someone, who holds Aristotle to be the greatest philosopher of antiquity, is lecturing on the philosophers of antiquity. To introduce Aristotle, he 
utters (4.9).

(4.9) The greatest philosopher of antiquity was a philosopher, but he might not have been. He wanted to be a shipbuilder.

Here the definite description binds or accommodates globally (depending on the previous discourse context) and we get a reading of the definite description according to which it picks out Aristotle, even if we assume that Aristotle has not yet been mentioned by name in the context. I claim that this is because the discourse is clearly about Aristotle. But now suppose some philosophers are having a conversation about how things might have been. Someone asks the others to imagine a world that is, say, better than this one. She asks them to describe the world. People start blurting out descriptions that would apply to their ideal world and one person says,

(4.10) The greatest philosopher of antiquity was a woman!

There is no modal operator in (4.10). The discourse has made relevant worlds other than the actual world, but one need not conclude on account of this that the discourse introduces a hidden modal operator that takes scope over the definite description. Yet the description is understood as describing a non-actual, possible world; the descriptive content of the definite description does not bind at $K_{0}$. This, I maintain, is because the discourse topic makes it clear that neither Aristotle nor the actual world is at issue here and the semantics of definite descriptions allow their interpretations to be sensitive to discourse topic. 
The discourses above are artificial and I am not suggesting that I have recreated the right discourse topic (if there is one) for the IMA. The point is that by shifting the discourse topic, we can influence the way that definite descriptions are understood in simple sentences. In particular, by explicitly detaching the discourse topic from the actual world, we can make the non-rigid reading of a definite description more salient. This, I claim, is exactly what happens in the IMA. The non-rigid reading of (S') requires that an interpreter not try to connect the use of the definite description with her representation of the actual world.

The idea that normally projective content can fail to project when brought into question is at the heart of Simons et al. (2010). Simons et al. distinguish between backgrounded content and 'at-issue' content to provide a solution to the classical projection problem for presuppositions, though the solution is intended to apply to all content that shows the ability to project over entailment-canceling operators, not only presuppositional content. According to Simons et al., an implication of an embedded sentence will project just in case it is not at-issue, where projection is defined in the traditional way as follows.

An implication projects if and only if it survives as an utterance implication when the expression that triggers the implication occurs under the syntactic scope of an entailment-cancelling operator.

Simons et al.'s notion of at-issueness is based on Roberts (1996). According to Roberts, discourses are structured around questions that the discourse seeks to answer. There is generally one main question under discussion, the Question Under 
Discussion (QUD), which provides the topic of the discourse, but there can also be sub-questions under discussion, answers to which will provide at least partial answers to the QUD. In Simons et al., content is at-issue if it provides at least a partial answer to the question under discussion. Any information that is irrelevant for answering the question will project outside of at-issue content; only at-issue content can be targeted by entailment-cancelling operators, so non-projection of content reveals at-issuenss. Here is their hypothesis in their words (p. 6):

(4.11) Hypotheses about what projects and why

a. All and only those implications of (embedded) sentences which are notat-issue relative to the Question Under Discussion in the context have the potential to project.

b. Operators (modals, negation, etc.) target at-issue content.

Simons et al. do not go into detail about how the at-issue/not-at-issue distinction interacts with the semantics of definite noun phrases, but they do offer the following example.

(4.12) QUD: Does France have a king?

a. Well, the King of France didn't attend the opening of Parliament.

b. Did the King of France attend the opening of Parliament?

c. Perhaps the King of France attended the opening of Parliament. 
In this example, they claim that because the QUD brings the existence of the King of France into question, the presupposition of the definite the King of France does not project outside of the entailment-canceling operators in (4.12a)-(4.12c). The resulting logical form in each of the responses is of the following form (or something along these lines), where $O$ is a variable for an operator: $O \exists ! x(\operatorname{KoF}(x) \wedge$ at-opening $(x))$.

Simons et al's theory motivates that claim that sometimes what information is understood as given in a discourse depends on broader discourse factors, notably discourse topic. Furthermore, their claim has a very broad scope: it applies not only to typically presuppositional expressions such as definite noun phrases, clefts, factives, particles like too, and aspectual verbs like stop, but also to non-presuppositional expressions and constructions that show the ability to project including appositives, non-restrictive relative clauses, epithets, and even politeness morphemes like those seen in languages such as German, French and Dutch where a distinction is made between a formal and informal second person pronoun. My focus in this chapter is on the behavior of indexicals and definites in general, but it is important to point out that the discourse-based analysis of the resolution preferences of definites would be motivated by a very widespread phenomenon in language and discourse.

The most interesting point for the purposes of this chapter, however, is that the combination of PI's hierarchical contexts and Simons et al.'s hypothesis about projection and discourse topic, strongly suggests that discourse topic could play a role in the projection of content even in simple sentences. PI, as we have seen, posits a distinction between the extra-linguistic context, $\mathrm{K}_{0}$, and the linguistic context, $\mathrm{K}_{1}$ and below - and it posits this distinction for reasons independent of the IMA. As a 
result of this distinction, however, projection of content becomes an issue even for simple sentences in PI-based theories of definites. There is always in principle a choice to be made between binding or accommodating at $\mathrm{K}_{0}$ and binding or accommodating at $\mathrm{K}_{1}$, as I explained above. Given that this choice is possible in PI, one would expect, given Simons et al.'s analysis of projection in terms of discourse topic, that discourse topic could affect the strategy of resolution ultimately chosen for a definite in a simple sentence.

Viewing the behavior of definite descriptions in the IMA from the perspective of the at-issue/not-at-issue framework would allow us to reframe our question about what makes indexicals special. Rather than asking why the presuppositions of indexicals cannot locally accommodate, we would ask why it is that indexical presuppositions cannot be made at-issue.

\subsubsection{Givenness}

Another way to view the nuanced behavior of definites is through the lens of what is sometimes called the Accessibility Heirarchy or Givenness Hierarchy. The Givenness Hierarchy, developed notably by Jeannette K. Gundel (see Gundel 1993) and Mira Ariel (see Ariel 1990), is a statistically-based model for noun phrase pref-

erences. Although work on the hierarchy was not originally understood in terms of presuppositions, in light of our current discussion, I will present the data as revealing preferences about presupposition resolution. What follows is one version of the 
hierarchy, taken from Aloni $(2005)^{5}$, with the condition for selection of each type of noun phrase given in parentheses. Following Aloni, I will call this hierarchy the Referential Device Principle (RDP).

(4.13) reflexive pronouns (c-command) $\rightarrow$ 1st and 2nd person pronouns (conversational participant) $\rightarrow$ demonstratives (presence in attention space), anaphoric pronouns (high salience through mention), attenuated definites (old, dependence on high salient), proper names (familiarity) $\rightarrow$ robust definites (new and unique) $\rightarrow$ indefinites (new)

The hierarchy is based largely on statistical research on the conditions under which different definites are chosen. The conditions in parentheses provide necessary conditions for use of a given noun phrase. A reflexive pronoun should be used only when the pronoun is c-commanded; first and second person pronouns can be used only to refer to conversational participants, etc. But the order of the hierarchy also reveals preferences for choosing one definite over another. For example, suppose a speaker wishes to refer to himself. He has a choice between using the first person pronoun $I$ or a designator from any of the categories ranked lower in the hierarchy. He could, for instance, refer to himself in the third person or by using a definite description. What the hierarchy shows, is that in such a situation, the first person

\footnotetext{
${ }^{5}$ Aloni borrows this from Zeevat (2002), but adds proper names. Also, what Aloni called 'short' and 'long' descriptions, I have called 'attenuated' and 'robust' descriptions, respectively. A more robust definite description does not necessarily contain more words than an attenuated definite description. Adding words can help make an attenuated description more robust and easier to accommodate, as we saw in (4.7) and (4.8), but adding words is not always necessary. The oldest person will probably be easier to accommodate than the old person, for example. Robustness, as I use the notion, is not well defined and I will not attempt to go beyond a rough, intuitive use of it.
} 
pronoun is preferred over lower ranked types of noun phrases. Again, the RDP is statistically based, so this does not mean that there won't be some situations which call for choosing a lower ranked expression (Who is she [pointing at a photograph]? Oh! She is me!). It simply means that the first person pronoun is generally preferred in such situations.

There are many factors that influence the choice of noun phrase in a context and many are not easy to define. There is still a lot of work being done on the RDP that focuses on trying to pin down notions such as distance (between a noun phrase and its antecedent) and robustness, and on studying the role of such factors as topic and focus in determining preference for one noun phrase over another. I do not pretend that these issues are settled. What emerges from all of the work on the RDP, however, is enough to bolster the point I have been urging. Different definites have different resolution strategies.

Note that indexicals, which I have argued have the most restrictive preferences, are almost at the top of the hierarchy, while robust or descriptively rich definite descriptions, which have the most liberal strategies, are at the bottom (ignoring indefinites). Noun phrases (both definite and indefinite) are used to talk about individuals and each has a context-insensitive level of meaning that helps them perform their function. There are semantic differences between, say indexicals and definite descriptions, but not because one is more equipped to 'refer' than another; rather, it is because their presuppositional meanings will make one a better candidate for picking out an individual in a given context rather than another. This point deserves reiteration for proper names. The picture that I am motivating does not privilege 
$\mathrm{K}_{0}$ for the presuppositions of proper names. Their presuppositions can bind easily at $\mathrm{K}_{1}$ or lower. The reason why names are not used more often in cases of local binding is not because names have a feature $+\mathrm{REF}$ ( or even $\uparrow$ ), but rather because there is a better choice for picking out highly salient entities: pronouns.

The RDP casts an interesting light on our question about why indexicals can't accommodate locally. The RDP suggests that if it is a more distant entity that we are interested in picking out, rather than an immediately accessible one, then we should use an expression from lower down in the hierarchy. For example, it suggests that we should use a definite description rather than an indexical in such a case. Using an expression from higher up when a lower one could be chosen suggests that the immediately accessible entity is the relevant one.

\subsection{Conclusion}

The IMA does not motivate a two-dimensional account of indexicals. A widescope, presuppositional theory like PI can generate the requisite readings of (I') and (S') so long as it distinguishes between the extra-linguistic and linguistic context. PI captures this distinction by letting the most global DRS, $\mathrm{K}_{0}$, represent information from the extra-linguistic context, while stipulating that information from discourse is represented at $\mathrm{K}_{1}$ or below. Once we make this distinction, it is no problem to show that definite descriptions, like the speaker in (S'), can have both a rigid and a non-rigid reading. The rigid reading arises when the presupposition of the definite description is bound or accommodated at $\mathrm{K}_{0}$, i.e. when the definite description is used to refer to an entity in the actual world. The non-rigid reading arises when the 
presupposition is accommodated locally at $\mathrm{K}_{1}$.

Although the IMA does not motivate a two-dimensional view, I have argued that it does show that we cannot extend PI in an entirely straightforward way. We cannot, for example, assume that all definites have presuppositions prefixed with $\uparrow$; rather, we must allow for a very nuanced picture of presupposition resolution for different definites. Definites give instructions on where to find their antecedents. Some definites, indexicals in particular, give very particular instructions on where to look for their antecedents. Other definites, like robust definite descriptions, are very liberal. For these definites, I have argued that factors like discourse topic can affect interpretation. 


\section{Chapter 5}

\section{'Descriptive' Indexicals}

Nunberg (1993) and Elbourne (2008) take data like (5.1) and (5.2) to pose insurmountable difficulties for any Kaplan-style theory of indexicals.

(5.1) Said by a U.S. Supreme Court Justice: If Democrats had won the last few presidential elections, we might have been liberals. (Nunberg, 1993)

(5.2) Uttered two days before Thanksgiving: Tomorrow is always the busiest day to travel.

The intended readings of (5.1) and (5.2) are (loosely) captured by (5.3) and (5.4), respectively.

(5.3) If Democrats had won the last few presidential elections, the Supreme Court Justices might have been liberals.

(5.4) The day before Thanksgiving is always the busiest day to travel.

Nunberg and Elbourne claim, correctly, that the descriptive readings of the indexicals in (5.1) and (5.2) are not explained by a Kaplan-style theory of indexicals and propose a revision of the semantics of indexicals to allow for such descriptive readings. They claim that from a semantic perspective, an indexical can always have a 
descriptive interpretation, but in certain cases, the indexical has a referential reading for pragmatic reasons.

Although PI rejects the two-dimensional framework of Kaplan's Logic of Demonstratives (LD), it does not reject the features of LD that Nunberg and Elbourne are criticizing. I in PI always refers to an agent of an utterance event; today refers to the day of utterance or, perhaps, a general period including the day of utterance as in Children today are addicted to electronic devices. Indexicals are never interpreted as definite descriptions in PI. PI and LD agree about the kinds of meaning that need to be analyzed in a semantics for indexicals; they simply disagree on the formal analysis of those meanings. In my discussion of Nunberg (1993) and Elbourne (2008), then, I will treat PI and LD as one of a kind.

I will argue that data like (5.1) and (5.2) do not motivate a rejection of PI or LD. ${ }^{1}$ At most, they call for a pragmatic supplementation of these theories. I will offer the outline of a solution according to which indexicals always keep their standard indexical meanings at the level of logical form but in certain cases, material is added to these interpretations during the composition process in order to repair problematic predications. My argument will proceed in two broad steps. First, I will argue that Nunberg and Elbourne's argument against a pragmatic account of descriptive indexicals, like that proposed in Recanati (1993), is not convincing. Next, I will sketch my pragmatic solution and argue that such a pragmatic approach is more desirable than a descriptive account of the Nunberg and Elbourne sort.

\footnotetext{
${ }^{1}$ Although I do not think that Kaplan's LD is the right theory for indexicals, it is not because of the points that Nunberg and Elbourne make.
} 


\subsection{Descriptive Readings of Indexicals}

The data on which I rely are either borrowed from or inspired by data presented in Nunberg (1993), but while Nunberg treated these data as exhibiting a single phenomenon - 'deferred reference'-I do not think that these data form a heterogeneous class. In this section, I focus on two subclasses of Nunberg's data. The first, which I call intensional reconstruction (IR), is exhibited in (5.1)-(5.9).

(5.1) Said by a U.S. Supreme Court Justice: If Democrats had won the last few presidential elections, we might have been liberals. (Nunberg, 1993)

(5.5) Because the last few presidents have been Republicans, we are mostly conservatives.

(5.6) Said to Nancy Pelosi/the House of Representatives: If the Taliban were in charge, you $u_{s i n g}$ would be a man/you

(5.7) You should have checked the peephole. I/she could have been a burglar. ${ }^{2}$

(5.8) If the Republicans had won the last election, he [pointing at Obama] would have been an old white guy.

(5.9) Said on November 25 by someone born on November 25: Had I been born a month later, I would have received a lot more gifts today.

\footnotetext{
${ }^{2}$ This is a close variation of an example given by Nunberg (1993) in his footnote 34. I believe the example is originally due to Hans Kamp.
} 
These examples can be (loosely) paraphrased by substituting definite descriptions for the italicized indexical expressions; the intended readings of (5.1) and (5.5), for example, can be captured by replacing we with the Supreme Court Justices. Moreover, the descriptive readings in these examples are triggered by the presence of intensional operators - were we to remove the intensional constructions, neither intuition nor charity would require descriptive readings of the indexicals. ${ }^{3}$

A similar phenomenon, which I will analyze as quantificational coercion (QC), can arise when indexicals interact with certain quantifiers:

(5.2) Tomorrow is always the busiest day to travel.

(5.10) The bookstore crowds usually abate a week from now. (Nunberg, 1993)

(5.11) There is always a post office around here. [uttered by the town hall]

(5.12) He is usually of a different party from the president. (Nunberg, 1993)

(5.13) We are often conservative/We have always been a conservative group.

(5.14) Traffic is rarely heavy this weekend.

(5.15) Sometimes, that/It is made of ice. [talking about a high-profile sculpture at a yearly gala]

\footnotetext{
${ }^{3}$ Following Kaplan, I will often use the term indexicals in this chapter to include both demonstrative and non-demonstrative, indexical expressions. From now on, I will explicitly mention demonstratives only when necessary.
} 
(5.2) and (5.10)-(5.15), like (5.1) and (5.5)-(5.9), can be (loosely) paraphrased by replacing the indexicals with definite descriptions. Suppose an agent utters (5.2) on November 25, 2009, which is two days before Thanksgiving in 2009. The intuitive reading of this example is not one equivalent to November 25, 2009 is always the busiest day to travel; a particular date does not have recurrent properties. Rather, the agent is understood as saying something like the day before Thanksgiving is always the busiest day to travel. As in IR cases, were we to remove the adverb of quantification from (5.10)-(5.15) the descriptive readings would not be forced upon us. ${ }^{4}$

\subsection{Previous Accounts: Nunberg, Elbourne, and Recanati}

Both Nunberg (1993) and Elbourne (2008) argue that a Kaplanian account of indexicals cannot handle IR and QC data. Let's look at how Kaplan would represent (5.2) and (5.16).

(5.2) Tomorrow is always the busiest day to travel.

(5.2') Always $\left(t_{2}\right.$ is the busiest day to travel)

(5.16) (If a Democrat had won the last gubernatorial election, then) I might have been Mexican.

\footnotetext{
${ }^{4}$ As stated, this is too strong. Sometimes tense and predication are sufficient to bring about a descriptive reading, as in Tomorrow is the busiest day to travel. I will discuss this in more detail below, but what is important is that there is an element of the sentence that requires a quantificational reading of the indexical and if we remove this element-by, for example, changing the tense - the quantificational reading is no longer required.
} 
$\left(5.16^{\prime}\right) \diamond(\operatorname{Mexican}(a))$, where $a$ refers to the agent

It is clear that Kaplanian account alone cannot generate the intended readings of (5.2) and (5.16). A Kaplanian treatment of (5.2) will yield a reading according to which the particular day after the day of utterance is always the busiest day to travel, as shown in (5.2'), and a Kaplanian treatment of (5.16) will yield a reading according to which the agent might have been Mexican, as shown in (5.16'). Furthermore, because PI will generate roughly the same logical forms for (5.2) and (5.56), it is clear that PI alone cannot generate the intended readings.

A reasonable hypothesis at this point would be that (5.2') and (5.16') are the logical forms for (5.2) and (5.16), but the contexts in which (5.2) and (5.16) receive their QC and IR readings, respectively, allow for pragmatic supplementation of the literal logical forms. The context makes it clear that the literal interpretation is not the desired one and so the interpreter uses her knowledge of the standard interpretation of the indexical plus the context to construct a new concept. For example, upon hearing an utterance of (5.2) two days before Thanksgiving, an interpreter might use her knowledge that the day after the day of utterance is also the day before Thanksgiving to construct a concept of the day before Thanksgiving. The interpreter will realize that the speaker does not intend to attribute the property of always being the busiest day to travel to a single day, so she will move from thinking about the day itself, which is given by the semantics of tomorrow, to thinking about a contextually salient property of that day. If this is right, then IR and QC do not require a major overhaul of a Kaplanian theory; they merely show that such a theory must be supplemented with pragmatic mechanisms. This is the explanation chosen by Recanati 
(1993) and it will be my choice as well.

Nunberg, and Elbourne after him, argue that the pragmatic account will not do. If it were true that (5.2') were the logical form of (5.2) and (5.16'), the logical form for (5.16), and that pragmatic mechanisms were responsible for delivering appropriately supplemented logical forms, then we would expect to see IR and QC examples with proper names. In both LD and PI, names and indexicals make the same contribution to truth-conditional (LD) or asserted (PI) content. In LD, both contribute an individual (or perhaps a constant that denotes the relevant individual) and in PI, both contribute a discourse referent. If the pragmatic mechanisms work on the logical forms for examples with indexicals, why wouldn't they work on the logical forms for examples with proper names? Here are some examples from Nunberg and Elbourne to show that IR and QC examples cannot be reproduced for names.

(5.1) a. we might have been liberals.

b. O'Connor, Rehnquist, Thomas etc. might have been liberals.

c. The first woman appointed to the Court, the Chief Justice, the most recent Supreme Court appointee, etc. might have been liberals.

(5.17) a. He is usually an Italian [pointing at Pope Benedict XVI].

b. Benedict XVI is usually an Italian.

(5.1a) is the consequent of example (5.1) above. Nunberg claims that if we list the Supreme Court Justices by name, as in (5.1b), or by using supposedly referential descriptions, as in $(5.1 \mathrm{c})$, then we cannot get the IR reading that we get for (5.1a). 
Similarly, Elbourne argues that while (5.17a) has a QC reading paraphrased as the Pope is usually Italian, (5.17b) does not have this reading. We might add, as Nunberg did, that replacing (he) in (5.17a) with a uniquely referring definite description like the current Pope does not give rise to a $\mathrm{QC}$ reading either.

Based on the data that they consider for proper names, Nunberg and Elbourne conclude that IR and QC do not arise through pragmatic mechanisms alone but are rather made possible by the unique semantics of indexicals and demonstratives. In effect, what they propose is that pragmatic mechanisms like those proposed by Recanati should be incorporated into the semantics of indexicals. This creates the desired asymmetry between indexicals and other definites; only indexicals have these pragmatic mechanisms built into their semantics. The general idea is that an indexical can in principle contribute any contextually salient description or property to truth-conditional content so long as the property or description contributed is related to the appropriate contextual parameter in a way that is constrained by the semantics of the indexical. Character, which for Kaplan was a function that delivered an interpretation of an indexical in a context, becomes a mere constraint on indexical interpretation and we find that IR and QC data is not special from the point of view of the semantics of indexicals, according to Nunberg. The fact that indexicals often appear to have standard, functional Kaplanian characters or consistent presuppositions (as in PI) is only a matter of pragmatics, not semantics.

Nunberg (1993) argues that true indexicals and demonstratives - or, more accurately, deictic uses of indexical and demonstrative expressions - have a three part semantics. First, they have a deictic component. For each indexical, this is a function 
from utterances of the indexical to an element of the context of utterance, which Nunberg calls an index. ${ }^{5}$ The deictic component of $I$, for example, will map every utterance of $I$ to the agent of that utterance; thus the index for $I$, as well as for we, will be the agent. Next there is a classificatory component, which determines the number, gender, animacy, etc. for the semantic contribution of a deictic expression. The classificatory component of he, for instance, will constrain the semantic value of he to be singular, masculine and animate. Finally, the relational component of a deictic expression constrains the relation that holds between the index of the expression and the interpretation of the expression in a context. The relational component of tomorrow, for example, requires that the interpretation of tomorrow be either the day that succeeds the day of utterance or a description or property that holds of the day that succeeds the day of utterance; the relational component for $I$ requires that its interpretation be either the agent of the utterance or a description or property that holds of the agent. (My proposal, by contrast, does not allow for the possibilities presented in the second disjuncts.) For pragmatic reasons, as an agent 'cannot ordinarily instantiate an individual person to whom he is not identical' (Nunberg 1993, p. 20), the interpretation of $I$ is normally the agent of the utternace, but this need not be the case.

It is not clear what the logical form of an IR or QC example would look like for Nunberg, but Elbourne (2008) offers a formalization of Nunberg's proposal. According to Elbourne, demonstratives, pronouns, and, one assumes, indexicals always con-

\footnotetext{
${ }^{5}$ Following Peirce, C.T.: 1955, 'Logic as Semiotic: The Theory of Signs', In Justice Buchler (ed.), Philosophical Writings of Peirce, Dover, New York.
} 
tribute definite descriptions to semantic content. ${ }^{6}$ The descriptions are determined in a Nunberg-ian fashion. First, the semantics of each demonstrative, pronoun, and indexical assign an index to the expression in a given context (as in LD). The index for a token of a demonstrative will be the demonstratum; the index for a token of $I$ will be the agent of the token; and so on. Next, the lexical entry of each demonstrative, pronoun, and indexical contains a relational component, which determines the relation that must hold between the index and the final interpretation of any token of the expression, as Nunberg proposed. Elbourne's proposal would deliver the following logical form for (5.2) (or something very close to it).

- $\forall s(\iota z(z$ is the day before Thanksgiving in $s)$ is the busiest day to travel in $s)$

Always is treated as a quantifier over situations. The expression $\iota z(z$ is the day before Thanksgiving in $s$ ) will restrict the set of relevant situations to those situations $s$ that contain a unique day $z$ that is the day before Thanksgiving in $s$. The whole formula will be true just in case every situation, $s$, which is such that it contains a unique day before Thanksgiving $(z)$ is also such that $z$ is the busiest day to travel in $s$. The most important point here, though, is that the description $\iota z(z$ is the day before Thanksgiving in $s$ ) would be the truth-conditional/asserted contribution of tomorrow in (5.2), according to Elbourne.

\footnotetext{
${ }^{6}$ Elbourne does not discuss non-demonstrative indexicals in detail, but it is clear that the proposal is meant to extend to non-demonstrative indexicals. The proposal is, after all, a particular formalization of Nunberg's proposal.
} 


\subsubsection{Proper Names and Definite Descriptions}

I agree with Nunberg and Elbourne that there is an asymmetry between names and indexicals in QC and IR, or at least in the examples that they consider. Nevertheless, I find their conclusions to be too rash. First, even if IR and QC are more difficult with proper names and descriptions, this does not entail that IR and $\mathrm{QC}$ arise from special mechanisms in the semantics of indexicals. In PI, it's not only the asserted content of a definite that matters; presupposed content is genuine content and can make a difference in how a definite is interpreted in the discourse and in determining which definite is appropriate in a particular context. Indexicals and names may have the same kinds of asserted contents, but they do not have the same overall content, so we cannot conclude that a pragmatic mechanism that gives rise to a certain effect when applied to an indexical should give rise to exactly the same effect when applied to a proper name. Recall that the RDP (introduced in the last chapter) suggests that a proper name will generally not be used when an indexical could be. In all of the cases that Nunberg and Elbourne consider, it is clear that a pronoun (indexical or otherwise) could be used. The choice of a proper name or description in these contexts would suggest that the way that the referent is being

picked out is relevant to what the speaker intends to communicate. It would be reasonable, then, to expect that it would be more difficult to ignore the descriptive content of a name or definite description as is required for IR and QC phenomena.

Moreover, I think that proper names can figure in IR data. Consider the following pair of sentences, understood to be about Nancy Pelosi. 
(5.18) I/she might have been a Republican.

(5.19) Nancy might have been a Republican.

It might simply be that using a list of names (as in (5.1b) above) is distracting and requires more processing on the part of the interpreter, which in turn makes it harder for her to construct an IR reading of the example. Indeed, I think there are IR examples involving short lists of names (i.e. far fewer than nine) that are more felicitous than Nunberg's example.

(5.20) If conservatives had fared better in the congressional elections...

a. They might have been Republicans (pointing at Nancy Pelosi and Harry Reid).

b. Pelosi and Reid might have been Republicans.

Sometimes IR readings appear to be possible with definite descriptions as well. That is, there are examples in which a definite description is used to pick out a certain individual $a$ so that we can consider another individual $b$ who might have had a property $P$ that $a$ has, but which is not the property determined by the definite description. Suppose that John is at home when his mother, Jane, knocks on the door. He opens without checking the peephole. 
(5.21) You should have checked the peephole...
a. I/She could have been a burglar.
b. Jane could have been a burglar.
c. Your mom could have been a burglar.

I get an IR style reading of the last example according to which it's not literally true that John's mom could have been a burglar, but that it might have been that someone else was knocking on the door and that person was a burglar. We can create similar examples for metaphysical possibilities.

(5.22) If you had chosen a partner with more money,

a. Pointing at the addressee's birthday gift: that would have been made out of platinum.

b. your birthday gift would have been made out of platinum.

Imagine a case in which a man has just given his girlfriend an engagement ring for her birthday. The description your birthday gift makes salient the ring's property of being her birthday gift, but the predication (would have been made out of platinum) concerns an engagement ring that she would have received had she been with a richer man. The property of being a birthday gift turns out to be irrelevant for the predication - the counterfactual fiancé might have chosen to give it to her on a day other than her birthday and the example would still work. This is, I believe, a true IR example involving a definite description. 
Proper names and definite descriptions might be more resistant than indexicals to IR readings, but we have seen that they can figure in IR examples. Their behavior is less free in QC.

(5.23) She [pointing at Nancy Pelosi] is usually male.

(5.24) ? Nancy is usually male.

It is very difficult to hear Nancy in (5.24) as anything but referential. However, if we pluralize Nancy, I suspect that the example (with the IR reading) is improved.

(5.25) Nancys are usually male.

This example would perhaps be more felicitous in Washington, where it is commonplace to think about Nancy Pelosi and to think of her qua Speaker. In any case, I find it better than $(5.24) .^{7}$

In fact, it seems that proper names can in general combine with quantificational adverbs when we pluralize the name.
a. *Vogel is almost always German.
b. Vogels are almost always German.

(5.27) a. *Einstein usually stands out at a fairly young age.

b. Einsteins usually stand out at a fairly young age.

\footnotetext{
${ }^{7}$ I have talked to a handful of native English speakers who are less bothered by (5.24) than I am. To the extent that (5.24) is felicitous, it only serves to support my argument that QC is not a character level phenomenon. However, most of the people that I have questioned have admitted that even if (5.24) is acceptable, they find (5.25) to be more so.
} 
In (5.26), for example, Vogels allows us to quantify over the group of all people named Vogel. In (5.27), Einstein(s) is meant to be read as geniuses - a true QC style reading. So names can figure in QC cases, but it appears that they prefer to be made plural first. I take it that pluralization allows a shift to a property reading of the name, which then allows a QC style reading. ${ }^{8}$

I don't think that there are true QC style examples involving definite descriptions.

(5.38) The gift that I gave you for your birthday is usually made out of gold.

(5.39) Your mom is usually male.

${ }^{8}$ As many have noted, proper names can have property readings even outside of QC contexts.

(5.28) True Einsteins are rare.

(5.29) She's a real Einstein.

(5.30) She's the next Einstein.

(5.31) She's the new Einstein I was telling you about.

Indexicals can figure in some of these constructions, but not all.

(5.32) *True wes/yous/hers are rare.

(5.33) ?She's a real you/me/her.

(5.34) She's the next you/me/*her.

(5.35) She's the new you/me/*her.

The latter two examples could be explained using the sort of coercion I will introduce below. Note that we can create similar examples with common nouns:

(5.36) Green is the new red.

(5.37) A billion is the new million.

yet I don't think anyone would want to argue that red and million have non-standard meanings on account of these examples. Rather, in these examples, the constructions the new and the next are allowing us to harness a property of red and a million (dollars, etc.) in a context and use that to talk about other things having that property. 
(5.40) Your birthday is always the busiest day to travel.

I cannot get the following readings of these examples (respectively):

(5.41) Engagement rings are usually made out of gold.

(5.42) Speakers of the House are/The Speaker of the House is usually male.

(5.43) The day before Thanksgiving is always the busiest day to travel.

even if the birthday gift was an engagement ring, the addressee's mom is the Speaker of the House and the addressee's birthday falls on the day before Thanksgiving in the year of the utterance.

Still, I don't think that QC data support a clear division between indexicals on the one hand and proper names and definite descriptions on the other. First of all, even though QC examples can sometimes work with singular personal indexical pronouns, indexicals, like proper names, are more felicitous with the plural forms.

(5.44) I'm usually tall.

(5.45) We're usually tall.

The second example is a far better way for Obama to communicate that American Presidents are usually tall. The problem is that not all indexicals can be made plural in the right way. When we make tomorrows plural, for example, we end up talking about the group of days which lie beyond the time of utterance. I'm not sure what heres or nows would mean, were they words in English. A set of regions 
overlapping the utterance location or a set of intervals overlapping the utterance time, respectively?

(5.46) a. Tomorrow is always the busiest day to travel.

b. *Tomorrows are always the busiest days to travel.

(5.47) a. The best mushrooms are usually found around here. (QC reading: around places relevantly similar to our current location)

b. *The best mushrooms are usually found around here (vs. places like this).

Furthermore, although both singular and plural demonstratives work in QCstyle examples, there might be pragmatic reasons for choosing the singular form in certain cases. I have in mind the contrast between (5.48) and (5.49)

(5.48) He is usually Italian.

(5.49) They are usually Italian.

where in both cases the speaker is pointing at Benedict XVI qua Pope to communicate the idea that Popes are usually Italian. It could be confusing for an addressee if the speaker were to point at an individual and use a plural indexical. The use of a plural demonstrative can easily be taken to mean that the demonstratum is a part of a group (or even that the speaker intends to demonstrate an entire group of individuals). While it is in a sense true that Benedict XVI is a part of the group of 
all Popes, there is only one Pope at any given time. The role is filled by a unique individual so using a plural indexical to talk about the Pope could be misleading. ${ }^{9}$

\subsection{Coercion and reconstruction}

Nunberg and Elbourne's rejection of a pragmatic account of IR and QC rested on their claim that IR and QC are impossible for proper names and definite descriptions. We have seen that that claim requires more justification. So far, neither Nunberg or Elbourne has shown that a pragmatic account would not fare just as well, if not better, than theirs. Their arguments therefore are consistent with a theory like LD or PI supplemented with the appropriate pragmatic mechanisms. I turn now to a sketch of how a pragmatic account would treat IR and QC

\subsubsection{Quantificational Coercion}

I say that QC examples involve a kind of coercion because there is a tension in these examples between the demands of an adverb of quantification and the standard interpretation of an indexical. The adverb of quantification wants to quantify over a group of entities - days, events, situations, etc.-but it is presented only with a single time or entity, namely, the value of the (singular) indexical. This leads to a

\footnotetext{
${ }^{9}$ Nunberg (1993) offers an interesting example with demonstratives to show that one can point at an individual object to talk about a group. Taking a variation of his example, a salesperson can point at a plate on sale in a store and say, 'I have those in the back' to mean that he has a set of plates of which that plate is a member or representative in the back of the store. This example is different from the Pope example because, as I said, there really is just one Pope at a time, so we do not simply think of him as being a member of a group of many Popes; rather, we think of him as the current Pope. Group membership in QC examples is importantly time sensitive.
} 
problem with the construction of logical form for QC examples that is driven in part by the types of predicates and arguments, not only by their contents. If a speaker says, tomorrow is usually $R$ for some $R$ and the interpreter doesn't hear what $R$ is, then she will still likely understand that the intended reading is a QC reading, even if she can't figure out what $R$ is or what property about tomorrow is relevant for the predication (e.g. its being the day before Thanksgiving). Similarly, if someone says, $Y$ is usually Romanian for some individual $Y$, then again, even if we assume that the interpreter doesn't hear the name or expression that the speaker used in place of $Y$, then she is still likely to figure out that a $\mathrm{QC}$ reading is intended. Being Romanian is just not the kind of property that one would have at most times but not all. ${ }^{10}$ Nunberg (1993) argues that literal interpretations of QC examples don't even seem possible, and I agree. While I do not think that QC licenses one to meddle with the semantics of indexicals, I do think that it suggests a process that arises during composition in order to repair a problematic predication. Therefore 'coercion' seems appropriate here.

Asher (forthcoming) provides a type-driven account of coercion that provides the mechanisms we need to give a formal account of coercion in QC examples without meddling with the semantics for indexicals offered by PI. In Asher's system, each lexical item is assigned a type, as in Montague grammar, but the types assigned are far finer-grained than the types posited by Montague. Each word root may have a distinct type and further types can be formed by combining types in

\footnotetext{
${ }^{10}$ One can change nationality, of course, one salient reading of this particular construction would make it sound like one could simply have Romanian and not-Romanian days in the way that someone can have happy and not-happy days.
} 
various ways. Predicates presuppose types of their arguments; that is, they make demands on what type their arguments must have. When these presuppositions fail, under certain conditions, Asher posits that a special kind of coercion can take place, due to an operation of (type) presupposition accommodation. A type clash during composition can trigger the addition of extra content to 'glue' together a predicate with its argument in a problematic predication. ${ }^{11}$ Asher applies his account to many examples inter alia:

(5.50) The guitar was deafening.

(5.51) John enjoyed the book.

In (5.50), the predicate was deafening wants to modify a sound, not a concrete object. It's not really the guitar that was deafening, but the sound made by the guitar. Through coercion, we do not change the meaning or type of guitar or deafening, but we add extra material so that it is the sound of the guitar that ends up having the property of being deafening. In (5.51), enjoy requires an event of some sort, but a book is not an event. Again, through coercion we get the result that John enjoyed doing something with the book, such as reading it, but we do this without changing the type or meaning of the argument or the predicate.

I think that this kind of coercion is exactly what is going on in QC. In these examples, there is a clash between the type demands of a quantificational adverb, or

\footnotetext{
${ }^{11}$ The coercion I'm talking about here is neither argument nor predicate coercion. See Asher's book for the formal details of coercion as well as detailed arguments about why simple argument or predicate coercion is not always appropriate.
} 
some kind of quantificational context, and the type of an indexical. Let's look first at a non-QC example involving a quantificational adverb.

(5.52) Nicholas always smokes after dinner.

Here we assume that the quantifier takes propositions as arguments, but it still needs to quantify over a set of times, situations or events. We get something like the following:

$$
\forall e(\operatorname{after}-\operatorname{dinner}(e) \rightarrow \text { Nicholas-smokes }(e))
$$

This means roughly that for all events $e$, if $e$ is an after-dinner event, then $e$ is an event of Nicholas smoking. This reading is too simple probably to be the correct reading of the example - we need to restrict the event to be one that holds shortly after dinner, for example, not five hours later. These details, however, are irrelevant to the basic point I want to make. The idea is that a quantificational adverb will quantify over a set of times (events or situations), and that it will take two propositions as arguments.

Let's look now at (5.2). Again, we assume that always wants to quantify over a set of times, events or situations, but the only time it is offered is the time given by the value of tomorrow and represented by $t_{2}$. Because $t_{2}$ is bound in a higher DRS, however, always cannot quantify over it; and as there is no other eventuality or time to quantify over, it has nothing to quantify over. In line with Asher's mechanisms, we could posit a coercion in this case that would allow always to quantify over a set of times that are like $t_{2}$ in some contextually salient way. For example, these times 
might all share the property of being the day before Thanksgiving in some year. What always needs is a shift like the following, where $\phi$ ranges over properties:

$$
\phi\left(t_{2}\right) \Rightarrow \lambda x\left(x \sim_{p} t_{2} \rightarrow \phi(x)\right)
$$

The term $\left(x \sim_{p} t_{2}\right)$ in the coerced formula denotes an equivalence class of individuals which are such that each $x$ in the class shares some contextually salient property $p$ with $t_{2}$. The relation $\sim_{p}$ should be read as 'same with respect to $p$ ' or 'shares $p$ with'. The variable $p$ ranges over properties; its final value is determined by context.

The question as to how this shift is implemented during composition is a delicate one. We can realize this shift for (5.2) by adding content around the value of tomorrow as follows.

$$
\lambda P\left(P\left(t_{2}\right)\right) \Rightarrow \lambda P \lambda x\left(x \sim_{p} t_{2} \rightarrow P(x)\right)
$$

Supposing that $p$ were the property of being the day before Thanksgiving, $\left(x \sim_{p} t_{2}\right)$ would denote the equivalence class of days that share the property of being the day before Thanksgiving (in some year) with $t_{2}$. Now always has a variable to quantify over.

One advantage of adopting an Asher-inspired analysis of IR and QC would be that Asher's coercion would allow us to restrict the supplemental mechanisms at work in IR and QC locally to a problematic predication. The result would be that the standard interpretation of the indexical would be unchanged and therefore available for subsequent predication and anaphoric reference that would require the standard 
meaning of the indexical. I will argue for the importance of this approach in the next section.

When I first introduced Asher's account, I introduced it as an example of a pragmatic account that could be used to supplement PI. To the extent that Asher's account involves coercion driven by type clashes, however, it is not a pragmatic account. QC readings might be brought about by pragmatic factors such as speaker intentions and discourse topic; for example, He is usually happy has a normal, nonQC reading, but it might also receive a QC reading in the right context. Nevertheless, once pragmatic factors make it clear that a $\mathrm{QC}$ reading is the intended one, the construction of the logical form triggers coercion for purely semantic reasons - to repair a problematic predication that would otherwise have failed due to a type clash. Asher's account, therefore, is a largely semantic account. Perhaps it would be better then, to simply say that QC shows that PI needs to be supplemented with extra mechanisms - pragmatic or semantic. The important point is that these mechanisms do not require that we change any of the tenets of PI, only that we supplement them.

\subsubsection{Intensional Reconstruction}

Consider (5.56):

(5.56) If a Democrat had won the last gubernatorial election, then $I$ might have been Mexican.

Suppose that (5.56) is uttered by the most recently elected Texas Supreme Court Justice, who happens to not be Mexican. Imagine further that the Democratic 
candidate implied that she would appoint a Mexican Justice if elected. Now, the antecedent of (5.56) makes relevant the set of worlds that are just like our world save that the Democrats won the last few gubernatorial elections (and all that this change entails). This set of worlds in turn serves as a modal background for the might claim in the consequent. ${ }^{12}$ Against this modal background, a literal interpretation of the consequent will conflict with what an interpreter is likely to believe about her world-world knowledge tells us that the outcomes of gubernatorial elections should have no effect on peoples' nationalities. The IR reading of (5.56) - according to which the role of the most recently appointed Justice, though actually filled by a non-Mexican, might have been filled by a Mexican—will therefore be preferred.

Where $x_{a}$ is a discourse referent bound in $\mathrm{K}_{0}$ that picks out the agent, a literal representation of the consequent of (5.56) would be:

$\left(5.56^{\prime}\right) \diamond\left(\operatorname{Mexican}\left(x_{a}\right)\right)$

This is not what we want. The intuitive, IR reading of (5.56) is not about the actual agent. Rather, it concerns individuals who in some possible world $w$ from the modal background determined by the antecedent have, in $w$, a contextually salient property that the agent has in the actual world - namely, the property of being the most recently elected Texas Supreme Court Justice (relative to the time of utterance, of course). Again, we will need to add content around the standard interpretation

\footnotetext{
${ }^{12}$ The context sensitivity of IR sentences would be naturally analyzed in a dynamic framework like Veltman (1996). As I will not exploit the dynamics of Veltman's system for the purposes of this paper, however, I will not pursue this point.
} 
of $I$ to build a class of individuals who share the property of being the most recently elected Supreme Court Justice with the agent of the utterance. In this case, however, the individuals will have to share the property across the space of possible worlds instead of sharing the property across time. We need a world sensitive equivalence relation. Let $\sim_{c}$ be such a relation, where $c$, like $r$ and $p$, is a property variable. After undergoing the shift in $(\mathrm{S})$ we get the logical form in (5.56") for the consequent of $(5.56)$.

$$
\lambda P\left(P\left(x_{a}\right)\right) \Rightarrow \lambda P \lambda x\left(x \sim_{c} x_{a} \rightarrow P(x)\right)
$$

$$
\diamond \forall x\left(x \sim_{c} x_{a} \rightarrow \operatorname{Mexican}(x)\right)
$$

The consequent will be true just in case there is a world $w$ in the modal background provided by the antecedent which is such that all of the individuals who have the property $c$ in $w$ that $x_{a}$ has in the actual world, are Mexican in $w .^{13}$

Although the mechanisms involved in QC and IR are similar, according to my account, I do not think that QC and IR are exactly the same. While QC examples involve some sort of clash between the demands of an adverb of quantification and the standard interpretation of an indexical, IR seems to arise only from a clash between a literal reading of a sentence and an interpreter's knowledge about her world. IR

\footnotetext{
${ }^{13}$ Note that for counterfactuals, the actual world will not be a member of the set of worlds in the modal background determined by the antecedent. This is exactly what we want. Suppose the consequent for (5.56") had been I would have been Mexican. Despite the fact that $x_{a}$ has the property of being the most recently elected Justice in the actual world, $x_{a}$ will not be one of the individuals who has the property $c$ in one of the worlds in the modal background, so we will not end up attributing the property of being Mexican to $x_{a}$, as desired.
} 
seems to be a much more pragmatic phenomenon. Were we to change the antecedent in (5.56), for example, a QC reading of the consequent would be less salient.

(5.57) If Mexico hadn't lost Texas to the US, then I might have been Mexican.

So it's not that there is a problem with the combination of the modal, the standard indexical interpretation and the predicate in IR examples. Rather, the literal meaning of the IR examples is not consistent with what the interpreter takes to be common knowledge given the modal background determined by the discourse. Also, QC data are more restricted than IR data: QC examples do not appear to work with definite descriptions and they do not work in French (except with demonstratives). IR examples, by contrast, seem to be far easier to generate than QC examples, work with definite descriptions, and work in French. It might be that these differences result from the fact that IR is a modal phenomenon while QC is not, or it might be because IR is less semantically constrained than QC. Exactly what underlies these differences I leave open for future research. ${ }^{14}$

\footnotetext{
even in the absence of operators like those present in IR or QC cases-Nunberg's 'I'm parked following are from Nunberg's 'Transfers of Meaning':

(5.58) This is parked out back and may not start. (ex. 4)

(5.59) *This fits only the left front door and is parked out back. (ex. 5)

(5.60) *I am parked out back and may not start. (ex. 9)

(5.61) I am parked out back and have been waiting for 15 minutes. (ex. 8)
}

${ }^{14}$ There are certain predications of non-demonstrative indexicals that seem to require coercion out back' is a good example. Even in these cases, however, there are clear differences between indexicals and deferred uses of demonstratives (cf. Nunberg 1993, appendix) that suggest that the non-demonstrative indexicals do not have non-standard meanings in these examples either. The

If we imagine the speaker holding up a set of keys, then the first two examples show that an agent can use his keys to successfully refer to his car - it is the car, not the keys, that is picked up in 


\subsubsection{Plural Indexicals}

Interestingly, an equivalence relation like $\sim_{p}$ might already be at work in standard uses of plural indexicals like we. Obama, for example, can say, 'We have all been men' to mean that the U.S. Presidents have all been men, even without an adverb of quantification (or an intensional operator). The semantics of we may require that the agent of an utterance of we be a member of the group picked out by the utterance, but the semantics do not determine the other members of the group in the same way. Factors such as speaker intentions and conversational topic play a crucial role in determining the other members of the group. Nunberg (1993) offers a perfect example to show that the interpretation of we depends on such factors:

We do not know much about this part of the brain, which plays such an important part in our lives, but we will see in the next chapter... (p. 11)

In each of the uses of a first person plural pronoun above, the agent of the utterance figures in the group picked out by the pronoun; it is left to context (in the broad

anaphora. The story with $I$ is very different: it is the agent - the standard meaning of $I$ - that is accessible for anaphora, not the car belonging to the agent. This strongly suggests that $I$ has its standard meaning in (5.60) and (5.61) and that in these cases, as in IR and QC cases, it behaves very differently from that in (5.58) and (5.59). The indexicals you, we, and even he and she, pattern with $I$ in variations on (5.58)-(5.61), giving us further support for the claim that examples of deferred ostension are very different from other seemingly abnormal examples involving indexicals.

I have relegated the discussion of the parked out back examples to a footnote because I think it is clear that they do not call for a revision of Kaplanian character. IR and QC data, by contrast, are the best candidates I know of to motivate a descriptive or polysemous descriptive/non-descriptive account of indexicals. Due to the nature of the equivalence relations involved in these data, it is much harder to use tests like co-predication and anaphora to argue that the indexicals in them have their standard meanings. 
sense that includes speaker intentions, etc.) to specify the other members of the group.

Many of the examples discussed in Nunberg (1993) involve plural indexicals. Nunberg used plural indexicals as a starting point and then generalized his claims to singular indexicals. If it is true that plural indexicals already contain something like $\sim_{p}$, then Nunberg was in a sense right to do this. Still one should be cautious in concluding from the premise that plural indexicals have $\sim_{p}$ in their semantics and the premise that IR and QC employ $\sim_{p}$ to the claim that $\sim_{p}$ must figure in the semantics of singular indexicals all of the time.

\subsection{Points for a Pragmatic Theory}

15 The main difference between the account that I am pushing and the accounts offered by Nunberg and Elbourne is that my account does not require one to revise either PI or LD. Proponents of the pragmatic account agree with Nunberg and Elbourne that IR and QC examples could be paraphrased by substituting a non-rigid, definite description for the relevant indexical in each example. We disagree only on how serious these readings should be taken by a semantic account of indexicals. PI and LD hold that a semantic theory of indexicals needs to provide an analysis only of the standard interpretations of indexicals - the ones that indexicals by and large have. Nunberg and Elbourne think that a semantic theory of indexicals should make

\footnotetext{
${ }^{15}$ As I said above, coercion is not an entirely pragmatic phenomenon, so the theory I am pushing requires supplementation with both semantic and pragmatic mechanisms. I will bracket this detail for the rest of the chapter, however. When I talk about pragmatic theories of IR and QC, I mean theories that do not require us to meddle with the semantics of indexicals.
} 
room in the semantics for the pragmatic mechanisms at work in IR and QC. The distinction is subtle and I don't have a knock-down argument to show that Nunberg and Elbourne's approach is wrong; I will, however, make some points in favor of the pragmatic theory.

First, note that neither Nunberg nor Elbourne actually overhauls Kaplanian character (or PI's presuppositions). What they do is make room in the semantics of indexicals for pragmatic mechanisms that function on top of LD's character or PI's presuppositions. Let's look again at (5.2). The index for tomorrow will be the time of utterance and, if Nunberg and Elbourne are right, the interpretation of tomorrow will be something like the day before Thanksgiving. But in order to get from the index to this interpretation, we must first pass through the standard interpretation of the indexical. The property of being the day before Thanksgiving holds of the day after the day of utterance, not the index. ${ }^{16}$ There is no getting around the fact that the standard interpretation of an indexical must be determined prior to the determination of the logical form for any IR or QC data, as the pragmatic account

\footnotetext{
${ }^{16}$ Compare the following examples.

(5.2) Tomorrow is always the busiest day to travel.

(5.62) Tomorrow is always a new day.

The second example can be uttered any day of the year and have the same meaning. This example might involve local binding of the presupposition of tomorrow, though I will not argue for that here. The important point is that this example is very different from (5.2). To get the QC reading of (5.2) that we have been considering, where tomorrow is understood as the day before Thanksgiving, one must utter (5.2) the day before the day before Thanksgiving, just as we would expect based on the indexical meaning of tomorrow. The difference in these examples has been a large part of my motivation to argue that QC (and IR) is not a character level phenomenon. One must first determine the standard indexical interpretation in a $\mathrm{QC}$ case and then use this interpretation, together with further contextual information, to figure out what is being said.
} 
predicts. This is not a direct argument against Nunberg and Elbourne's way of treating IR and QC data; it's an argument against their use of this data to revise a theory like PI or LD.

Despite the similarities between Nunberg and Elbourne's semantic account of IR and QC and the pragmatic account that I am defending, the accounts do make different predictions. First, because Nunberg and Elbourne posit the relevant pragmatic mechanisms in the semantics of indexicals only, they predict that no other definites will give rise to IR and $\mathrm{QC}$ examples. We have seen, however, that this prediction is not borne out. IR happens with both proper names and definite descriptions, and QC works for proper names. There is an asymmetry between the behavior of indexicals in IR and QC and the behavior of other definites, but Nunberg and Elbourne need something stronger than an asymmetry to support their claims. Moreover, as I have already argued, the asymmetry that we see with different definites in IR and QC is not surprising given that the class of definites is not homogenous. Of course, Nunberg and Elbourne could build the pragmatic mechanisms into the semantics of proper names and definite descriptions as well so that they could account for the data while maintaining their semantic account. IR and QC data with proper names or definite descriptions do not show that the semantic account is wrong. Nevertheless, I'm not sure what benefits the semantic account will bring if it cannot be shown that IR and QC data are tied to a particular class of expressions. The semantic account holds that sometimes the semantics of indexicals deliver a standard interpretation and sometimes they deliver a standard interpretation supplemented with some pragmatic content. The pragmatic account is simpler: it says that indexicals always have 
standard interpretations and then leaves the pragmatics to the pragmatics.

Another prediction that Nunberg and Elbourne make, though they do not put it in these terms, is that in IR and QC examples, what I am calling the standard interpretation of the indexical will be completely inaccessible. Tomorrow in (5.2) actually means (in the context we are considering) the day before Thanksgiving, so we should not be able to access the standard meaning of tomorrow in subsequent utterances without either reusing tomorrow or using some other expression to pick out the day after the day of utterance. In particular, it should be impossible for indexicals to figure in co-predications where one predicate requires the standard interpretation of the indexical and the other requires an IR or QC reading. This prediction needs to be defended, especially since such examples of co-predication appear to be possible.

(5.63) a. We, all Southern Baptists, might have been liberal North-Easterners if the last election had gone differently.

b. We are staunch Southern Baptists but/who might have been crazy liberals if the Democrats had won the last election.

c. If Democrats had won the last few presidential elections, things might have been different for this case. We, who just took a very conservative stance on $\mathrm{X}$ vs. Y, might have been liberals and then $\mathrm{X}$ probably would have won. 
(5.64) a. Today, the day my ever-thoughtful sister is flying in, is always the most popular day of the year to travel.

b. My sister is arriving today, which, unfortunately, is always the most popular day to travel.

c. Tomorrow is my 30th birthday and always the biggest party night of the year.

QC cases, moreover, figure in similar examples of co-reference:

(5.65) It's really surprising that today is so calm, since it's usually the most popular day to travel.

(5.66) Tomorrow is sure to be a disaster - it always is.

(5.67) Tomorrow is usually the busiest shopping day of the year, but I expect it to be slow this year because of the economy.

According to Nunberg, an indexical offers either its standard interpretation (as I have been calling it) to logical form or a property or description that holds of the standard interpretation. If an indexical contributes a property, then it cannot contribute its standard interpretation unless it is reused. Thus, the standard interpretations are not available for co-predication or anaphora in his theory.

This problem can be made more explicit in Elbourne's theory. Consider (5.68).

(5.68) Tomorrow is my 30th birthday and, unfortunately, always the biggest party night of the year. 
Suppose that I utter (5.68) in Austin on the night before the last day of classes for the universities in Austin. Suppose further that what will make the day after the day of my utterance the biggest party night is its being the night of the last day of classes. What description does tomorrow contribute to the logical form of (5.68) in Elbourne's system? Ignoring the first predication for the time being, the contribution of tomorrow must be something like this ${ }^{17}$ :

- $\lambda \operatorname{s.\iota z}(z$ is the last day of classes [for the fall semester at the universities in Austin...] in $s$ )

Suppose we take this to be the meaning of tomorrow in (5.68). Always is a quantifier over situations in Elbourne's system, so we get the following logical form.

(5.68') $\forall s(\iota z(z$ is the last day of classes in $s)$ is my 30th birthday in $s$. is the biggest party night of the year in $s$ )

In this case, always quantifies over all situations in which there is a unique day that is the last day of classes (for a given semester, for the universities in Austin, etc.). The problem is that $\left(5.68^{\prime}\right)$ will come out false in Elbourne's system even when (5.68) is intuitively true. Even if the day after the day of my utterance is in fact my 30th birthday and the biggest party night of the year, it will not be true that in all situations in which there is a unique day that is the last day of classes, that day will be my 30th birthday. I only have one 30th birthday, after all.

\footnotetext{
${ }^{17}$ If we construct the contribution of tomorrow based on the first predication, we won't be able to explain the QC reading determined by the second predication. The contribution for tomorrow that follows provides, I think, the only hope for an adequate analysis of (5.68) in Elbourne's system.
} 
Elbourne and Nunberg actually change the interpretations of indexicals in order to handle $\mathrm{QC}$ and IR data. We must choose between a standard, rigid interpretation of the indexical or a $\mathrm{QC}$ ( or IR), non-rigid interpretation; we cannot have it both ways, though we need to for co-predication cases. The pragmatic account that I have presented, however, can have it both ways. IR and $\mathrm{QC}$ readings require pragmatic content to be added to the literal logical form delivered by the semantics of indexicals, but this content does not replace the indexical's interpretation; it is added to it. The standard interpretation sticks around and can therefore be picked up in predication and anaphora.

Nunberg claims that indexicals are not capable of entering into co-predications of the sort I am taking seriously here. It is true that many co-predications are questionable: (5.69), for example, is very difficult to interpret (though I'm hesitant to say it is uninterpretable given the right context).

(5.69) ? Today, November 25, 2009, is always the busiest day to travel.

Nevertheless, this does not justify the claim that indexicals do not have their standard interpretations in $\mathrm{QC}$ examples. Indexicals appear to place weaker constraints on how interpreters are to think about their referents than do some other definites. By using a proper name, and even more so, a definite description, when an expression higher up in the RDP hierarchy could be chosen, a speaker will in general indicate that the particular choice of definite is important for her point. Not only is the referent of the definite important, but the context-invariable, presupposed content of the definite is important as well. In (5.69), the fact that the speaker chooses the 
richer definite November 25, 2009 over, say, November 25 suggests that the year is important for what she wants to say. She then proceeds to make no use of this additional information and, in fact, indicate to her interpreter that it should be ignored by using a QC predication. It's no wonder that (5.69) sounds incoherent. But this doesn't show that November 25, 2009 and today (in (5.69)) make different contributions to truth-conditional or asserted content; at most it shows that they make different contributions to the content of the discourse as a whole. This claim is consistent with both PI and LD.

\subsubsection{Conventions}

The pragmatic view that I have defended in this chapter holds that IR and QC arise only in certain predicational environments, i.e. environments created by a modal or adverb of quantification. Yet it is clear that IR and QC will not take place just any time that an adverb of quantification or modal operator is present. The mere salience of a relevant property - i.e. a property that could be used to construct an equivalence class from the standard interpretation of an indexical - is not sufficient. Suppose, for instance, that I am about to give birth to my $20^{\text {th }}$ child tomorrow; I tell you this and make salient the days of birth of my last 19 children. Even though the property of being a day on which one of my children is born is salient, it still seems odd to say, 'tomorrow is always such a special day'. ${ }^{18}$

Let's look at QC examples first. My hunch is that whatever the property is that is relevant for $\mathrm{QC}$ cases (that is, the property $p$ ), it has to specify a role (speaking

\footnotetext{
${ }^{18}$ Thanks to Aidan McGlynn for this example.
} 
loosely enough to allow the day before Thanksgiving to be a role played by exactly one day every year) that interlocutors expect to be filled by different individuals at different times. We expect there to be multiple Speakers of the House and multiple Popes through time and for there to be multiple days before Thanksgiving through time. We do not expect - it is not a matter of convention to expect - that I will continue having children, much less that I will continue having them at any regular intervals. ${ }^{19}$ Roles of this special sort — roles that we expect to be filled by different individuals through time at more or less regular intervals - are what allow the move from the standard interpretation of a singular indexical to a group interpretation in QC examples; conversely, they are also what justifies the use of a singular indexical when a group is really under discussion, as I explained in section (5.2.1).

In IR cases, the property $p$ must again specify some sort of role. It is hard to imagine an IR-style case in which 'Einstein' is used to talk about an individual other than Einstein who might have been a genius (the genius?) under certain conditions. There may be many geniuses in other worlds - which one do we check to evaluate IRstyle examples about Einstein? In contrast to QR examples, however, the role need not be one that interlocutors expect to be filled by multiple people through time.

\footnotetext{
${ }^{19}$ I use the notion of regular intervals loosely here. Josh Dever offered the following example. Suppose Josh is teaching a course that meets one day a week throughout the semester (15 weeks). He doesn't have a set time for his seminar, but determines the time of the seminar every week based on his and his students' schedules. One day, he runs over time by 20 minutes. He can say, 'I'm normally home by now' to mean something like 'I'm usually home 20 minutes after the class is supposed to end'. In this case, there need be no regular intervals between the time one seminar ends and the time the next one ends. Still, this example works because there is an expected recurring property. The class meets weekly and is meant to meet for three hours each time. In this case, the relevant property of the time of utterance is not its being a particular time, but it's being 20 minutes after the class was supposed to end.
} 
What is needed in these cases is for multiple individuals to play the role across the space of possible worlds, which is exactly what possible worlds give us. We can take a situation in this world in which an individual is playing a certain role-someone is knocking on the door, for example - and then look at other possible worlds and ask how things might have been if another individual had knocked on the door.

(5.70) You should have checked the peephole. He could have been a burglar

\subsection{Conclusions}

I have argued that although IR and QC data seem at first glance to motivate a descriptive theory of indexicals, these data are actually compatible with both PI and LD. IR and QC show that PI and LD need to be supplemented with pragmatic mechanisms, of course - simply combining the predicate with the standard interpretation of the indexical in an IR or QC example will not be enough to construct the logical forms for the IR and QC readings. But forcing the pragmatic mechanisms into the semantics of indexicals, as Nunberg and Elbourne do, does not yield a superior analysis of IR and QC; it only complicates the semantics of indexicals. Moreover, Nunberg and Elbourne's accounts make the wrong prediction with regard to other definites. While they predict that proper names and definite descriptions cannot enter into either IR or QC data, I have argued that there are QC examples involving proper names and IR examples with both proper names and definite descriptions. Furthermore, Nunberg and Elbourne's treatment of IR and QC entail that once an indexical enters into a QC or IR predication, the standard meaning of the indexical will be unavailable for anaphoric reference or co-predication. This prediction, too, 
appears to be incorrect. Viewing QC and IR as pragmatic phenomena that arise in order to repair problematic or literally false predications, as Recanati and I do, actually doesn't require any more pragmatic mechanisms than Nunberg and Elbourne's theories do; but by keeping the pragmatic mechanisms out of the semantics of indexicals, a pragmatic theory allows for a wider range of data. Furthermore, it also puts IR and QC in a more general class of pragmatic coercion phenomena, like those discussed in Nunberg (1995), Pustejovsky (1991), and Asher (forthcoming), or quantificational phenomena, like those discussed in Aloni (2000, 2005), which suggests interesting avenues for future research on 'descriptive' indexicals. 


\section{Chapter 6}

\section{Conclusion}

\subsection{Recapitulation}

My primary aim in this dissertation was to show that a wide-scope, presuppositional theory of indexicals can replace a Kaplanian, two-dimensional theory. My secondary aim was to show that a wide-scope account paves the way to a general theory of definite noun phrases and is therefore preferable to a two-dimensional theory. The distinction between presupposed and asserted content provides a solid foundation to achieve both of these goals. Presuppositional content does not (normally) show up in asserted content. By treating Kaplanian character as a presupposition and treating an indexical's Kaplanian 'content' (in a context) as its contribution to asserted content, therefore, we attain the result that the context-invariable meanings of indexicals do not show up in truth-conditional content. Furthermore, presuppositional frameworks have already been used with much success to treat third person pronouns and definite descriptions. A presuppositional framework is more appropriate than a character-based framework for these definites because it allows for the interaction between presupposed content and asserted content that is so important for third person pronouns and definite descriptions. This suggests that a presuppositional theory of indexicals will be more easily extended to a general theory of definites than will a character-based theory. 
The trick for a presuppositional theory of indexicals is to show that a presuppositional theory — which in principle allows for the interaction between presupposed and asserted contents - can satisfy the constraints (a)-(e) introduced in the introduction and repeated below. In particular, a presuppositional theory needs to show that it can secure rigidity for indexicals, at least in paradigmatic cases. In Presuppositional Indexicals I presented my presuppositional theory, PI, and laid the groundwork for PI's treatment of (a)-(e). PI adds two features to a basic, discourse-based presuppositional theory in order to capture the idiosyncrasies of indexical semantics. First, PI extends the notion of a structured discourse context by adding a layer in the context dedicated only to information from the extra-linguistic context. This layer, $\mathrm{K}_{0}$, represents information gained through perception and, perhaps, encyclopedic knowledge and common knowledge and is evaluated relative to the actual world. $\mathrm{K}_{0}$ is more global than the layers of the context that represent the content of a discourse; it is assumed that discourse takes place within the extra-linguistic environment and is therefore subordinate to it. This hierarchy is further supported by the fact that while the extra-linguistic context can affect the interpretation of what is said in a discourse, what is said in a discourse cannot affect the nature of the extra-linguistic context. ${ }^{1}$ The second feature that PI introduces is the $\uparrow$ operator. $\uparrow$ forces the resolution of material in its scope at the highest context possible. By prefixing the presuppositions of indexicals with $\uparrow$, PI secures rigidity for indexicals. Indexical presuppositions can almost always be resolved in $\mathrm{K}_{0}$, so because $\mathrm{K}_{0}$ is evaluated relative

\footnotetext{
${ }^{1}$ It may be that interpreters add information to their representation of the extra-linguistic context as a result of what is said in discourse, but this is very different from changing the nature of the extra-linguistic context itself.
} 
to the actual world, it follows that the presuppositions of indexicals will be evaluated relative to the actual world, as desired.

$\uparrow$ secures rigidity for paradigmatic uses of indexicals by forcing indexical presuppositions to scope out of contexts created by logical operators whenever possible. Interestingly, however, $\uparrow$ leaves open the possibility that an indexical presupposition could bind in a lower context, if the conditions were right. Such interaction is prohibited by a two-dimensional theory. In What 'Now'? I argued that the flexibility offered by $\uparrow$ is more than just a curiosity; it is motivated by the behavior of indexicals. Certain indexicals, including now, actual, actually and here can bind in contexts introduced in discourse when a) binding in the global context is blocked and b) the structure of the local discourse context provides the right conditions. In the examples I considered, what is needed was a certain kind of contrast between two clauses. The indexical then modifies the clause that the speaker wishes to emphasize.

In Wider Scope, I considered a potential problem for PI's wide-scope approach in order to clarify PI's notion of a discourse context. The worry was that even if PI manages to secure rigidity for indexicals, it cannot provide the basis of a more general theory of definites because it does not have enough structure to distinguish between rigid and non-rigid readings of definites in simple sentences. While indexicals do not have non-rigid readings in simple sentences, other definites do, so PI's contexts will need to allow for these readings. Fortunately, PI's contexts do allow for these readings. PI distinguishes between the extra-linguistic context, represented by $\mathrm{K}_{0}$, and the linguistic context, represented by $\mathrm{K}_{1}$ and below. Rigid readings are brought about by binding or accommodating at $\mathrm{K}_{0}$ while non-rigid readings for sim- 
ple sentences are brought about by binding or accommodating at $\mathrm{K}_{1}$. PI has all of the structure that it needs. Still, one might wonder if we need to say more than PI does about what makes indexicals special given that indexicals cannot have non-rigid readings when other definites can. I maintain that while this difference shows that PI cannot be straightforwardly extended to a theory of definites, i.e. by prefixing the presuppositions of all definites with $\uparrow$, this is not a problem for PI. The answer to what makes indexicals different from other definites is found in their particular strategies for the resolution of their presuppositions. If we want to know more about how indexicals are different from other definites, we will have to extend our view and look at how the resolution strategies vary for different definites. I offered various paths that one might take to explore this question.

In 'Descriptive' Indexicals, I considered data that Nunberg (1993) and Elbourne (2008) argue motivate a descriptive theory of indexicals. Descriptive readings of indexicals appear to pose a problem for PI because PI, like Kaplan's LD, does not allow for indexicals to have descriptive interpretations. However, I showed that these examples do not in fact challenge PI (or LD). All that they show is that we must supplement PI with pragmatic mechanisms.

\subsection{Responding to (a)-(e)}

As a final demonstration of how PI works, I now show how PI responds to each of the constraints presented in Chapter 1.

(a) Indexicals are not anaphoric pronouns (in the traditional sense). First of all, this 
claim is not entirely accurate. I argued in What 'Now'? that in certain cases, indexicals can bind to antecedents introduced in discourse. Nevertheless, this constraint holds in most cases and the fact that is does is accounted for by the semantics of $\uparrow$. $\uparrow$ forces the presuppositions of indexicals to be resolved in the highest context possible. Because $\mathrm{K}_{0}$ is almost always accessible, indexical presuppositions almost always bind there, regardless of their linguistic environment.

(b) Indexicals are modally rigid. Rigidity is secured for indexicals as explained above and in Presuppositional Indexicals. First, the conditions in the global context, $\mathrm{K}_{0}$, are evaluated relative to the actual world. This appropriately restricts the assignment functions that survive update with $\mathrm{K}_{0}$, thereby ensuring that all discourse referents in the universe of $\mathrm{K}_{0}$ have a rigid interpretation. Second, indexical presuppositions are normally bound at $K_{0}$ due the the $\uparrow$ operator in their lexical entries. That is, they are bound to discourse referents with rigid interpretations. It follows that the contribution of an indexical to asserted content will normally be rigid because of the relation that holds between its presupposed and asserted contents, as specified in the lexical entry of the indexical.

(c) The context-invariable meaning of indexicals never figures in truth-conditional content. The only way for the context-invariable meaning of an indexical to figure in truth-conditional content would be for it to be locally accommodated at the trigger site. The semantics of $\uparrow$ together with the structure of discourse contexts in PI ensure that this is all but impossible. One might wish, however, to have a 
deeper explanation. The question of why indexicals - or demonstratives, third person pronouns, and proper names for that matter - cannot locally accommodate is an interesting one. I do not have a deeper explanation of why this is the case, and, to my knowledge, neither does anyone else. But I offered some interesting frameworks in which to consider the question in Wider Scope.

(d) Indexicals are not blocked by plugs. First, it is not a foregone conclusion that indexicals are never blocked by plugs. Suppose that I am very upset and have been sitting outside in a park at night on a bench talking to myself outloud. Suddenly, I start to wonder if one of the people who often takes shelter in the park at nighttime is listening to my complaints. It seems that I could say,

(6.1) If there is someone around who has been listening to me complain all this time, then you are a very patient listener.

I have a hunch that someone is listening but I really don't know. To my ear, this would be felicitous even if I were to later find out that there was in fact no eavesdropper in the context; it would certainly be more acceptable in that context than would be my saying, 'You are a very patient listener' when I am not sure anyone is around.

Other indexicals are more resistant to plugs, but this makes sense. The fact that there is an agent, time, location and world of utterance is manifest to an interpreter any time an utterance is made, so it is difficult to see how a plug could block 
the entailment of indexical presuppositions.

(e) Indexicals cannot be accommodated. Following Zeevat (2000) and Zeevat and Beaver (2007), accommodation is impossible for demonstratives and indexicals because if the presuppositions of these expressions fail to hold, then under normal circumstances, it will be obvious to the conversational participants that they fail to hold. Adding the information that they do hold would therefore lead to inconsistency. $^{2}$

\subsection{Looking Ahead: Bound and Shifted Indexicals}

One of the more interesting features of PI is that it allows for the possibility of bound indexicals. I have argued for some cases of local binding in What 'Now'?, but an interesting avenue for future research would be to explore how PI could be applied to other examples of supposedly bound indexicals in the literature. Schlenker (2003) and Anand (2006) argue that many indexicals shift under speech and/or attitude report verbs in some languages. A now well-worn example of such shifting is Schlenker's (6.2): ${ }^{3}$

(6.2) $\mathrm{John}_{j}$ says that $\mathrm{I}_{j}$ am a hero.

\footnotetext{
${ }^{2}$ Zeevat (2000) discusses examples in which someone overhears a speaker using a demonstrative but is not in a position to witness the accompanying demonstration. In this case, the eavesdropper will certainly add the information that there was a demonstration, but according to Zeevat, this does not count as true accommodation because the speaker did not, and could not, intend it as such.

${ }^{3}$ cf. Anand 2006 for a careful study of supposed monstrous verbs in other languages.
} 
In the Amharic translation of (6.2), I refers not to the speaker making the report, but to John; in English, this would be translated as, 'John said that he is a hero'. Judging from the data used by both Schlenker and Anand (among others), such shifted uses of indexicals appear to be sufficiently widespread to deserve consideration by PI. ${ }^{4}$

Examples involving so-called 'fake' indexicals also suggest that indexicals can have both bound and referential readings. ${ }^{5}$

(6.3) I'm the only one around here who can take care of my children. (Kratzer 2009; modeled after Partee 1989:fn. 3)

(6.4) Only you remember our first appointment. (Kratzer 2009)

(6.3) has a sloppy reading according to which only the speaker is an $x$ such that $x$ takes care of $x$ 's children. There is also a bound reading of (6.4) according to which the addressee is the only individual $y$ such that $y$ remembers $y$ 's first appointment with the speaker. The following examples also suggest that indexicals can be bound outside of $\mathrm{K}_{0}$.

(6.5) Tomorrow is always a new day.

(6.6) If you leave the class without telling the teacher, then you get in trouble.

I discussed (6.5) in a footnote in 'Descriptive' Indexicals. This example is unlike a QC example because tomorrow does not seem to refer to a particular day. The

\footnotetext{
${ }^{4}$ See Maier (2009) for a treatment of Amharic $I$ that employs the operator $\Uparrow$ from Hunter \& Asher (2005). $\Uparrow$ is a stronger version of $\uparrow$ that does not allow binding in lower levels.

${ }^{5} \mathrm{cf}$. Kratzer (2009) for a recent study of these uses of indexicals.
} 
QC example Tomorrow is always the busiest day to travel, recall, has to be uttered two days before Thanksgiving in order to give rise to the reading The day before Thanksgiving is always the busiest day to travel. By contrast (6.5) can be uttered any day of the year with the same meaning. No particular day seems to be under discussion. (6.6) is interesting if we imagine, say, that the speaker is a child talking to one of her parents. She uses you, but she need not mean that the parent is going to get in trouble if the parent leaves the class without telling the teacher. Here you is used like the indefinite one or someone and the second occurrence of you seems to be bound. Interestingly, politeness features in some languages such as French, which distinguish between a polite and informal second person pronoun, will be adjusted for the addressee.

I will not attempt to give an account of these data here. However, I will say that to the extent that these examples show that indexicals can bind outside of $\mathrm{K}_{0}$, they offer prima facie support for a presuppositional theory of indexicals that, like PI, allows the presuppositions of indexicals to be bound. 


\section{Bibliography}

[Abbott(2000)] Barbara Abbott. Presuppositions as nonassertions. Journal of Pragmatics, 32, 2000.

[Aloni(2000)] Maria Aloni. Conceptual covers in dynamic semantics. In Nick Braisby Patrick Blackburn and Atsushi Shimojima, editors, Logic, Language and Computation, volume 3. CSLI, Stanford, 2000.

[Aloni(2005)] Maria Aloni. Individual concepts in modal predicate logic. Journal of Philosophical Logic, 34(1):1-64, 2005.

[Anand(2006)] Pranav Anand. De De Se. PhD thesis, Massachusetts Institute of Technology, 2006.

[Ariel(2006)] M. Ariel. Accessibility theory. In Keith Brown, editor, Encyclopedia of Language ${ }^{3}$ Linguistics. Elsevier, 2006.

[Asher(1986)] Nicholas Asher. Belief in discourse representation theory. Journal of Philosophical Logic, 15:127-189, 1986.

[Asher(1993)] Nicholas Asher. Reference to Abstract Objects in Discourse. Number 50 in Studies in Linguistics and Philosophy. Kluwer, Dordrecht, 1993.

[Asher(2006)] Nicholas Asher. Aspects of things. Philosophical Issues: A Supplement to Nous, Philosophy of Language, 7:1-20, 2006. 
[Asher(2010)] Nicholas Asher. Lexical Meaning in Context: Web of Words. Cambridge University Press, 2010.

[Asher and Lascarides(1998a)] Nicholas Asher and Alex Lascarides. Bridging. Journal of Semantics, 15:83-113, 1998a.

[Asher and Lascarides(1998b)] Nicholas Asher and Alex Lascarides. The semantics and pragmatics of presupposition. Journal of Semantics, 15:239-299, 1998b.

[Asher et al.(2006)Asher, Denis, and Reese] Nicholas Asher, Pascal Denis, and Brian Reese. Names, pops and discourse structure. In Candy Sidner, John Harpur, Anton Benz, and Peter Khnlein, editors, Constraints in Discourse (CID), pages 11-19, http://www.nuim.ie, 2006. National University of Ireland.

[Banfield(1982)] Ann Banfield. Unspeakable Sentences: Narration and Representation in the Language of Fiction. Routledge \& Kegan Paul, London, 1982.

[Beaver(1997)] David Beaver. Presupposition. In J. van Benthem and A. ter Meulen, editors, The Handbook of Logic and Language, pages 939-1008. Elsevier,The MIT Press, Cambridge, MA, 1997.

[Beaver(2001)] David Beaver. Presupposition and Assertion in Dynamic Semantics. CSLI Publications, Stanford, 2001.

[Beaver(2002)] David Beaver. Presupposition projection in drt: A critical assessment. In David Beaver, Stefan Kaufmann, Brady Clark, and Luis Casillas, editors, Stanford Papers on Semantics. CSLI Publications, 2002. 
[Beaver and Geurts(2010)] David Beaver and Bart Geurts. Presupposition. Unpublished, June 2010.

[Beaver and Zeevat(2007)] David Beaver and Henk Zeevat. Accommodation. In Gillian Ramchand and Charles Reiss, editors, The Oxford Handbook of Linguistic Inerfaces, Studies in Theoretical Linguistics, pages 503-539. Oxford, 2007.

[Carlson(1977)] Gregory Carlson. Reference to Kinds in English. PhD thesis, University of Massachusetts-Amherst, Amherst, Massachusetts, 1977. Distributed by GLSA.

[Davidson(1967)] Donald Davidson. The logical form of action sentences. In N. Rescher, editor, The Logic of Decision and Action. University of Pittsburgh Press, Pittsburgh, 1967.

[Dever(2004)] Josh Dever. Binding into character. Canadian Journal of Philosophy Supplementary Volume, 30:29-80, 2004.

[Donnellan(1966)] Keith Donnellan. Reference and definite descriptions. The Philosophical Review, 77:281-304, 1966.

[Doron(1991)] Edit Doron. Point of view as a factor of content. In S. Moore and A.Z. Wyner, editors, Proceedings of SALT 1, Ithaca, NY, 1991. CLC Publication.

[Elbourne(2008)] Paul Elbourne. Demonstratives as individual concepts. Linguistics and Philosophy, 31:409-466, 2008. 
[Elbourne(2010)] Paul Elbourne. The existence entailments of definite descriptions. Linguistics and Philosophy, 33:1-10, 2010.

[Frege(1956)] Gottlob Frege. The thought: A logical inquiry. Mind, 65(259):289311, July 1956.

[Frege(1985)] Gottlob Frege. On sense and meaning. In A. P. Martinich, editor, The Philosophy of Language. Oxford University Press, 1985.

[Geurts(1997)] Bart Geurts. Good news about the description theory of names. Journal of Semantics, 14:319-348, 1997.

[Geurts(1999)] Bart Geurts. Presuppositions and Pronouns, volume 2 of CRiSPI. Elsevier, Amsterdam, 1999.

[Geurts and Beaver(2007)] Bart Geurts and David Beaver. Discourse representation theory. http://plato.stanford.edu/entries/discourse-representation-theory/, 2007.

[Geurts and van der Sandt(1997)] Bart Geurts and Rob van der Sandt. Presuppositions and backgrounds. In Proceedings of the 11th Amsterdam Colloquium. The University of Amsterdam, 1997.

[Geurts and van der Sandt(1999)] Bart Geurts and Rob van der Sandt. Domain restriction. In P. Bosch and R. A. van der Sandt, editors, Focus: Linguistic, Cognitive and Computational Perspectives, pages 268-292. Cambridge University Press, 1999. 
[Groenendijk and Stokhof(1991)] Jeroen Groenendijk and Martin Stokhof. Dynamic predicate logic. Linguistics and Philosophy, 14(1):39-100, 1991.

[Gundel et al.(1993)Gundel, Hedberg, and Zacharski] Jeanette K. Gundel, Nancy Hedberg, and Ron Zacharski. Cognitive status and the form of referring expressions in discourse. Language, 69:274-307, 1993.

[Heim(1982)] Irene Heim. Definite and Indefinite Nouns Phrases. PhD thesis, University of Massachusetts at Amherst, 1982.

[Heim(1983)] Irene Heim. On the projection problem for presuppositions. In Michael Barlow, Daniel Flickinger, and Michael Westcoat, editors, Second Annual West Coast Conference on Formal Linguistics, pages 114-126, Stanford University, 1983.

[Hunter(2010)] Julie Hunter. PI: The formal theory. Unpublished, 2010.

[Hunter and Asher(2005)] Julie Hunter and Nicholas Asher. A presuppositional account of indexicals. In P. Dekker and M. Franke, editors, The Proceedings of the Fifteenth Amsterdam Colloquium, pages 119-124, 2005.

[Kamp(1971)] Hans Kamp. Formal properties of 'now'. Theoria, 37:227-273, 1971.

[Kamp(1981)] Hans Kamp. A theory of truth and semantic representation. In Jeroen Groenendijk, Theo Janssen, and Martin Stokhof, editors, Formal Methods in the Study of Language, Part 1, volume 135 of Mathematical Center Tracts, pages 277-322. Amsterdam, 1981. Reprinted in Jeroen Groenendijk, 
Theo Janssen and Martin Stokhof (eds), 1984, Truth, Interpretation, and Information; Selected Papers from the Third Amsterdam Colloquium, Foris, Dordrecht, pp. 1-41.

[Kamp(1985)] Hans Kamp. Context, thought and communication. Proceedings of the Aristotelian Society, 85:239-261, 1985.

[Kamp and Reyle(1993)] Hans Kamp and Uwe Reyle. From Discourse to Logic. Kluwer Academic Publishers, 1993.

[Kaplan(1985)] David Kaplan. Dthat. In A. P. Martinich, editor, The Philosophy of Language. Oxford University Press, 1985.

[Kaplan(1989a)] David Kaplan. Afterthoughts. In Joseph Almog, John Perry, and Howard Wettstein, editors, Themes from Kaplan. Oxford University Press, USA, 1989a.

[Kaplan(1989b)] David Kaplan. Demonstratives. In Joseph Almog, John Perry, and Howard Wettstein, editors, Themes from Kaplan. Oxford University Press, USA, $1989 \mathrm{~b}$.

[Karttunen(1973)] Lauri Karttunen. Presuppositions of compound sentences. Linguistic Inquiry, 4(2):169-194, 1973.

[Karttunen(1974)] Lauri Karttunen. Presupposition and linguistic context. Theoretical Linguistics, 1:181-194, 1974. 
[Karttunen and Peters(1979)] Lauri Karttunen and Stanley Peters. Conventional Implicature. In Choon-Kyo Oh and David A. Dinneen, editors, Presupposition, number 11 in Syntax and Semantics, pages 1-55. Academic Press, Harcourt Brace Jovanovich, New York, 1979.

[King(2001)] Jeff King. Complex Demonstratives: A Quantificational Approach. MIT Press, 2001.

[Kratzer(1998)] Angelika Kratzer. More structural analogies between pronouns and tenses. In SALT 8. MIT, 1998.

[Kripke(1980)] Saul Kripke. Naming and Necessity. Harvard University Press, Cambridge, MA, 1980. Originally published in 1972.

[Kripke(1985)] Saul Kripke. Speaker's reference and semantic reference. In A. P. Martinich, editor, The Philosophy of Language. Oxford University Press, 1985.

[Kripke(2005)] Saul Kripke. Russell's notion of scope. Mind, 114:1005-1037, 2005.

[Lewis(1975)] David Lewis. Adverbs of quantification. In Edward L. Keenan, editor, Formal Semantics of Natural Language, pages 3-15. Cambridge University Press, Cambridge, 1975.

[Lewis(1979a)] David Lewis. Scorekeeping in a language game. Journal of Philosophical Logic, 8(1):339359, 1979a. Reprinted in Philosophical Papers, Volume I, pp. 233-249. 
[Lewis(1979b)] David Lewis. Attitudes de dicto and de se. The Philosophical Review, 88(4):513-543, 1979b.

[Maier(2006)] Emar Maier. Belief in Context: Towards a unified semantics of de re and de se attitude reports. $\mathrm{PhD}$ thesis, Dept. of Philosophy, Radboud University Nijmegen, 2006.

[Maier(2009)] Emar Maier. Proper names and indexicals trigger rigid presuppositions. Journal of Semantics, 23:253-315, 2009.

[Martinich(1996)] A.P. Martinich, editor. The Philosophy of Language. Oxford University Press, third edition, 1996.

[Montague(1974)] R. Montague. The proper treatment of quantification in ordinary english. In R. H. Thomason, editor, Formal Philosophy: Selected papers of Richard Montague, pages 188-221. Yale University Press, New Haven, CO, 1974.

[Muskens(1996)] Reinhard Muskens. Combining Montague semantics and discourse representation. Linguistics and Philosophy, 19:143-186, 1996.

[Nunberg(1993)] Geoffrey Nunberg. Indexicality and deixis. Linguistics and Philosophy, 16:1-43, 1993.

[Nunberg(1995)] Geoffrey Nunberg. Transfers of meaning. Journal of Semantics, 12:109-132, 1995. 
[Nunberg(2004)] Geoffrey Nunberg. Descriptive indexicals and indexical descriptions. In Marga Reimer and Anne Bezuidenhout, editors, Descriptions and Beyond. Oxford University Press, 2004.

[Partee(1973)] Barbara Partee. Some structural analogies between tenses and pronouns in english. Journal of Philosophy, 70(18):601-609, 1973.

[Partee(1978)] Barbara Partee. Bound variables and other anaphors. Theoretical Issues In Natural Language Processing 2, pages 79-85, 1978.

[Partee(1989)] Barbara Partee. Binding implicit variables in quantified contexts. In Caroline Wiltshire, Randolph Graczyk, and Bradley Music, editors, Papers from the 25th Regional Meeting of the Chicago Linguistic Society, pages 342365, Chicago, 1989. University of Chicago. Part One, The General Session.

[Perry(1977)] John Perry. Frege on demonstratives. The Philosophical Review, 86 (4):474-497, 1977.

[Perry(1979)] John Perry. The problem of the essential indexical. Noûs, 13(1):3-21, 1979.

[Potts(2007)] Christopher Potts. The expressive dimension. Theoretical Linguistics, 33(2), 2007.

[Predelli(1998a)] Stefano Predelli. I am not here now. Analysis, 58(2):107-115, 1998a. 
[Predelli(1998b)] Stefano Predelli. Utterance, interpretation and the logic of indexicals. Mind \& Language, 13(3):400-414, 1998b.

[Prior(1968)] A. N. Prior. 'now'. Noûs, 2(2):101-119, 1968.

[Pustejovsky(1995)] James Pustejovsky. The Generative Lexicon. MIT Press, 1995.

[Putnam(1975)] Hilary Putnam. The meaning of 'meaning'. In Philosophical Papers, Volume 2: Mind, Language and Reality. Cambridge University Press, 1975.

[Quine(1956)] W.V.O Quine. Quantifiers and propositional attitudes. Journal of Philosophy, 53, 1956.

[Recanati(1993)] François Recanati. Direct Reference: From Language to Thought. Blackwell, 1993.

[Recanati(2004)] François Recanati. Indexicality and context shift. Harvard University, 2004.

[Recanati(2009)] François Recanati. Singular thought: In defence of acquaintance. In Singular Thought, Barcelona, 2009.

[Roberts(1989)] Craige Roberts. Modal subordination and pronominal anaphora in discourse. Linguistics and Philosophy, 12:683-721, 1989.

[Roberts(2002)] Craige Roberts. Demonstratives as definites. In Kees van Deemter and Rodger Kibble, editors, Information Sharing. CSLI Press, 2002. 
[Roberts(2004)] Craige Roberts. Pronouns as definites. In Marga Reimer and Anne Bezuidenhout, editors, Descriptions and Beyond. Oxford University Press, 2004.

[Russell(1905)] Bertrand Russell. On denoting. Mind, 14:479-493, 1905.

[Russell(1985)] Bertrand Russell. Descriptions. In A.P. Martinich, editor, The Philosophy of Language, pages 213-219. Oxford University Press, 1985.

[Sainsbury(2002a)] R. M. Sainsbury. Reference and anaphora. Language and Mind, 16, 2002a.

[Sainsbury(2005)] R. M. Sainsbury. Reference Without Referents. Oxford University Press, 2005.

[Sainsbury(2002b)] R. Mark Sainsbury. Departing From Frege: Essays in the Philosophy of Language. Routledge, 2002b.

[Salmon(2005)] Nathan Salmon. On denoting. Mind, 114:1069-1133, 2005.

[Schiffer(1981)] Stephen Schiffer. Demonstrative and indexical reference, part i. Synthese, 49(1):43-100, 1981.

[Schlenker(1999)] Philippe Schlenker. Propositional Attitudes and Indexicality: A Cross-Catgeorial Approach. PhD thesis, Massachusetts Institute of Technology, Cambridge, Massachusetts, 1999.

[Schlenker(2003a)] Philippe Schlenker. Indexicality, logophoricity, and plural pronouns. In Benjamins J. Lecarme, editor, Research in Afroasiatic Grammar II 
(Selected Papers from the Fifth Conference on Afroasiatic Languages, Paris, 2000), pages 409-428, 2003a.

[Schlenker(2003b)] Philippe Schlenker. A plea for monsters. Linguistics and Philosophy, 26(1):29-120, 2003b.

[Schlenker(2004)] Philippe Schlenker. Context of thought and context of utterance. Mind \& Language, 19(3):279-304, 2004.

[Schlenker(2005)] Philippe Schlenker. Person and binding: A partial survey. Italian Journal of Linguistics/Rivista di Linguistica, 16(1):155-218, 2005.

[Sellars(1954)] Wilfred Sellars. Presupposing. The Philosophical Review, 63(2): 197-215, 1954.

[Simons et al.(2010)Simons, Tonhauser, Beaver, and Roberts] Mandy Simons, Judith Tonhauser, David Beaver, and Craige Roberts. What projects and why. In David Lutz, editor, Proceedings of SALT XX, 2010.

[Stalnaker(1973)] Robert Stalnaker. Presuppositions. Journal of Philosophical Logic, 2:447-457, 1973.

[Stalnaker(1974)] Robert Stalnaker. Pragmatic presuppositions. In M. K. Munitz and P. Unger, editors, Semantics and Pragmatics. New York University Press, New York, 1974.

[Stalnaker(1978)] Robert Stalnaker. Assertion. In P. Cole, editor, Syntax and Semantics 9. New York University Press, New York, 1978. 
[Stalnaker(1999)] Robert Stalnaker. Context and Content: Essays on Intentionality in Speech and Thought. Oxford University Press, Oxford, 1999.

[Stalnaker(1972)] Robert C. Stalnaker. Pragmatics. In A. P. Martinich, editor, The Philosophy of Language. Oxford University Press, Oxford, 1972.

[Stanley(1997a)] Jason Stanley. Names and rigid designation. In Bob Hale and Crispin Wright, editors, A Companion to the Philosophy of Language. Blackwell Press, Oxford, 1997a.

[Stanley(1997b)] Jason Stanley. Rigidity and content. In Richard G. Heck Jr., editor, Language, Thought, and Logic: Essays in Honour of Michael Dummett. Oxford University Press, 1997b.

[Stojanovic(2002)] Isidora Stojanovic. Resolving Indexicals. PhD thesis, École Polytechnique, 2002.

[Strawson(1950)] Peter Strawson. On referring. Mind, 59:320-344, 1950.

[van der Sandt(1992)] Rob van der Sandt. Presupposition projection as anaphora resolution. Journal of Semantics, 9:333-377, 1992.

[Veltman(1996)] Frank Veltman. Defaults in update semantics. Journal of Philosophical Logic, 25(3):221-261, 1996.

[von Fintel(2004)] Kai von Fintel. Would you believe it? the king of france is back! In Marga Reimer and Anne Bezuidenhout, editors, Descriptions and Beyond. Oxford University Press, 2004. 
[Wechsler(2010)] Stephen Wechsler. What 'you' and 'i' mean to each other: Person marking, self-ascription, and theory of mind. Language, 86(2):332-365, 2010.

[Zeevat(2000)] Henk Zeevat. Demonstratives in discourse. Journal of Semantics, 16:279-313, 2000. 


\section{Vita}

Julie Joanna Hunter was born in Houston, Texas on November 19, 1979. She received the Bachelor of Arts degree in Philosophy from the University of Texas in 2004 before entering the Graduate School at the University of Texas in the Fall of 2004 .

Permanent address: 5402 Viking Drive

Houston, Texas 77092

This dissertation was typeset with $\mathrm{AT}_{\mathrm{E}} \mathrm{X}^{\dagger}$ by the author.

\footnotetext{
${ }^{\dagger} \mathrm{HAT}_{\mathrm{E} X}$ is a document preparation system developed by Leslie Lamport as a special version of Donald Knuth's TEX Program.
} 